\title{
APLICAÇÃO DE EQUAÇÕES DE MODELOS MISTOS EM TESTES CLONAIS DE EUCALYPTUS SPP
}

\section{CARLOS HENRIQUE GARCIA}

\begin{abstract}
Dissertação apresentada à Escola Superior de Agricultura "Luiz de Queiroz", Universidade de São Paulo, para obtenção do título de Mestre em Agronomia, Área de Concentração: Estatística e Experimentação Agronômica.
\end{abstract}

P I R A C I C A B A

Estado de São Paulo - Brasil

Outubro - 2004 


\title{
APLICAÇÃO DE EQUAÇÕES DE MODELOS MISTOS EM TESTES CLONAIS DE EUCALYPTUS SPP
}

\section{CARLOS HENRIQUE GARCIA}

\author{
Engenheiro Florestal
}

Orientadora: Prof $\underline{\underline{a}} \operatorname{Dr}^{\underline{\underline{a}}}$ MARIA CRISTINA STOLF NOGUEIRA

\begin{abstract}
Dissertação apresentada à Escola Superior de Agricultura "Luiz de Queiroz", Universidade de São Paulo, para obtenção do título de Mestre em Agronomia, Área de Concentração: Estatística e Experimentação Agronômica.
\end{abstract}

P I R A C I C A B A

Estado de São Paulo - Brasil

Outubro - 2004 


\section{Dados Internacionais de Catalogação na Publicação (CIP) DIVISÃO DE BIBLIOTECA E DOCUMENTAÇÃO - ESALQ/USP}

\section{Garcia, Carlos Henrique}

Aplicação de equações de modelos mistos em testes clonais de Eucalyptus spp / Carlos Henrique Garcia. - - Piracicaba, 2004.

74 p. : il.

Dissertação (Mestrado) - - Escola Superior de Agricultura Luiz de Queiroz, 2004.

Bibliografia.

1. Componentes de variância 2. Clonagem 3. Eucalipto 4. Genética estatística 5. Seleção genética 6 . Verossimilhança I. Título

CDD 634.9734

"Permitida a cópia total ou parcial deste documento, desde que citada a fonte - O autor" 


\section{DEDICATÓRIA}

Aos meus pais Henrique e Albina,

aos meus irmãos Dimas, Pedro, Paulo e Sandra

OFEREÇO.

À minha esposa Daisy

e aos meus queridos filhos Caroline e Matheus

DEDICO. 


\section{AGRADECIMENTOS}

À Professora Maria Cristina Stolf Nogueira, pela amizade, dedicação e orientação.

Aos professores Clarice Demétrio, Décio Barbin e Roseli Ap. Leandro, pela confiança e apoio na elaboração da dissertação.

Aos professores Augusto Garcia, Silvio Zochi e Sônia Stefano Piedade, pelos ensinamentos e amizade.

Ao Prof. Frederico Pimentel Gomes, pela amizade e companheirismo.

Ao CNPq - Conselho Nacional de Desenvolvimento Científico e Tecnológico, pela bolsa de estudos.

À Veracel Celulose, pela disponibilização dos dados para análise.

À Diretoria do CNPF/EMBRAPA pela disponibilização do software SELEGEN e ao amigo Marcos Deon V. de Resende, pela colaboração e orientação.

Aos funcionários do Departamento de Ciências Exatas da ESALQ/USP, pelo carinho, respeito e amizade.

Aos funcionários da biblioteca da ESALQ, pela ajuda e atenção.

Aos amigos do curso de pós-graduação em Estatística e Experimentação Agronômica, Antônio Moita, Ana Pilon e Juliana Cespedes, pelo companheirismo, entusiasmo e amizade.

À minha esposa e filhos queridos, pelo incentivo e apoio em todos os momentos.

A todos aqueles que de alguma forma colaboraram para a realização deste trabalho. 


\section{SUMÁRIO}

Página

LISTA DE TABELAS . . . . . . . . . . . . . . . . . vii

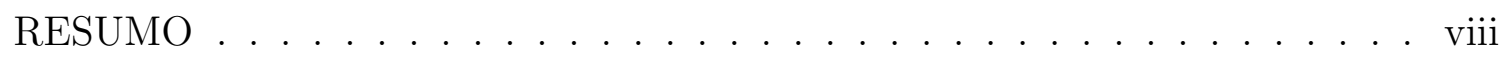

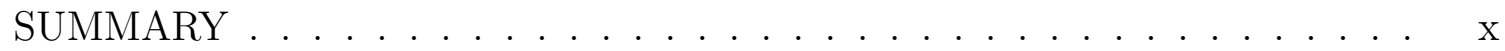

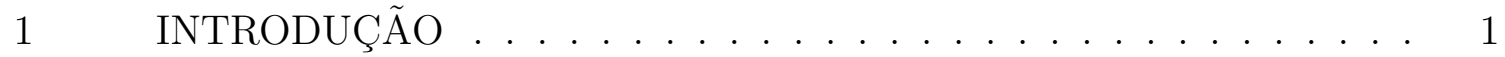

2 REVISÃO DE LITERATURA . . . . . . . . . . . . . . . 4

$2.1 \quad$ A Cultura do Eucalipto . . . . . . . . . . . . . . . . . 4

2.2 Delineamentos Estatísticos . . . . . . . . . . . . . . 7

2.3 Estimadores REML/BLUP de Componentes de Variância . . . . . . . 10

2.4 Metodologia de Modelos Mistos . . . . . . . . . . . . 15

2.5 Melhor Predição Linear não Viesada (BLUP) . . . . . . . . . . . 19

2.6 Algoritmo EM - Maximização de Esperanças . . . . . . . . . . . . 20

2.7 Método da Máxima Verossimilhança Restrita (REML) para Estimação de Componentes de Variância . . . . . . . . . . . . . . . . . 22

3 MATERIAL E MÉTODOS . . . . . . . . . . . . . . . . . 28

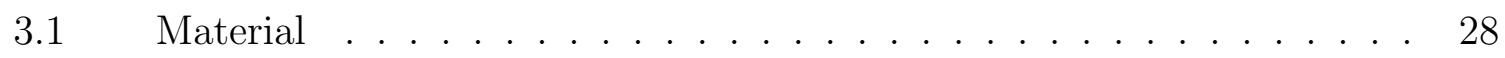

$3.2 \quad$ Métodos . . . . . . . . . . . . . . . . . . . . . . . . . . 31

$4 \quad$ RESULTADOS E DISCUSSÃO . . . . . . . . . . . . . . . 39

$4.1 \quad$ Estatísticas Descritivas . . . . . . . . . . . . . . . . . 39

4.2 Resultados Preliminares - Análise de Variância e Estimativas de Componentes de Variância . . . . . . . . . . . . . . . . . . . . . 40

4.3 Resultados de Análise pelo Método REM/BLUP . . . . . . . . . . . . 44 


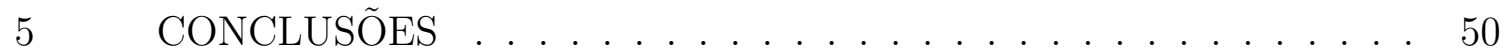

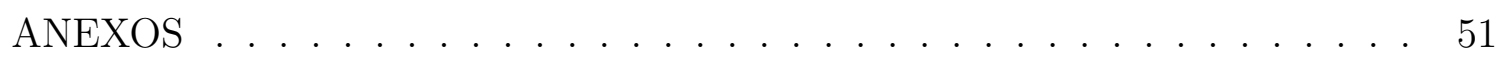

REFERÊNCIAS BIBLIOGRÁFICAS . . . . . . . . . . . 63

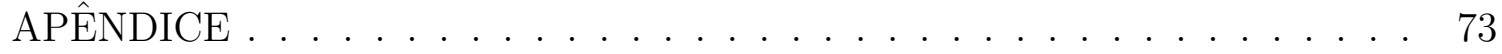




\section{LISTA DE TABELAS}

Página

1 Frequência observada de árvores em função de sua situação no campo . 30

2 Identificação dos clones perdidos por bloco . . . . . . . . . . . . . . . . 31

3 Estrutura da análise da variância com as esperanças matemáticas dos quadrados médios e teste $\mathrm{F} \ldots \ldots$. . . . . . . . . . . . 37

4 Estatísticas descritivas das variáveis DAP (cm), Altura (metros) e Volume $\left(\mathrm{m}^{3}\right)$ das árvores avaliadas no experimento . . . . . . . . . . . . . . 39

5 Resultados da análise da variância tradicional . . . . . . . . . . . . . . . 40

6 Valores de Quadrados Médios e respectivas Esperanças obtidos para as características DAP, Altura e Volume . . . . . . . . . . . . . . . . . . 41

7 Estimativas preliminares de componentes de variância, herdabilidades, coeficientes de correlação intra-classe e lâmbdas obtidas para as variáveis DAP, Altura e Volume . . . . . . . . . . . . . . . . . . . . 43

8 Estimativas obtidas com o programa SELEGEN para as variáveis DAP, Altura e Volume ... . . . . . . . . . . . . . . . . . . . . 44

9 Clones selecionados em função dos valores genotípicos preditos para a variável Volume . . . . . . . . . . . . . . . . . . . . . . . . . 49

10 Identificação dos tratamentos - codificação e procedência do material genético . . . . . . . . . . . . . . . . . . . . 52

11 Valores obtidos pelo SELEGEN para a variável DAP . . . . . . . . . 54

12 Valores obtidos pelo SELEGEN para a variável Altura . . . . . . . . . 57

13 Valores obtidos pelo SELEGEN para a variável Volume . . . . . . . . . 60 


\section{APLICAÇÃO DE EQUAÇÕES DE MODELOS MISTOS EM TESTES CLONAIS DE EUCALYPTUS SPP}

Autor: CARLOS HENRIQUE GARCIA Orientadora: Prof $\underline{\underline{a}}$ Dr $\underline{a}$ MARIA CRISTINA STOLF NOGUEIRA

\section{RESUMO}

A avaliação genética dos candidatos à seleção é um processo fundamental ao melhoramento genético de plantas e animais. Em plantas perenes, a seleção propriamente dita deve basear-se nos valores genéticos aditivos (quando o interesse é a propagação sexuada dos indivíduos selecionados) e genotípicos (quando o interesse é a propagação assexuada dos indivíduos selecionados) preditos de todos os indivíduos avaliados em campo. As técnicas ótimas de avaliação genética envolvem simultaneamente a predição de valores genéticos e a estimação de componentes de variância, sob modelos estatísticos em nível de indivíduos. O procedimento ótimo e padrão para predição de valores genéticos é o BLUP (melhor predição linear não viciada) individual, usando estimativas de componentes de variância obtidas pelo método da máxima verossimilhança restrita (REML) sob modelo individual. No 
presente estudo, foram testados 312 clones de um experimento de Eucalyptus spp instalado em Eunápolis, BA, incluindo as espécies grandis, pellita e híbridos urograndis aos 7 anos de idade. Com o objetivo de selecionar os melhores clones foi obtida a Melhor Predição Linear não Viesada (BLUP) dos efeitos genotípicos via metodologia de modelos mistos e estimados os componentes de variância e parâmetros genotípicos pelo processo da Máxima Verossimilhança Restrita (REML). O vetor de soluções das equações de modelos mistos processadas pelo programa SELEGEN, desenvolvido pela Embrapa, apresenta os efeitos genotípicos preditos, ganhos de seleção e valores genotípicos preditos para cada clone. A seleção dos clones com desempenho relativo superior a $80 \%$ resultou numa nova média para volume igual a $0,519 \mathrm{~m}^{3}$ correspondendo a um aumento de 22,8\% em relação à média das testemunhas (clones de $E$. grandis, origem Rio Claro), que foi de $0,415 \mathrm{~m}^{3}$, e ganho de $36,8 \%$ em relação à média do experimento, que foi equivalente a $0,380 \mathrm{~m}^{3}$. Foram selecionados 26 clones, sendo 23 procedentes da Aracruz (E. urograndis), dois de Avaré (híbridos de E. urophylla) e um originário de Cardwell, Austrália (E. grandis puro). 


\title{
THE APLICATION OF MIXED MODELS EQUATIONS IN THE EUCALYPTUS SPP CLONAL EXPERIMENTS
}

\author{
Author: CARLOS HENRIQUE GARCIA
}

Adviser: Prof $\underline{a}$ Dr $\underline{a}$ MARIA CRISTINA STOLF NOGUEIRA

\section{SUMMARY}

The genetic evaluation of candidates to the selection is a fundamental process to the genetic improvement of plants and animals. In perennial plants, the selection properly said should be based in the addictive genetic values (when the interest is the sexuated propagation of the selected individuals) and genotypics (when the interest is the vegetative propagation of selected individuals) predicted of all the individuals evaluated in field. The optimized techniques of genetic evaluation involve the simultaneous prediction of genetic values and the estimate of variance components, under statistical models in individual level. The optimum and standard procedure for prediction of breeding values is the BLUP (best linear unbiased prediction) individual, using estimates of variance components obtained by the method of the restricted maximum likelihood (REML) under individual model. A clonal test of Eucalyptus spp was evaluated in Eunápolis, Bahia state. The objective of this work 
was selecting the best clones based on Best Lineal Unbiased Prediction (BLUP) of the genotypic effects using the Mixed Models Methodology. The variance components and genotypic parameters were obtained by using the Maximum Restricted Likelihood (REML) process. The vector of solutions of mixed models equations, processed by the program SELEGEN, developed by Embrapa, presents the predicted genotypic effects, gain of selection and predicted genotypic values for each clone. The selection of the best clones by the REM/BLUP methodology was efficient with high gain by selection. The selection of the clones with superior relative acting at $80 \%$ resulted in a new average for volume equal to $0,519 \mathrm{~m}^{3}$ corresponding to an increase of $22,8 \%$ in relation to the average of the witness (clones of E. grandis, from Rio Claro), and a gain of $36,8 \%$ in relation to the average of the experiment, that was equivalent at $0,380 \mathrm{~m}^{3}$. From total, 26 clones were selected, being 23 of Aracruz (E. urograndis), 2 of Avaré (hybrid of E. urophylla) and 1 of Cardwell, Australia (E. grandis). 


\section{INTRODUÇÃO}

O Eucalyptus grandis Hill (ex Maiden) é considerado por Ferreira (1993), entre as espécies pertencentes ao gênero Eucalyptus, a de maior importância social e industrial para os Estados de São Paulo, Paraná, Bahia, Espírito Santo e Minas Gerais. Por superar qualquer outra espécie em incremento volumétrico de madeira e possuir qualidades excelentes tanto para serraria como para produção de celulose, a espécie, pura ou híbrida, tem sido objeto dos principais programas de melhoramento genético no país.

Segundo Garcia \& Mora (2000), graças aos resultados obtidos com programas de pesquisa, os incrementos de produtividade saltaram de $15 \mathrm{~m}^{3}$ /ha/ano no início da década de 60 para $50 \mathrm{~m}^{3} / \mathrm{ha} /$ ano em 2000. O Brasil passou a ocupar em 2001, de acordo com a Associação Brasileira de Celulose e Papel (2002), a posição de segundo maior produtor mundial de celulose de fibra curta e sétimo produtor mundial de papel. Atualmente, segundo a Sociedade Brasileira de Silvicultura (2003), o segmento de florestas plantadas ocupa uma área de 4,8 milhões de hectares e oferece mais de 500 mil empregos diretos e 2 milhões indiretos, contribuindo positivamente para a conservação de florestas naturais e com o superávit da balança comercial do país. Esses resultados não seriam obtidos sem a condução de importantes programas de pesquisa destacando-se os estudos de preparo do solo, adubação, controle fitossanitário e, principalmente, o melhoramento genético de plantas.

Segundo Resende (2000), além da variabilidade do material genético experimental, o sucesso do melhoramento genético depende quase que totalmente da adoção de métodos precisos de seleção. O autor afirma ainda que as técnicas de 
estimação baseadas no método de quadrados mínimos como as aplicadas na análise da variância, não são as mais recomendadas para a aplicação ao melhoramento de plantas perenes, principalmente porque, em muitos casos, ocorre desbalanceamento excessivo no experimento ou os dados observados não apresentam homogeneidade de variância. O autor, baseando-se em Henderson (1973), cita como principal restrição ao emprego dos quadrados mínimos a impossibilidade de se estimar o valor genético de indivíduos não observados. Já as técnicas de avaliação genética utilizando a metodologia de modelos mistos desempenham papel fundamental pois permitem a estimativa de componentes de variância e a predição dos valores genéticos dos candidatos à seleção.

Atualmente, de acordo com Resende (2000), o procedimento padrão de estimação de componentes de variância é o da Máxima Verossimilhança Restrita (REML), desenvolvido por Patterson \& Thompson (1971), sendo que o procedimento ótimo de predição de valores genéticos é o BLUP - Melhor Predição Linear não Viesada - em nível individual.

O procedimento de predição de valores genéticos denominado BLUP foi desenvolvido por Henderson em 1949 e apresentado formalmente em 1973. A partir de 1990, com o desenvolvimento da tecnologia computacional, o BLUP, associado ao modelo animal, tornou-se o procedimento padrão de avaliação genética em bovinos de leite, bovinos de corte, ovinos e suínos. Portanto, torna-se fundamental o conhecimento dos princípios e interpretações associados à utilização deste modelo para aplicação também no melhoramento vegetal visando à predição de valores genéticos e a estimação de componentes de variância otimizados.

A pesquisa se refere à aplicação de equações de modelos mistos para seleção de clones de eucalipto, uma vez que essa metodologia é de aplicação bastante recente no Brasil. Assim, os objetivos deste trabalho são: i) aplicar a metodologia de modelos mistos via REML-BLUP para ajuste a dados de um experimento de melhoramento genético de 312 clones de Eucalyptus spp visando à estimação de 
componentes de variância e à predição de valores genotípicos; ii) obter as estimativas dos componentes de variância para cálculo das herdabilidades e ganhos genotípicos para os caracteres avaliados; iii) selecionar os melhores indivíduos, com base nos caracteres de crescimento da árvore e produtividade de madeira. 


\section{REVISÃO DE LITERATURA}

\subsection{A Cultura do Eucalipto}

Dentre as inúmeras espécies arbóreas existentes, de acordo com a Sociedade Brasileira de Silvicultura (2003), o eucalipto tem sido extensivamente utilizado em plantios florestais devido às características de rápido crescimento e alta produtividade, ampla variação de espécies, grande capacidade de adaptação e variadas aplicações industriais.

O corte do eucalipto para industrialização, segundo Luz (1993), ocorre normalmente aos 7 anos de idade, num regime que permite até 3 rotações sucessivas e econômicas, com ciclo de até 21 anos, sendo que a madeira oriunda de florestas plantadas é utilizada principalmente para produção de celulose, papel, postes, chapas, lâminas, compensados, aglomerados, carvão vegetal, madeira serrada, e móveis. Produtos não madeireiros também podem ser obtidos, a exemplo de óleos essenciais e mel.

Higa (1995) afirma que o Brasil está pesquisando o eucalipto há mais de 90 anos, sendo que a pesquisa florestal tem sido reconhecida mundialmente e os resultados podem ser vistos não só nas publicações científicas mas, principalmente, no campo, onde altíssimas produtividades são encontradas.

A disseminação de sementes de eucaliptos no mundo começou, segundo Ferreira (1993), no início do século XIX. Na América do Sul o primeiro país a introduzir o eucalipto foi o Chile em 1823 e, posteriormente, a Argentina e Uruguai. Somente por volta de 1850, países como Portugal, Espanha, Estados Unidos e Índia começaram a testar o eucalipto. Destaca, também, que as espécies mais utilizadas no 
mundo são o E. grandis, E. camaldulensis, E. tereticornis, E. globulus, E. urophylla, E. viminalis, E. saligna e E. citriodora.

No Brasil, de acordo com Garcia \& Mora (2000), as primeiras mudas de eucalipto foram plantadas no Rio Grande do Sul em 1868, mas o reflorestamento em grande escala começou no Estado de São Paulo. O horto de Rio Claro foi o principal fornecedor de sementes de E. grandis e E. saligna para as florestas plantadas nos Estados do Rio Grande do Sul, Paraná, Espírito Santo e São Paulo.

Os autores afirmam, ainda, que as plantações florestais tiveram início com a introdução do eucalipto em 1904 como matéria-prima destinada à produção de lenha e dormentes no Estado de São Paulo. Segundo os mesmos autores, Navarro de Andrade, considerado o pai da eucaliptocultura no Brasil, desenvolveu os primeiros trabalhos experimentais no Horto de Jundiaí-SP, comparando várias espécies nativas (Peroba, Cabreúva, Jequitibá, Jacarandá Paulista e Pinheiro do Paraná) com o eucalipto. Nos ensaios realizados o eucalipto se sobressaiu em relação às demais espécies. Assim, a partir de 1909, a Cia. Paulista de Estradas de Ferro iniciou o plantio de eucalipto em escala comercial, de acordo com Andrade (1961).

Segundo Silva (1999), Edmundo Navarro de Andrade criou, no ano de 1916, no Horto Florestal de Rio Claro, o Museu do Eucalipto, único do gênero em todo o mundo, além de instalar importantes experimentos de introdução de espécies e procedências de eucalipto.

A partir 1920, de acordo com Ferreira (1993), foram importadas da Austrália sementes de várias espécies de eucalipto, escolhendo-se regiões ecológicas semelhantes às de suas origens. Na década de 50 o departamento de Horticultura da Escola Superior de Agricultura "Luiz de Queiróz" já realizava pesquisas com várias espécies do gênero.

Mas foi a partir de 1968, segundo Garcia \& Mora (2000), com a criação do IPEF - Instituto de Pesquisas e Estudos Florestais, que os trabalhos de pesquisa envolvendo o melhoramento genético do eucalipto alcançaram maior dimensão. Foi 
instalada uma ampla rede de ensaios nas áreas de melhoramento genético e silvicultura os quais serviram de base para que o setor florestal brasileiro alcançasse níveis significativos da produtividade nos plantios comerciais. Nessa época, afirmam os autores, a espécie E. grandis procedência Coff's Harbour foi eleita como sendo a mais produtiva, apresentando madeira com características apropriadas para produção de celulose.

A partir de 1975, continuam os autores, com a seleção de áreas para a produção de sementes geneticamente melhoradas e aplicação dos resultados obtidos em testes de adubação, os plantios comerciais passaram a produzir florestas com incrementos de 30 a $40 \mathrm{~m}^{3} / \mathrm{ha} /$ ano, representando grande avanço silvicultural. A década de 80 foi marcada pela aplicação de técnicas de propagação vegetativa, em que plantios clonais de eucalipto alcançaram incrementos de $50 \mathrm{~m}^{3} / \mathrm{ha} /$ ano.

De acordo com a Sociedade Brasileira de Silvicultura (2003) o E. grandis é a espécie de eucalipto mais utilizada e a que apresenta melhores qualidades para produção de celulose e papel no Brasil.

Sua área de ocorrência natural na Austrália estende-se, segundo Eldridge (1993), em forma descontínua e fragmentada por uma longa faixa costeira, desde Newcastle até Atherton. De acordo com o autor, embora estas duas localidades estejam situadas em diferentes regiões latitudinais, a primeira temperada e a segunda tropical, não existem diferenças climáticas apreciáveis entre ambas, já que no setor meridional os povoamentos estão situados quase ao nível do mar e no setentrional estão entre 600 e 1.250 metros de altitude.

Ferreira (1993) destaca que o E. grandis é uma espécie que possui qualidades excelentes, superando qualquer outra em incremento, quando as condições ambientais são adequadas, sendo essa a causa de sua grande aceitação. Entre suas várias características o autor ressalta que a espécie tem o hábito de desramar-se espontaneamente, o que dá origem a fustes lisos com aspecto colunar e que sua madeira é boa para serraria e excelente para celulose, ressaltando, assim, sua im- 
portância na pesquisa florestal.

Atualmente, os autores Garcia \& Mora (2000), consideram a espécie como prioritária para pesquisa florestal. Os principais projetos de pesquisa florestal têm como objetivo a melhoria da qualidade da madeira para produção de celulose através da condução de programas de melhoramento genético da espécie tanto por propagação sexuada como por processos de propagação vegetativa. Outras espécies importantes e muito utilizadas industrialmente são o E. pellita e o E. urophylla. A importância do E. urophylla se dá pela sua resitência ao cancro, doença provocada por fungos que atacam o tronco das árvores, comprometendo seu crescimento. Por essa razão, a produção de híbridos entre as espécies E. grandis e E. urophylla tem sido muito importante para o sucesso da atividade florestal no Brasil.

\subsection{Delineamentos Estatísticos}

De acordo com Resende (2002a) os delineamentos experimentais mais utilizados e recomendados para a experimentação no campo são os de blocos casualizados completos e incompletos, sendo os de blocos incompletos especialmente indicados na situação de grande número de tratamentos e alta variabilidade ambiental na área experimental.

De acordo com Fu et al. (1988), o delineamento de blocos casualizados tem sido o mais utilizado nos experimentos de melhoramento florestal conduzidos na América do Norte. Complementando as informações, Willians \& Matheson (1994), destacam que os delineamentos em blocos incompletos têm sido os mais empregados na Austrália, na África do Sul e na Ásia. No Brasil, segundo os mesmos autores, ambos os tipos de delineamentos têm sido adotados.

Com relação aos testes de comparação de médias Resende (2002a) afirma que os mesmos não apresentam qualquer relevância no contexto do delineamento de experimentos de melhoramento genético com espécies perenes, uma vez que, por definição, os efeitos genéticos são considerados aleatórios, não existindo qualquer 
significado para testes cujos métodos são baseados na suposição de efeitos fixos de tratamentos.

O autor esclarece também que a análise tradicional de experimentos de campo parte do princípio de que todas as observações tomadas em posições adjacentes (em plantas ou parcelas vizinhas) são não correlacionadas. Desta forma, a matriz de covariância residual, ou dos erros, é modelada com $R=I \sigma_{e}^{2}$, ou seja, os erros são assumidos como homocedásticos e independentes. Segundo Steel \& Torrie (1980), citados por Resende (2000), a casualização concorre para a neutralização dos efeitos da correlação espacial e, portanto, para a geração de uma análise de variância fidedigna.

Por fim, Resende (2002a), apresenta justificativas para considerar o efeito de blocos como principal efeito fixo associado às avaliações genéticas em plantas perenes. De acordo com o autor, o vetor de efeitos fixos deve contemplar os efeitos ambientais identificáveis, e o principal efeito ambiental identificável nos experimentos com plantas perenes é o efeito de blocos, o qual não contribui com informação genética a respeito dos indivíduos. O bloco é o principal estrato homogêneo para comparação de indivíduos, de forma que dentro de blocos os indivíduos são prontamente comparáveis de uma maneira não viciada. Para comparação de indivíduos através dos blocos, torna-se necessário ajustar os valores individuais para os efeitos de blocos, de maneira que as comparações sejam não viciadas. A forma de se conseguir isso é tratar os efeitos de blocos como fixos, fato que torna as avaliações genéticas invariantes aos efeitos de blocos e não viciadas devido à associação entre efeitos de blocos e nível genético dos indivíduos que nele se desenvolvem.

Para aumentar as chances de sucesso no processo seletivo Farias Neto et al. (1999), sugerem o emprego de um pequeno número de repetições associado à avaliação de grande número de progênies. Os autores, ao obter estimativas dos parâmetros genéticos e fenotípicos de 21 progênies de meios-irmãos de Taxibranco (Sclerolobium paniculatum) aos quatro anos de idade com variados números 
de repetições, constataram não haver vantagem em empregar mais do que três, visto que a precisão experimental praticamente não se alterou. O mesmo ocorreu com as estimativas dos parâmetros genéticos e seus desvios padrão associados.

Estudos do efeito do tamanho amostral na estimativa da herdabilidade em espécies perenes em progênies de meios-irmãos de acácia-negra (Acacia mearnsii) avaliadas no Rio Grande do Sul conduzidos por Resende et al. (1991) levaram a concluir que para uma precisa estimação da herdabilidade no sentido restrito recomendam-se os tamanhos amostrais aproximados de 8.000, 4.000 e 2.600 observações para herdabilidades de 0,$10 ; 0,20$ e 0,30 respectivamente e que para ensaios com tamanho amostral inferior a 1.000 não se recomenda a estimação de parâmetros genéticos.

Resende \& Higa (1994), ao estudarem os valores genéticos obtidos no melhoramento de Eucalyptus spp, a partir de testes de progênies instalados no delineamento de blocos casualizados com várias e com uma planta por parcela concluíram que, para o melhoramento de eucalipto deve-se utilizar, no mínimo, cinco plantas por parcela, com pelo menos 3 repetições. Os autores salientam, também, que o número de graus de liberdade do resíduo não deve ser inferior a 10, recomendando que sejam utilizadas, no mínimo, 30 progênies.

Em experimentos de eucalipto, principalmente testes de progênies ou de procedências, a perda de informações de plantas e blocos são esperadas. Segundo Resende (2002a), quando a perda ocorre somente em nível de plantas, existem modelos para estimações de componentes de variância por mínimos quadrados ordinários que resolvem satisfatoriamente o problema. Entretanto, a perda de informações de bloco causa um viés muito grande nestas estimativas e as hipóteses testadas pela ANOVA tornam-se mais complexas, devendo ser utilizandos modelos de blocos desbalanceados. Assim, para estimação mais precisa de componentes de variância com dados desbalanceados, o autor recomenda a utilização do procedimento de máxima verossimilhança restrita. 


\subsection{Estimadores REML/BLUP de Componentes de Variância}

A teoria estatística desenvolvida para análise de dados desbalanceados por meio de modelos lineares tem sido amplamente estudada, principalmente sob o prisma dos modelos de efeitos fixos. Ocorre, no entanto, que em muitas situações experimentais, conforme apresentado por Perri \& Iemma (1996), um ou mais efeitos podem estar associados a processos de amostragem, pois nem sempre é possível levar em consideração toda a população. Efeitos desse tipo são, em geral, chamados aleatórios, e caracterizam os modelos de efeitos aleatórios. Os modelos mistos, de acordo com Milliken \& Johnson (1992) são utilizados para descrever dados de experimentos cujas estruturas de tratamentos envolvem alguns efeitos que são fixos e outros que são aleatórios.

Nestes casos, Resende (2000) afirma que técnicas clássicas de análise muitas vezes não podem ser utilizadas ou por não atenderem às pressuposições necessárias, ou porque algumas observações foram perdidas, ou ainda porque o delineamento é excessivamente desbalanceado. Além disso, nos modelos mistos, algumas estruturas de variâncias e covariâncias consideram em sua formação tanto fatores fixos como aleatórios, que não podem ser estimados pelo método dos mínimos quadrados. Assim, segundo o autor, é necessário utilizar técnicas mais sofisticadas como a metodologia de modelos mistos, que avalia separadamente a parte fixa da aleatória.

Henderson (1977) cita que uma grande restrição ao emprego da metodologia de mínimos quadrados ordinários é a impossibilidade de estimar o valor genético de indivíduos não observados e destaca que o emprego da metodologia de modelos lineares mistos, obtendo-se os melhores preditores lineares não viesados, é um método adequado para predição de valores genéticos, podendo inclusive ser utilizado para predição de cruzamentos não realizados.

Uma das principais características que distinguem a metodologia de 
modelos mistos dos métodos de modelos lineares convencionais é a possibilidade de se estimarem efeitos aleatórios específicos ou funções lineares de efeitos aleatórios. Henderson (1973) desenvolveu um procedimento para predição de valores de produtividade de touros selecionados aleatoriamente em experimentos de genética animal em que foram utilizadas estimativas dos efeitos aleatórios de touros em um modelo misto. O procedimento foi denominado como BLUP (Best Linear Unbiased Prediction), ou seja, Melhor Predição Linear não Viesada. Harville (1977) demonstrou que o procedimento de Henderson poderia ser considerado como uma extensão do teorema de Gauss-Markov.

Já a estimação de parâmetros genéticos associados à seleção no contexto do melhoramento genético de plantas anuais foi bem descrita por vários autores no Brasil, a exemplo de Vencovsky (1987); Vencovsky \& Barriga (1992); Ramalho et al. (1993); Cruz \& Regazzi (1994); Cruz (1997) e Ramalho et al. (2000).

Resende (2000), em concordância com os artigos publicados por Bueno Filho (1997) e Resende \& Mendes (1996), considera que a estimação e a predição no contexto de plantas perenes demanda o uso da metodologia de modelos mistos (REML/BLUP) em nível individual.

Valores genéticos preditos referem-se, de acordo com Falconer (1989) à avaliação do somatório dos efeitos médios dos alelos que o indivíduo (animal ou planta) possui. De maneira geral, os valores genéticos preditos não são iguais aos valores genéticos verdadeiros dos indivíduos. Resende \& Perez (1999) destacam que a proximidade entre estes dois valores pode ser avaliada por sua exatidão (do inglês accuracy, termo erroneamente traduzido pelos autores como acurácia), apresentada inicialmente por Van Vleck et al. (1987), a qual refere-se à correlação entre os valores genéticos preditos e os valores genéticos verdadeiros dos indivíduos. Em geral, segundo os autores, quanto maior a exatidão na avaliação de um indivíduo, maior é a confiança na avaliação e no valor genético predito deste indivíduo.

Também, de acordo com Resende \& Mendes (1996), a predição de va- 
lores genéticos e os métodos de seleção dependem, essencialmente, de estimativas de componentes de variância. O método de predição de valores genéticos denominado melhor predição linear não viesada (BLUP) é fundamental no conhecimento ou estimação precisa dos componentes de variância genética e fenotípica. Estudos realizados pelos autores, em que foram comparados cinco procedimentos de estimação/predição de valores genéticos no melhoramento de Pinus, revelaram que, em situações de dados balanceados e homogeneidade de variâncias genética e ambiental, os métodos de quadrados mínimos ordinários (Ordinary Least Squares - OLS), quadrados mínimos generalizados (Generalized Least Squares - GLS), melhor predição (Best Prediction BP), melhor predição linear (Best Linear Prediction - BLP) e melhor predição linear não viesada (Best Linear Unbiased Prediction - BLUP) se equivalem para efeitos de ordenamento de materiais genéticos mas não para estimação de componentes de variância genéticos e predição de valores genéticos. Em qualquer situação, o método BLUP foi igual ou superior aos demais.

Esses resultados foram confirmados por Bueno Filho (1997) que estudou diferentes formas de predição de valores genéticos aditivos na seleção de matrizes e de árvores dentro de progênies de eucalipto, em testes de progênies florestais de polinização livre envolvendo quatro caracteres: diâmetro medido a 1,30 m de altura (DAP), altura das árvores, volume cilíndrico e densidade básica da madeira. No estudo foram confrontados os resultados da análise pelo modelo de látice com recuperação da informação interblocos com os da análise de modelo misto, aplicando-se o método usual de ordenamento com base em médias gerais de progênies (BV, do inglês breeding value), a seleção pelo melhor preditor linear (BLP) e o melhor preditor linear não viesado (BLUP). Concluiu-se que a abordagem BLUP foi superior às demais apresentando propriedades estatístico-genéticas superiores, como maior dispersão das predições, maior confiabilidade e maiores predições de progressos genéticos.

Henderson (1953) propôs três métodos de estimação de componentes de variância para dados desbalanceados, denominados métodos I, II e III de Hender- 
son. Esses três métodos são adaptações do método da análise da variância (ANOVA) para dados balanceados, que consiste em igualar os quadrados médios da análise de variância aos seus valores esperados. Barbin (2000) também apresenta um trabalho sobre componentes de variância, enfatizando o método ANOVA para modelos com dados balanceados e aplicando um método prático, o Método de Hicks, para obtenção das esperanças matemáticas dos quadrados médios nos modelos com dados balanceados. Visando a coerência entre os resultados obtidos pelos dois métodos, Barbin (2000) apresenta, também, uma modificação no método de Hicks, denominandoo método de Hicks modificado. Entretanto, Searle et al. (1992) ressalta que o princípio do método ANOVA usado com dados balanceados pode ser generalizado para dados desbalanceados. A generalização é feita com a utilização de qualquer forma quadrática em lugar das somas de quadrados.

O Método da Máxima Verossimilhança (ML) é, segundo Milliken \& Johnson (1992), o mais comum para estimação de componentes de variância. O processo, desenvolvido por Fisher em 1925, utiliza a distribuição dos dados observados à qual aplica uma função de verossimilhança que, por sua vez, é função dos parâmetros do modelo. Os estimadores de máxima verossimilhança são os valores dos parâmetros que maximizam a função de verossimilhança.

De acordo com Kennedy (1981) os estimadores de máxima verossimilhança apresentam as seguintes propriedades desejáveis: translação invariante (não afetados por mudanças nos efeitos fixos); suficiência, consistência e eficiência. Por outro lado, Shaw (1987) afirma que os estimadores de máxima verosimilhança são viciados em decorrência de dois aspectos: imposição de restrição de não negatividade e perda de graus de liberdade devido à estimativa dos efeitos fixos.

Vários algoritmos foram desenvolvidos por Corbeil \& Searle (1976), Hartley \& Rao (1967) para maximizar a função de verossimilhança e apresentar estimativas de máxima verossimilhança para os parâmetros do modelo. Alguns exemplos foram apresentados por Searle (1971) com a obtenção de estimadores de máxima ve- 
rossimilhança e respectivas variâncias para vários delineamentos experimentais.

Os algoritmos para obtenção das estimativas de máxima verossimilhança, segundo Resende et al. (1996a), podem ser agrupados de acordo com a ordem das derivadas usadas. Assim, tem-se o algoritmo baseado em procura direta ou seja, livre de derivadas "Derivative Free" (DF-REML), de Graser et al. (1987); o algoritmo "Expectation Maximization", ou maximização de esperanças (EM-REML) de Dempster et al. (1977), baseado em derivadas de primeira ordem e o algoritmo "Average Information" (AI-REML) de Gilmour et al. (1995), baseado em derivadas parciais de primeira e segunda ordens. O algoritmo AI é um procedimento melhorado, o qual fundamenta-se no uso dos métodos de Newton, que usam as derivadas primeira e segunda da função de verossimilhança. O Algoritmo EM é o mais exato, mas também o mais lento. Os estimadores obtidos pelo EM são idênticos aos de Harville (1977) e Meyer (1989). Se valores iniciais positivos forem utilizados, a convergência para valores não negativos é garantida, de acordo com Harville (1977). O algoritmo DF é rápido e exato quando o número de componentes de variância não é muito grande e apresenta vantagens computacionais, pois evitam a inversão de matrizes de ordem elevada. Para modelos complexos, o algoritmo AI é mais rápido e exato do que o DF, conforme apresentado por Johnson \& Thompson (1995) e citado por Resende (2002a).

Segundo Resende et al. (1996b), o algoritmo EM é muito estável, numericamente, apresentando convergência mesmo que os valores iniciais não tenham sido adequados. Entretanto, uma inconveniência é a lentidão para estimativas próximas ao limite do espaço de definição paramétrica, por exemplo, quando uma variância tende a zero. Já os algoritmos livres de derivadas (DF) apresentam vantagens computacionais, pois evitam a inversão de matrizes de ordem elevada.

Visando eliminar os aspectos indesejáveis das estimativas por máxima verossimilhança, Patterson \& Thompson (1971) propuseram modificações ao método, generalizando-o para qualquer modelo de análise de variância. A idéia consiste na 
estimação de componentes de variância por máxima verossimilhança sem considerar os efeitos fixos. Eles dividem a função de verossimilhança em duas partes independentes, uma referente aos efeitos fixos e outra aos aleatórios. A maximização da função de verossimilhança da parte referente aos efeitos aleatórios fornece os estimadores de máxima verossimilhança para os componentes de variância e a outra fornece os estimadores para os efeitos fixos. Esse método passou a ser denominado método REML - Estimativa de Máxima Verossimilhança Restrita. Além de manter as propriedades positivas das apresentadas pelo método da máxima verossimilhança, a modificação realizada conduz a estimativas idênticas àquelas obtidas por análise de variância se o delineamento for balanceado e as restrições de não negatividade forem ignoradas.

Mais recentemente Resende \& Mendes (1996) avaliaram diferentes procedimentos de estimação de componentes de variância. Os autores compararam três procedimentos distintos visando à predição de valores genéticos: mínimos quadrados (Least Squares - LS), máxima verossimilhança (Maximum Likelihood - ML) e máxima verossimilhança restrita (Restricted Maximum Likelihood - REML). A estimação pelo método ML apresentou convergência mais rápida do que pelo método REML. As herdabilidades obtidas pelos métodos ML e REML foram bastante similares e de magnitudes superiores à obtida pelo método LS. O procedimento REML, embora computacionalmente mais complicado, foi o mais preciso. Concluíram que a seleção e a estimação de ganhos genéticos devem ser realizadas pelo procedimento REML interagindo nas equações de modelo misto (BLUP).

\subsection{Metodologia de Modelos Mistos}

Essa metodologia, inicialmente proposta por Henderson (1949), consiste na obtenção de predições dos valores genéticos, tratados como sendo de efeitos aleatórios, corrigidos para os demais efeitos fixos contidos no modelo. Foi denominada Metodologia de Modelos Mistos (MMM), sendo que através dela pode-se 
obter o Melhor Preditor Linear não Viesado ou "Best Linear Unbiased Predictor" (BLUP) dos valores genéticos de cada indivíduo, além do Melhor Estimador Linear Não Viesado ou "Best Linear Unbiased Estimator" (BLUE) dos efeitos fixos.

A seguir são apresentadas algumas discussões teóricas a respeito da Metodologia de Modelos Mistos, de acordo com Henderson (1974) e citados por IEMMA (2003).

Um modelo misto pode ser expresso matricialmente da seguinte forma:

$$
Y=X \beta+Z u+\varepsilon
$$

em que:

$Y=$ o vetor de dados;

$X=$ matriz de incidência dos efeitos fixos;

$\beta=$ vetor de efeitos fixos a serem estimados;

$Z=$ matriz de incidência dos efeitos genotípicos, tomados como aleatórios;

$u=$ vetor de valores genotípicos, ou de efeitos aleatórios a serem preditos;

$\varepsilon=$ vetor de erros aleatórios associados a cada observação tal que $\varepsilon \sim N\left(0, \sigma^{2}\right)$.

As dimensões dessas matrizes e vetores dependem do delineamento experimental empregado.

Henderson et al. (1959) apresentam uma forma para a obtenção do melhor preditor linear não viesado (BLUP) dos efeitos aleatórios desse modelo misto, através da maximização da função densidade de probabilidade conjunta de Y e u, em relação aos efeitos fixos e aleatórios.

Tomando-se o modelo apresentado, assume-se que:

$$
\left[\begin{array}{c}
Y \\
u \\
e
\end{array}\right] \sim N\left(\left[\begin{array}{c}
X \beta \\
0 \\
0
\end{array}\right],\left[\begin{array}{ccc}
Z G Z^{\prime}+R & Z G & R \\
G Z^{\prime} & G & \emptyset \\
R^{\prime} \emptyset & Z G & R
\end{array}\right]\right)
$$

em que:

$0=$ vetor nulo; 
$\emptyset=$ matriz nula;

$G=A \sigma_{g}^{2}$, em que $A$ é a matriz que indica o grau de associação genética entre os indivíduos (matriz de parentesco genético) e $\sigma_{g}^{2}=$ variância genotípica; $R=$ matriz de variâncias e covariâncias dos resíduos.

A função densidade de probabilidade conjunta de $\mathrm{Y}$ e u pode ser escrita como o produto entre a função densidade condicional de $\mathrm{Y}$, dado $\mathrm{u}$, e a função de densidade de probabilidade de $\mathrm{u}$ :

$$
\begin{gathered}
f(Y, u)=1 /\left[(2 \pi)^{n / 2}|R|^{1 / 2}\right] \exp \left\{-\frac{1}{2}\left[(Y-X \beta-Z u)^{\prime} R^{-1}(Y-X \beta-Z u]\right\}\right. \\
1 /\left[(2 \pi)^{n / 2}|G|^{1 / 2}\right] \exp \left\{-\frac{1}{2}\left[(u-0)^{\prime} G^{-1}(u-0)\right]\right\} .
\end{gathered}
$$

Para se proceder à maximização de $f(Y, u)$, pode-se usar o artifício da transformação por logaritmo. Assim, fazendo-se $L=\log [f(Y, u)]$, tem-se:

$$
\begin{gathered}
L=\frac{1}{2} 2 n \log (2 \pi)-\frac{1}{2}(\log |R|+\log |G|)-\frac{1}{2}\left(Y^{\prime} R^{-1} Y-2 Y^{\prime} R^{-1} X \beta-2 Y^{\prime} R^{-1} Z u\right)+ \\
+2 \beta^{\prime} X^{\prime} R^{-1} Z u+\beta^{\prime} X^{\prime} R^{-1} X \beta+u^{\prime} Z^{\prime} R^{-1} Z u+u^{\prime} G^{-1} u
\end{gathered}
$$

Derivando-se L em relação a $\beta$ e $u$, tem-se:

$$
\left[\begin{array}{c}
\frac{\delta L}{\delta \beta} \\
\frac{\delta L}{\delta u}
\end{array}\right]=\left[\begin{array}{c}
-X^{\prime} R^{-1} Y+X^{\prime} R^{-1} X \beta+X^{\prime} R^{-1} Z u \\
-Z^{\prime} R^{-1} Y+Z^{\prime} R^{-1} X \beta+Z^{\prime} R^{-1} Z u+G^{-1} u
\end{array}\right]
$$

Resolvendo-se o sistema

$$
\left\{\begin{array}{l}
\frac{\delta L}{\delta \beta}=0 \\
\frac{\delta L}{\delta u}=0
\end{array}\right.
$$

obtém-se:

$$
\left[\begin{array}{c}
X^{\prime} \hat{R}^{-1} X \hat{\beta}^{0}+X^{\prime} \hat{R}^{-1} Z \hat{u} \\
Z^{\prime} \hat{R}^{-1} X \hat{\beta}^{0}+Z^{\prime} \hat{R}^{-1} Z \hat{u}+\hat{G}^{-1} \hat{u}
\end{array}\right]=\left[\begin{array}{c}
X^{\prime} \hat{R}^{-1} Y \\
Z^{\prime} \hat{R}^{-1} Y
\end{array}\right] .
$$


Dessa forma, a solução conjunta para os efeitos fixos e aleatórios, segundo Henderson (1984), é dada a partir do seguinte sistema de equações:

$$
\left[\begin{array}{cc}
X^{\prime} \hat{R}^{-1} X & X^{\prime} \hat{R}^{-1} Z \\
Z^{\prime} \hat{R}^{-1} X & Z^{\prime} \hat{R}^{-1} Z+\hat{G}^{-1}
\end{array}\right]\left[\begin{array}{c}
\hat{\beta}^{0} \\
\hat{u}
\end{array}\right]=\left[\begin{array}{c}
X^{\prime} \hat{R}^{-1} Y \\
Z^{\prime} \hat{R}^{-1} Y
\end{array}\right] .
$$

Essas são as chamadas Equações de Modelos Mistos (EMM), que permitem obter o melhor estimador não viesado (BLUE) para os efeitos fixos $\left(\hat{\beta}^{0}\right)$, bem como o melhor preditor linear não viesado (BLUP) para os efeitos aleatórios $(\hat{u})$. A solução do sistema será:

$$
\begin{gathered}
\hat{\beta}^{0}=\left\{\left(X^{\prime}\left[\hat{R}^{-1}-\hat{R}^{-1} Z\left(Z^{\prime} \hat{R}^{-1} Z+\hat{G}^{-1}\right)^{-1} Z^{\prime} \hat{R}^{-1}\right] X\right)\right\}^{g} \\
X^{\prime}\left[\hat{R}^{-1}-\hat{R}^{-1} Z\left(Z^{\prime} \hat{R}^{-1} Z+\hat{G}^{-1}\right)^{-1} Z^{\prime} \hat{R}^{-1}\right] Y . \\
\hat{u}=\left(Z^{\prime} \hat{R}^{-1} Z+\hat{G}^{-1}\right)^{g} Z^{\prime} \hat{R}^{-1}\left(Y-X \hat{\beta}^{0}\right) .
\end{gathered}
$$

e como $\hat{V}(Y)=\hat{V}=Z \hat{R}^{-1} Z^{\prime}+\hat{G}$, temos que

$$
\hat{V}^{-1}=\hat{R}^{-1}-\hat{R}^{-1} Z\left(Z^{\prime} \hat{R}^{-1} Z+\hat{G}^{-1}\right)^{-1} Z^{\prime} \hat{R}^{-1} .
$$

Assim:

$$
\hat{\beta}^{0}=\left(X^{\prime} \hat{V}^{-1} X\right)^{g} X^{\prime} \hat{V}^{-1} Y
$$

$\mathrm{e}$

$$
\hat{u}=\hat{G} Z^{\prime} \hat{V}^{-1}\left(Y-X \hat{\beta}^{0}\right)
$$

admitindo que $\mathrm{R}$ e $\mathrm{G}$ são não singulares.

Matricialmente, isso equivale a:

$$
\left[\begin{array}{c}
\hat{\beta}^{0} \\
\hat{u}
\end{array}\right]=\left[\begin{array}{cc}
X^{\prime} \hat{R}^{-1} X & X^{\prime} \hat{R}^{-1} Z \\
Z^{\prime} \hat{R}^{-1} X & Z^{\prime} \hat{R}^{-1} Z+\hat{G}^{-1}
\end{array}\right]^{g}\left[\begin{array}{c}
X^{\prime} \hat{R}^{-1} Y \\
Z^{\prime} \hat{R}^{-1} Y
\end{array}\right]
$$

em que o expoente $\mathbf{g}$ representa qualquer inversa generalizada. 


\subsection{Melhor Predição Linear não Viesada (BLUP)}

Alguns conceitos básicos e terminologias da melhor predição linear não viesada são encontrados na publicação "SAS System for Mixed Models, capítulo 6 Best Linear Unbiased Prediction" (SAS Institute Inc., 1996) e reproduzidos a seguir: Seja um modelo misto apresentado na forma de matrizes (Henderson, 1984):

$$
Y=X \beta+Z u+\varepsilon
$$

Tem-se, por definição, que combinações lineares de efeitos fixos, denotadas por $\Sigma K_{i} \beta_{i}$ são chamadas funções estimáveis se puderem ser construídas a partir de uma combinação linear de médias incondicionais das observações. As funções estimáveis, não dependem, portanto, de efeitos aleatórios.

Funções lineares de efeitos aleatórios e fixos, $K^{\prime} \beta+M^{\prime} u$ podem ser formadas de combinações lineares de médias condicionais e são denominadas funções de predição. A média condicional corresponde a uma média específica obtida a partir de um determinado conjunto de efeitos aleatórios. Uma função $K^{\prime} \beta+M^{\prime} u$ é preditiva se o componente $K^{\prime} \beta$ é estimável.

Utilizando soluções de equações de modelos mistos (EMM) para $\beta$ em uma função estimável resulta na Melhor Estimativa Linear não Viesada (BLUE) de $K^{\prime} \beta$. Para funções de predição, as soluções para $\beta$ e $u$ resultam na Melhor Predição Linear não Viesada (BLUP) para $K^{\prime} \beta+M^{\prime} u$.

Resolvendo o sistema de equações de modelos mistos obtêm-se os preditores ou BLUP's para $K^{\prime} \beta+M^{\prime} u$.

White e Hodge (1989) e André (1999) apresentam várias propriedades úteis do BLUP, referentes ao melhoramento genético vegetal, dentre as quais destacam-se:

a) estimação e predição não-viesadas num procedimento único; 
b) pode-se levar em conta efeitos de seleção e de endogamia ao longo das gerações, desde que o grau de relacionamento genético (parentesco) entre os indivíduos avaliados seja conhecido;

c) a correlação entre os valores genéticos verdadeiros e os preditos é máxima dentre as classes de preditores lineares não viesados;

d) pode-se predizer o valor genético de indivíduos observados ou não;

e) as variâncias e os erros do melhor preditor de $\beta$ não ignoram a presença dos efeitos genéticos, porque esses são tomados como aleatórios e considerados no modelo.

Ainda, segundo Resende (2002a), o BLUP tem o menor erro quadrático médio dentre todos os preditores lineares não viciados de $\beta$.

Observa-se, entretanto, que a predição dos valores genéticos requer o conhecimento prévio dos componentes de variância e covariâncias envolvidos (matrizes $R$ e $G$ ).

\subsection{Algoritmo EM - Maximização de Esperanças}

O algoritmo EM (Maximização de Esperanças ou Expectation - Maximization), apresentado inicialmente por Dempster et al. (1977), é um processo iterativo utilizado para calcular estimativas de máxima verossimilhança em situações em que as observações possam ser consideradas como tendo dados incompletos.

De acordo com Dempster et al. (1977), o significado mais geral deste conceito implica na existência de dois espaços amostrais: $X$ e $Y$ e de uma relação entre $X$ e $Y$. As observações $y$ são uma realização de $Y$. O correspondente $x$ em $X$ não é observável diretamente, mas através de $y$. Assume-se que há uma relação de $X$ em $Y$, e que $x$ é conhecido apenas por estar em $X(y)$, um subconjunto de $X$ determinado pela equação $y=y(x)$, onde $y$ são os dados observados e $x$ corresponde aos dados completos, que podem incluir alguns parâmetros. 
De acordo com Castellano et al. (2002), a verossimilhança associada aos dados completos $f(x \mid \theta)$, dependente do parâmetro $\theta$, determina a verossimilhança associada aos dados incompletos $g(y \mid \theta)$ da seguinte forma:

$$
g(y \mid \theta)=\int_{x(y)} f(x \mid \theta) d x .
$$

O algoritmo EM é utilizado para encontrar uma sucessão de valores de $\theta$ que convergem ao estimador de máxima verossimilhança do parâmetro $\theta$ de $g(y \mid \theta)$ fazendo uso da verossimilhança da família associada a $f(x \mid \theta)$.

Cada iteração do algoritmo EM consiste em dois passos, denominados passo $\mathbf{E}$ (Esperança) e passo $\mathbf{M}$ (Maximização). O passo $\mathbf{M}$ corresponde ao processo de estimação de máxima verossimilhança e só pode ser realizada a partir do passo E.

Quando a distribuição dos dados completos pertence à família exponencial regular, em que as estimativas de máxima verossimilhança são facilmente obtidas, o passo da maximização do algoritmo EM é obtido sem dificuldades (Castellano et al., 2002).

Supondo que $f(x \mid \theta)$ pertença à família exponencial, por exemplo:

$$
f(x \mid \theta)=b(x)^{\frac{\theta t(x)^{\prime}}{a(\theta)}},
$$

em que:

$\theta=$ vetor paramétrico $1 \times r$ e se restringe a um espaço amostral $\mathrm{r}$-dimensional $\Omega$. $t(x)=$ vetor de dados completos $1 \times r$;

Supondo que $\theta^{(i)}$ corresponda ao valor corrente de $\theta$ após $i$ iterações do algoritmo. O próximo passo pode ser descrito por:

Passo E: Estimar as estatísticas suficientes $\left(t^{(i)}\right)$ para as observações completas $t(x)$ dadas as observações de $y$, obtendo:

$$
t^{(i)}=E\left[t(x) \mid Y, \theta^{(i)}\right]
$$


Passo M: Determinar o valor de $\theta^{(i+1)}$ que maximiza $\theta^{(i)}$ :

$$
E[t(x) \mid \theta]=\theta^{(i)}
$$

O passo M define o estimador de máxima verossimilhança de $\theta$ dada a observação $y$.

Segundo Fioravante (1993), a dificuldade do passo M é que nem sempre as soluções pertencem ao espaço amostral $\Omega$. Em alguns casos, o valor de $\theta$ se encontra na vizinhança de $\Omega$ e uma definição mais geral precisa ser utilizada. Entretanto, quando existe solução de $\theta$ em $\Omega$, então a solução é única, de acordo Resende (2002a).

\subsection{Método da Máxima Verossimilhança Restrita (REML) para Estimação de Componentes de Variância}

Segundo Resende (2002a), uma vez que o procedimento BLUP considera que os componentes de variância são conhecidos, e que as propriedades dos preditores somente são asseguradas nestas condições, o procedimento padrão para estimação dos componentes de variância no contexto dos modelos lineares mistos é o da Máxima Verossimilhança Restrita (REML) descrito detalhadamente por Searle el al. (1992) e Rao (1997).

Ainda, segundo o mesmo autor, dentre as propriedades que os estimadores de componentes de variância devem apresentar destacam-se:

a) Não viciado, tal que a esperança matemática do preditor seja o próprio parâmetro;

b) Consistência, tal que, com o aumento do tamanho da amostra, a esperança do preditor convirja para o parâmetro e a variância para zero. Refere-se, portanto, ao aumento da precisão da estimativa com o aumento do tamanho da amostra; 
c) Eficiência, tal que o preditor apresente variância mínima;

d) Suficiência, tal que o preditor condense o máximo possível a informação contida na amostra e não seja função dependente do parâmetro;

e) Completitude, que está ligada à unicidade do estimador;

f) Invariância à translação, tal que a estimação dos componentes de variância não seja afetada por mudanças nos efeitos fixos.

O autor concluiu que, em inferência estatística, os principais métodos de estimação são: método dos momentos (mínimos quadrados), máxima verossimilhança e máxima verossimilhança restrita.

O método da máxima verossimilhança restrita foi proposto inicialmente por Patterson \& Thompson (1971) para delineamentos em blocos casualizados. O método possibilita estimar simultaneamente os efeitos fixos e aleatórios de um modelo misto, segundo Hartley \& Rao (1967). Corbeil \& Searle (1976) apresentaram a função de verossimilhança em duas partes, uma envolvendo os efeitos fixos e outra envolvendo a parte aleatória. A obtenção das estimativas de máxima verossimilhança dos componentes de variância da parte livre dos efeitos fixos resulta nos estimadores de máxima verossimilhança restrita - REML. Assim, o REML mantém as demais propriedades do método da máxima verossimilhança: é não viciado e permite a imposição de restrições de não negatividade, sendo portanto, considerado ideal para estimação de componentes de variância com dados desbalanceados.

Segundo Henderson $(1973,1975)$, exceto para delineamentos completamente balanceados, o método REML demanda procedimentos iterativos, realizados através de equações de modelo misto, pelo procedimento BLUP. Assim, o procedimento REML sob modelo misto realiza, simultaneamente, as operações de estimação (BLUE) dos efeitos fixos por quadrados mínimos generalizados, de estimação de componentes de variância por REML e de predição (BLUP) de valores genéticos. 
De acordo com Resende \& Higa (1994), considerando um modelo misto linear simples, tem-se:

$$
Y=X \beta+Z u+\varepsilon
$$

em que:

$Y=$ o vetor de dados;

$X=$ matriz de incidência dos efeitos fixos;

$\beta=$ vetor de efeitos fixos a serem estimados;

$Z=$ matriz de incidência dos efeitos genotípicos, tomados como aleatórios;

$u=$ vetor de efeitos genotípicos, ou efeitos aleatórios a serem preditos;

$\varepsilon=$ vetor de erros aleatórios associados a cada observação tal que $\varepsilon \sim N\left(0, \sigma^{2}\right)$.

Para o caso univariado e sendo

$$
R=\operatorname{Var}(\varepsilon)=I \sigma_{e}^{2}
$$

$\mathrm{e}$

$$
G=\operatorname{Var}(u)=A \sigma_{g}^{2}
$$

tem-se que

$$
V(Y)=Z G Z^{\prime}+R=Z A Z^{\prime} \sigma_{g}^{2}+I \sigma_{e}^{2}
$$

Os parâmetros $\beta$ e $u$ podem ser obtidos a partir das seguintes equações de modelo misto:

$$
\left[\begin{array}{l}
\hat{\beta} \\
\hat{u}
\end{array}\right]=\left[\begin{array}{cc}
X^{\prime} X & X^{\prime} Z \\
Z^{\prime} X & Z^{\prime} Z+A^{-1}\left(\hat{\sigma}_{e}^{2} / \hat{\sigma}_{g}^{2}\right)
\end{array}\right]^{-1}\left[\begin{array}{c}
X^{\prime} Y \\
Z^{\prime} Y
\end{array}\right]
$$


em que,

$I=$ matriz identidade;

$A=$ matriz de parentesco entre os indivíduos avaliados;

$\hat{\sigma}_{e}^{2}=$ variância residual ou ambiental;

$\hat{\sigma}_{g}^{2}=$ variância genotípica entre clones.

Assim, desde que $\sigma_{g}^{2}$ e $\sigma_{e}^{2}$ ou a herdabilidade $\left(h^{2}=\sigma_{g}^{2} /\left(\sigma_{g}^{2}+\sigma_{e}^{2}\right)\right)$ sejam conhecidas, a estimativa de $\beta$ e a predição de $u$ podem ser obtidas a partir das equações de modelo misto (EMM) apresentadas. A herdabilidade $h_{g}^{2}$ em nível de médias de progênies é, geralmente, o parâmetro inicial utilizado no processo iterativo, considerando a relação $\lambda=\sigma_{e}^{2} / \sigma_{g}^{2}=\frac{1-h_{g}^{2}}{h_{g}^{2}}$. De acordo com Resende (2002a), $\lambda$ corresponde ao fator de "shrinkage" dos efeitos aleatórios nas equações de modelos mistos ou fator de regressão em direção à média geral, conforme apresentado por Mood (1950).

Uma vez aceita a condição de homogeneidade de variâncias genéticas e ambientais tem-se $V(Y)=Z A Z^{\prime} \sigma_{g}^{2}+I \sigma_{e}^{2}$. Mas, como clones não são aparentados entre si, a matriz de parentesco $(A)$, no caso de testes clonais, é uma matriz identidade, assim, considera-se $V(Y)=Z Z^{\prime} \sigma_{g}^{2}+I \sigma_{e}^{2}$ e o sistema de equações lineares mais adequado é definido por:

$$
\left[\begin{array}{l}
\hat{\beta} \\
\hat{u}
\end{array}\right]=\left[\begin{array}{cc}
X^{\prime} X & X^{\prime} Z \\
Z^{\prime} X & Z^{\prime} Z+I \lambda
\end{array}\right]^{-1}\left[\begin{array}{c}
X^{\prime} Y \\
Z^{\prime} Y
\end{array}\right]
$$

O método iterativo BLUP através das equações de modelo misto (EMM) segue os seguintes passos:

a) Partindo-se de um valor inicial (estimado previamente ou assumido) de $\hat{\lambda}=$ $\hat{\sigma}_{e}^{2} / \hat{\sigma}_{g}^{2}$, obtêm-se $\hat{u}$ e $\hat{\beta}$ a partir das equações de modelo misto;

b) Obtêm-se $\hat{\sigma}_{e}^{2}$ e $\hat{\sigma}_{g}^{2}$ a partir das seguintes expressões, apresentadas por Harville (1977) e Meyer (1989): 


$$
\begin{gathered}
\hat{\sigma}_{e}^{2}=\left[Y^{\prime} Y-\hat{\beta}^{\prime} X^{\prime} Y-\hat{u}^{\prime} Z^{\prime} Y\right] /[N-r(X)] \\
\hat{\sigma}_{g}^{2}=\left[\hat{u}^{\prime} \hat{u}+\hat{\sigma}_{e}^{2} \operatorname{tr} C_{22}\right] / s,
\end{gathered}
$$

em que:

$N$ : número total de observações;

$r(X)$ : posto da matriz $\mathrm{X}$ ou número de colunas linearmente independentes de $\mathrm{X}$; $s$ : número de elementos aleatórios (ou de valores genotípicos a serem preditos); tr: operação traço matricial ou soma dos elementos da diagonal da matriz $C_{22}$. $C_{22}$ : é obtida a partir de

$$
C=\left[\begin{array}{ll}
C_{11} & C_{12} \\
C_{21} & C_{22}
\end{array}\right]=\left[\begin{array}{cc}
X^{\prime} X & X^{\prime} Z \\
Z^{\prime} X & Z^{\prime} Z+I \lambda
\end{array}\right]^{-1}
$$

c) São substituídos nas equações de modelo misto, $\hat{\sigma}_{e}^{2}$ e $\hat{\sigma}_{g}^{2}$ obtidos no passo (b) e obtêm-se novos valores para $\beta$ e $u$.

d) Volta-se novamente em (b), usando-se $\hat{\beta}, \hat{u}$ e $\hat{\sigma}_{e}^{2} / \hat{\sigma}_{g}^{2}$ e repete-se o processo até a convergência.

Após a convergência, os valores finais de $\hat{\beta}$ e $\hat{u}$ são utilizados na predição dos valores genotípicos dos clones através da expressão $\hat{g}_{i k}=\hat{\beta}_{i}+\hat{u}_{i k}$ sendo que $\hat{\beta}_{i}$ é o efeito do clone $i$ e $\hat{u}_{i k}$ é o efeito da planta $k$ no clone $i$.

Na convergência examinam-se os valores assumidos por $\hat{\beta}, \hat{u}, \hat{\sigma}_{g}^{2}$ e $\hat{\sigma}_{e}^{2}$. A velocidade de convergência é tanto maior quanto mais próxima da verdadeira for a informação inicial utilizada.

Segundo Resende et al. (1996), o critério de convergência utilizado pode ser de 4 casas decimais para os parâmetros $\hat{\lambda}$ e $\hat{h}_{g}^{2}$ e 7 casas decimais para os componentes $\hat{\sigma}_{g}^{2}$ e $\hat{\sigma}_{e}^{2}$. 
Na maioria dos casos, $A \sigma_{g}^{2}$ e $I \sigma_{e}^{2}$ devem ser substituídos por matrizes de variância-covariância $G$ e $R$, devido à heterogeneidade de variâncias genéticas e ambientais associadas aos diferentes dados.

Na predição de valores genéticos de vários caracteres, G e R (matrizes não singulares) encerram também covariâncias entre caracteres e os requerimentos computacionais são enormes. Assim, procedimentos que implicam em redução de tempo de processamento têm sido desenvolvidos, tais como a transformação do REML multivariado para univariado, através do método denominado transformação canônica apresentado por Thompson \& Hill (1990) e por Freitas et al. (1994).

Os estimadores iterativos de compoentes de variância $\hat{\sigma}_{e}^{2}$ e $\hat{\sigma}_{g}^{2}$ são obtidos pela aplicação do algoritmo EM a partir da maximização da seguinte função, dada por Meyer (1989) e por Resende (2002a).

$$
L=-\frac{1}{2}\left[\left(N-r(X)-N_{a}\right) \log _{e} \hat{\sigma}_{e}^{2}+\log _{e}|C|+N_{a} \log _{e} \hat{\sigma}_{g}^{2}+y^{\prime} P y / \hat{\sigma}_{e}^{2}\right]
$$

em que:

$N_{a}=$ número de níveis no efeito aleatório a;

$|C|=$ determinante de uma submatriz não singular de $\mathrm{C}$ com posto máximo, em que $\mathrm{C}$ é a matriz dos coeficientes das equações de modelo misto. 


\section{MATERIAL E MÉTODOS}

\subsection{Material}

Para alcançar os objetivos propostos nesse estudo, foram utilizados dados de um experimento (teste clonal) de Eucalyptus spp, denominado MG-12, conduzido pela Veracel Celulose, instalado na área experimental Gabiarra, Talhão 12, no município de Eunápolis - BA, em que são comparados 312 clones de Eucalyptus spp, identificados na Tabela 10, em anexo. O experimento foi instalado no período de 22 a 25 de novembro de 1994.

Embora existam dados dendrométricos coletados desde o primeiro ano após instalação do experimento, a análise foi conduzida apenas com os dados observados relativos a uma única medição, realizada aos sete anos, suficiente para a seleção de clones, conforme apresentado por Resende \& Araújo (1993).

No experimento foram testados 312 clones, sendo 153 procedentes da Aracruz Florestal (urograndis), 90 da Austrália (E. grandis puro), 32 de Rio Claro (E. grandis híbridos), 25 de Avaré (híbridos de E. urophylla), 1 da África do Sul (E. grandis puro) e 11 E. grandis de procedência não registrada. Como testemunha foram utilizados os clones 361 e 373, ambos E. grandis de Rio Claro, incluídos no total de tratamentos. Devido ao grande número de clones e diversidade de procedências, aliados à falta de informações dos progenitores, os clones foram considerados como não aparentados para efeito de análise.

O delineamento utilizado foi o de blocos ao acaso. Cada tratamento (clone) foi representado por 20 plantas, dispostas em parcelas lineares de cinco plantas, distribuídas em 4 blocos. Utilizou-se bordadura tripla ao redor do experimento 
e dupla entre blocos. A área total do experimento foi de 7,2 hectares.

A escolha da área para plantio, segundo informações da Veracel Celulose, foi efetuada levando-se em consideração a homogeneidade do solo e a representatividade da mesma para que as extrapolações pudessem ser efetuadas com sucesso. A área experimental era anteriormente ocupada por cerrado.

As mudas foram produzidas no viveiro pertencente à Veracel, no município de Eunápolis, BA e foi utilizada a mesma metodologia de produção de clones empregada na produção comercial. Todo material vegetal existente resultante da operação de destoca foi retirado da área sem utilização de fogo.

No preparo do solo foram aplicados 4,0 litros/ha de herbicida 10 dias antes do plantio em toda a área e foi feita subsolagem a $50 \mathrm{~cm}$ de profundidade a cada 3 metros, formando assim as linhas de plantio. Realizou-se a adubação com $250 \mathrm{~kg} /$ ha de Fosfato da Carolina do Norte distribuído no momento da subsolagem e $150 \mathrm{~kg} /$ ha de NPK 5:38:5 incorporado na cova 3 dias antes do plantio. Devido à alta incidência de cupim foi aplicado cupinicida nas covas.

As alturas das árvores foram medidas com o hipsômetro "Blume-Leiss", graduado em pés e os dados convertidos para metros. A medição do diâmetro à altura do peito - DAP (medida do diâmetro do tronco tomada à altura de 1,30 metros do solo) de cada árvore foi realizada com suta, graduada em $0,5 \mathrm{~cm}$.

Do experimento foram coletados dados de 4.675 árvores das quais foram utilizadas 4.149, correspondendo a $88,75 \%$ do total. O experimento contou, portanto, com sobrevivência acima de $88 \%$ aos 7 anos de idade, podendo ser considerado como de excelente desempenho, tendo como comparação resultados verificados por Kikuti (1988) que obteve sobrevivência de $86 \%$ para matrizes de um experimento clonal de E. grandis, aos 30 meses de idade e por Vettorazzo (1989), que obteve sobrevivência média de 90\% em teste clonal da mesma espécie, aos 4,5 anos de idade. Falhas e árvores cortadas corresponderam a 5,46\% do total.

Por solicitação da Veracel Celulose, foram consideradas no estudo as 
árvores normais, árvores com cancro, bifurcadas abaixo do DAP, bifurcadas acima do DAP e árvores com seca de ponteira. Na ocorrência de árvores bifurcadas acima de 1,30 metros, foram utilizadas somente as medidas correspondentes às árvores com maior diâmetro do tronco. Foram anotadas as incidências de pragas e doenças. Não foram consideradas as árvores com doença no caule (cancro), inclinadas, mortas, quebradas e dominadas. A frequência observada de árvores em cada situação no experimento é apresentada na Tabela 1.

Tabela 1. Frequência observada de árvores em função de sua situação no campo

\begin{tabular}{lrr}
\hline Descricao & árvores & frequência \% \\
\hline Normais & 3789 & 81,05 \\
Cancro & 5 & 0,11 \\
Bifurcadas abaixo DAP & 305 & 6,52 \\
Bifurcadas acima DAP & 21 & 0,45 \\
Seca de ponteira & 29 & 0,62 \\
Doente no caule & 1 & 0,02 \\
Inclinadas & 178 & 3,81 \\
Mortas & 69 & 1,48 \\
Quebradas & 9 & 0,19 \\
Dominadas & 15 & 0,32 \\
Cortadas & 38 & 0,81 \\
Falhas & 216 & 4,62 \\
\hline Total & $\mathbf{4 . 6 7 5}$ & $\mathbf{1 0 0 , 0 0}$
\end{tabular}

No presente estudo tem-se um tamanho amostral superior a 4.500 árvores, com herdabilidades esperadas entre 0,40 a 0,47 para as características DAP, Altura e Volume, podendo ser considerado dentro do recomendado, de acordo com Resende et al. (1991).

As árvores utilizadas para análise estiveram bem distribuídas dentro dos 3 blocos, alcançando, cada bloco, cerca de 33\% do total de árvores do experimento.

Apesar do número de árvores estar bem distribuído em todos os blocos, o mesmo não ocorreu com o número de parcelas. A retirada de árvores para análise tecnológica da madeira resultou em perdas de parcelas em todos os blocos do 
experimento. O bloco 1 foi menos prejudicado, com perda de apenas 4 parcelas. Já os blocos 2 e 3 tiveram 7 parcelas perdidas (Tabela 2).

Tabela 2. Identificação dos clones perdidos por bloco

\begin{tabular}{rrr}
\hline Bloco 1 & Bloco 2 & Bloco 3 \\
\hline 13 & 19 & 202 \\
276 & 83 & 204 \\
278 & 201 & 228 \\
843 & 843 & 844 \\
& 276 & 234 \\
& 279 & 853 \\
& 833 & 1074 \\
\hline
\end{tabular}

Além do desbalanceamento dentro de blocos, verificou-se desbalanceamento dentro das parcelas. O número de plantas por parcela variou de 2 a 5 árvores.

\subsection{Métodos}

Para a análise dos dados observados, o caracter de produtividade (volume de madeira) foi estimado indiretamente a partir de observações efetuadas em campo (caracteres DAP e Altura). As metodologias para obtenção dessas estimativas são apresentadas a seguir.

A altura $(\mathrm{H})$ foi computada em metros, o DAP em centímetros e o volume de cada árvore foi expresso em metros cúbicos com casca $\left(m^{3} \mathrm{cc}\right)$.

A estimativa do volume de madeira produzido por árvore foi obtida a partir da equação de regressão utilizada comercialmente pela Veracel Celulose, fornecida pelo Departamento de Inventário Florestal da Empresa. A equação é dada por:

$$
V=\exp \{-10,0954+1,7907 * \operatorname{Ln}(D A P)+1,1306 * \operatorname{Ln}(H)\},
$$

em que

$V=$ Volume do tronco (comercial) da árvore, em $m^{3}$ com casca; 
$L n=$ Logaritmo natural;

$D A P=$ Diâmetro à Altura do Peito, em cm;

$H=$ Altura, em metros.

Os coeficientes da equação de regressão foram obtidas, segundo informações do Departamento de Inventário Florestal da Veracel, pela regressão linear do volume individual das árvores em função dos logaritmos do diâmetro e altura correspondentes.

Foram estimadas as médias aritméticas dos valores de DAP, Altura e Volume comercial das árvores utilizáveis para cada parcela. Foram, também, calculadas estatísticas descritivas como média geral, variância, desvio padrão, amplitude e intervalo de confiança para cada característica.

A seleção dos clones será feita com base nos clones que apresentarem desempenho relativo superior a $80 \%$ para o valor genotípico da variável Volume, conforme sugerido por Mora (2002). Para efeito de comparação, serão utilizados os valores das testemunhas 361 e 373 .

Para escolha do valor representativo de um clone, os valores genotípicos de cada caráter avaliado serão obtidos a partir do procedimento REML - Máxima Verossimilhança Restrita, aplicada ao modelo linear misto, que na forma matricial, utilizado para avaliação de clones não aparentados no delineamento em blocos ao acaso com várias árvores por parcela, sugerido por Resende (2000), é:

$$
Y=X b+Z g+W p+e
$$

em que:

$Y=$ Vetor de observações fenotípicas para um caráter, de dimensões $n \times 1$;

$X=$ Matriz de incidência para os efeitos fixos, conhecida, de dimensões $n \times p$; $b=$ Vetor de efeitos fixos (média geral e efeitos de blocos), desconhecidos, de dimensões $p \times 1$;

$Z=$ Matriz de incidência para os efeitos genotípicos, conhecida, de dimensões $n \times q$; 
$g=$ Vetor de efeitos (aleatórios) genotípicos, desconhecidos, de dimensões $q$ x 1 ;

$W=$ Matriz de incidência para os efeitos de parcelas, conhecida, de dimensões $n \mathrm{x}$ $k$;

$p=$ Vetor de efeitos (aleatórios) de parcelas, desconhecidos, de dimensões $k \times 1$;

$e=$ Vetor dos efeitos de erros aleatórios não observáveis, de dimensões $n \times 1$.

Assume-se que os efeitos aleatórios e erros (resíduos) têm distribuição normal com média zero e são não correlacionados, com matrizes de variância e covariâncias, positivas definidas, por hipótese, e, portanto, não singulares, dadas por:

$Y \mid \beta, V \sim N(X \beta, V) ;$

$g \mid \sigma_{g}^{2} \sim N\left(0, I \sigma_{g}^{2}\right)$;

$p \mid \sigma_{p}^{2} \sim N\left(0, I \sigma_{p}^{2}\right)$;

$e \mid \sigma_{e}^{2} \sim N\left(0, I \sigma_{e}^{2}\right)$

$\operatorname{Var}(g)=I \sigma_{g}^{2}=$ variância genotípica;

$\operatorname{Var}(p)=I \sigma_{p}^{2}=$ variância entre parcelas;

$\operatorname{Var}(e)=I \sigma_{e}^{2}=$ variância ambiental ou residual;

$\operatorname{Var}(Y)=Z I \sigma_{g}^{2}+W I \sigma_{p}^{2}+I \sigma_{e}^{2}$.

$\operatorname{Cov}\left(g, p^{\prime}\right)=0 ; \quad \operatorname{Cov}\left(g, e^{\prime}\right)=0 ; \quad \operatorname{Cov}\left(p, e^{\prime}\right)=0$.

A estrutura de médias e variâncias do modelo fica, portanto:

$$
E\left[\begin{array}{c}
Y \\
g \\
p \\
e
\end{array}\right]=\left[\begin{array}{c}
X b \\
0 \\
0 \\
0
\end{array}\right] ; \quad \operatorname{Var}\left[\begin{array}{c}
g \\
p \\
e
\end{array}\right]=\left[\begin{array}{ccc}
I \sigma_{g}^{2} & 0 & 0 \\
0 & I \sigma_{p}^{2} & 0 \\
0 & 0 & I \sigma_{e}^{2}
\end{array}\right] .
$$

As equações do modelo misto para estimar os efeitos fixos e predizer os efeitos aleatórios pelo procedimento BLUP, apresentados por Resende (2000) são dadas por: 


$$
\left[\begin{array}{c}
\hat{b} \\
\hat{g} \\
\hat{p}
\end{array}\right]=\left[\begin{array}{ccc}
X^{\prime} X & X^{\prime} Z & X^{\prime} W \\
Z^{\prime} X & Z^{\prime} Z+I \hat{\lambda}_{1} & Z^{\prime} W \\
W^{\prime} X & W^{\prime} Z & W^{\prime} W+I \hat{\lambda}_{2}
\end{array}\right]^{-1}\left[\begin{array}{c}
X^{\prime} Y \\
Z^{\prime} Y \\
W^{\prime} Y
\end{array}\right]
$$

sendo que

$$
\begin{gathered}
\hat{\lambda}_{1}=\frac{\hat{\sigma}_{e}^{2}}{\hat{\sigma}_{g}^{2}}=\frac{1-h_{g}^{2}-c^{2}}{h_{g}^{2}} ; \\
\hat{\lambda}_{2}=\frac{\hat{\sigma}_{e}^{2}}{\hat{\sigma}_{p}^{2}}=\frac{1-h_{g}^{2}-c^{2}}{c^{2}} ; \\
\hat{h}_{g}^{2}=\frac{\hat{\sigma}_{g}^{2}}{\hat{\sigma}_{g}^{2}+\hat{\sigma}_{p}^{2}+\hat{\sigma}_{e}^{2}} ; \\
\hat{c}^{2}=\frac{\hat{\sigma}_{e}^{2}}{\hat{\sigma}_{g}^{2}+\hat{\sigma}_{p}^{2}+\hat{\sigma}_{e}^{2}},
\end{gathered}
$$

em que

$I=$ matriz de identidade de ordem apropriada aos dados;

$h_{g}^{2}=$ herdabilidade individual no sentido amplo no bloco;

$c^{2}=$ correlação intraclasse devida ao ambiente comum na parcela.

$\sigma_{g}^{2}=$ variância genotípica entre clones;

$\sigma_{p}^{2}=$ variância entre parcelas;

$\sigma_{e}^{2}=$ variância residual ou ambiental dentro de parcelas.

Os parâmetros $\lambda_{1}$ e $\lambda_{2}$ são obtidos a partir dos valores iniciais dos componentes de variância estimados pelo método da análise da variância aplicado ao modelo matemático do experimento.

O vetor de soluções das Equações de Modelos Mistos apresentará as estimativas BLUE das médias dos blocos e as predições BLUP dos efeitos genotípicos para as matrizes e para as parcelas. 
Dessa forma, tendo-se os dados observados (Y), conhecendo-se a herdabilidade $\left(h_{g}^{2}\right)$ da característica e obtendo-se as matrizes $X, Z$ e $W$, pode-se predizer de maneira eficiente o valor genotípico de cada indivíduo.

Para obtenção das estimativas de verossimilhança será utilizado o algoritmo EM (Expectation - Maximization), ou seja, Maximização de Esperanças, proposto por Dempster et al. (1977).

Os estimadores dos componentes de variância obtidos a partir da maximização da função de verossimilhança restrita pelo algoritmo EM são (Resende, 2000):

$$
\begin{gathered}
\hat{\sigma}_{e}^{2}=\left[Y^{\prime} Y-\hat{b}^{\prime} X^{\prime} Y-\hat{g}^{\prime} Z^{\prime} Y-\hat{p}^{\prime} W^{\prime} Y\right] /[N-r(X)] ; \\
\hat{\sigma}_{g}^{2}=\left[\hat{g}^{\prime} \hat{g}+\hat{\sigma}_{e}^{2} \operatorname{tr}\left(C^{22}\right)\right] / q \\
\hat{\sigma}_{p}^{2}=\left[\hat{p}^{\prime} \hat{p}+\hat{\sigma}_{e}^{2} \operatorname{tr}\left(C^{33}\right)\right] / s ;
\end{gathered}
$$

sendo que as matrizes $C^{22}$ e $C^{33}$ advêm de:

$$
C^{-1}=\left[\begin{array}{lll}
C_{11} & C_{12} & C_{13} \\
C_{21} & C_{22} & C_{23} \\
C_{31} & C_{32} & C_{33}
\end{array}\right]^{-1}=\left[\begin{array}{lll}
C^{11} & C^{12} & C^{13} \\
C^{21} & C^{22} & C^{23} \\
C^{31} & C^{32} & C^{33}
\end{array}\right]
$$

e que:

$C=$ Matriz dos coeficientes das equações do modelo misto;

$r(X)=$ Posto da matriz $\mathrm{X}$;

$t r=$ Operador traço matricial ou traço da matriz;

$N=$ Número total de dados;

$q=$ Número de indivíduos;

$s=$ Número de parcelas . 
Com o objetivo de realizar uma avaliação preliminar dos dados e obter as estimativas iniciais de componentes de variância e herdabilidades para aplicar no processo iterativo, serão realizadas as análises da variância para DAP, Altura e Volume utilizando o PROC GLM do programa SAS, que utiliza a metodologia dos mínimos quadrados.

O modelo matemático do experimento em estudo é:

$$
y_{i j k}=m+g_{i}+b_{j}+e_{i j}+\varepsilon_{i j k}
$$

em que

$y_{i j k}=$ observação relativa à árvore $\mathrm{k}$, do clone $\mathrm{i}$, no bloco j;

$m=$ média geral;

$g_{i}=$ efeito (aleatório) de clones;

$b_{j}=$ efeito (fixo) de blocos;

$e_{i j}=$ erro experimental (erro entre parcelas);

$\varepsilon_{i j k}=$ erro amostral (erro entre plantas dentro de parcelas), e

$i=1,2,3, \ldots I ; j=1,2,3, \ldots J ; k=1,2,3, \ldots K$.

Como, por atribuição, o efeito de blocos é fixo e o de clones é aleatório, o modelo apresentado foi considerado misto (Barbin, 2000). Assim tem-se:

$m$ fixo, portanto

$\mathrm{E}[m]=m \mathrm{e}$

$\mathrm{E}\left[m^{2}\right]=m^{2}$;

$b_{j}$ fixo, portanto

$\mathrm{E}\left[b_{j}\right]=b_{j} \mathrm{e}$

$\mathrm{E}\left[b_{j}^{2}\right]=b_{j}^{2}$;

$g_{i}$ tem distribuição normal e identicamente distribuído (NID), com média 0 e variância $\sigma_{g}^{2}, \log \mathrm{o}, \mathrm{E}\left[g_{i}\right]=0$ e $\mathrm{E}\left[g_{i}^{2}\right]=\sigma_{g}^{2}$;

$e_{i j}$ é NID, com média 0 e variância $\sigma_{p}^{2}, \operatorname{logo}, \mathrm{E}\left[e_{i j}\right]=0$ e $\mathrm{E}\left[e_{i j}^{2}\right]=\sigma_{p}^{2}$;

$\varepsilon_{i j k}$ é NID, com média 0 e variância $\sigma_{e}^{2}$, logo, $\mathrm{E}\left[\varepsilon_{i j k}\right]=0$ e $\mathrm{E}\left[\varepsilon_{i j k}^{2}\right]=\sigma_{e}^{2}$; 
Um aspecto importante a ser considerado é que as plantas do bloco 4 foram cortadas aos 4 anos para realização de análise tecnológica da madeira e posteriormente, de forma aleatória, foram retiradas 7 parcelas do bloco 3, também para realização de análise tecnológica. Além disso, alguns clones não foram plantados em todos os blocos em função da falta de material genético (mudas). Sendo assim, o experimento apresenta desbalanceamento em relação ao número de repetições. Serão, portanto, analisados somente os dados de três blocos (blocos 1, 2 e 3), o que pode ser considerado suficiente segundo estudos realizados por Farias Neto et al. (1999).

O quadro da análise da variância com as esperanças dos quadrados médios para experimentos com dados desbalanceados é apresentado na Tabela 3.

Tabela 3. Estrutura da análise da variância com as esperanças matemáticas dos quadrados médios e teste $\mathrm{F}$

\begin{tabular}{lcccc}
\hline Causas de Variação & G.L. & Q.M. & E[Q.M.] & Teste F \\
\hline Blocos & $\mathrm{J}-1$ & $\mathrm{~V} 1$ & $\sigma_{e}^{2}+n^{\prime \prime} \sigma_{p}^{2}+\Phi_{b}$ & $\mathrm{~V} 1 / \mathrm{V} 3$ \\
Clones & $\mathrm{I}-1$ & $\mathrm{~V} 2$ & $\sigma_{e}^{2}+n^{\prime} \sigma_{p}^{2}+n_{1} \sigma_{g}^{2}$ & $\mathrm{~V} 2 / \mathrm{V} 3$ \\
Resíduo & $(\mathrm{I}-1)(\mathrm{J}-1)$ & $\mathrm{V} 3$ & $\sigma_{e}^{2}+n \sigma_{p}^{2}$ & - \\
Parcelas & $\mathrm{IJ}-1$ & - & - & \\
Entre plantas dentro de Parcelas & $\mathrm{IJ}(\mathrm{K}-1)$ & $\mathrm{V} 4$ & $\sigma_{e}^{2}$ & \\
\hline Total & $\mathrm{IJK}-1$ & & &
\end{tabular}

Em função do desbalanceamento dos dados, os coeficientes $n, n^{\prime}, n " \mathrm{e}$ $n_{1}$ dos componentes de variância têm seus valores determinados segundo metodologia apresentada por Searle (1971) e citada por Barbin (1977), e $\Phi_{b}=\frac{\hat{\Sigma b_{j}^{2}}}{J-1}$.

Os estimadores de componentes de variância são dados por:

$\hat{\sigma}_{e}^{2}=V_{4}=$ Quadrado médio do erro entre plantas dentro de parcelas, associado a $\mathrm{IJ}(\mathrm{K}-1)$ graus de liberdade; 
$\hat{\sigma}_{p}^{2}=\frac{V_{3}-V_{4}}{K}$, com $n_{p}$ graus de liberdade efetivos a ele associado, obtidos pela fórmula de Satterthwaite:

$$
n_{p}=\frac{\left(V_{3}-V_{4}\right)^{2}}{\frac{V_{3}^{2}}{(I-1)(J-1)}+\frac{V_{4}^{2}}{I J(K-1)}} ;
$$

$\hat{\sigma}_{g}^{2}=\frac{V_{2}-V_{3}}{J K}$, com $n_{g}$ graus de liberdade a ele associado, dados por Satterthwaite, conforme mostrado a seguir:

$$
n_{g}=\frac{\left(V_{2}-V_{3}\right)^{2}}{\frac{V_{2}^{2}}{I-1}+\frac{V_{3}^{2}}{(I-1)(J-1)}} ;
$$

Para o processamento dos dados será utilizado o programa SELEGEN - Seleção Genética Computadorizada, desenvolvido pelo Centro Nacional de Pesquisa de Florestas da Embrapa - Empresa Brasileira de Pesquisa Agropecuária em 2002, que utiliza técnicas ótimas de avaliação genética envolvendo simultaneamente a predição de valores genéticos e a estimação de componentes de variância. O procedimento adotado pelo aplicativo para predição de valores genéticos é o BLUP (melhor predição linear não viesada), utilizando estimativas de componentes de variância obtidas pelo método da máxima verossimilhança restrita (REML). O programa emprega os modelos, estimadores e preditores apresentados por Resende (2002b) e pode ser utilizado para plantas alógamas, autógamas e com sistema reprodutivo misto. 


\section{RESULTADOS E DISCUSSÃO}

\subsection{Estatísticas Descritivas}

Pela metodologia proposta, foram coletados dados de DAP (diâmetro à altura do peito, em centímetros) e Altura (em metros) das árvores do experimento e, com essas informações, estimados os volumes das árvores que compõem cada uma das parcelas. As estatísticas descritivas para DAP, Altura e Volume podem ser observadas na Tabela 4 .

Tabela 4. Estatísticas descritivas das variáveis DAP (cm), Altura (metros) e Volume $\left(\mathrm{m}^{3}\right)$ das árvores avaliadas no experimento

\begin{tabular}{lrrr}
\hline & \multicolumn{3}{c}{ Variável } \\
Estatística & DAP $(\mathrm{cm})$ & Altura $(\mathrm{m})$ & Volume $\left(\mathrm{m}^{3}\right)$ \\
\hline Média geral & 16,55 & 25,95 & 0,283 \\
Variância & 18,87 & 22,80 & 0,027 \\
Desvio padrão & 4,34 & 4,77 & 0,165 \\
Erro padrão da Média & 0,067 & 0,074 & 0,002 \\
Máximo & 30,40 & 36,00 & 1,023 \\
Mínimo & 5,73 & 10,00 & 0,013 \\
Amplitude & 24,67 & 26,00 & 1,009 \\
Intervalo de confiança para a média $\mathrm{p}(0,05)$ & 0,13 & 0,14 & 0,005 \\
\hline
\end{tabular}

Esses resultados revelam crescimento vigoroso podendo ser comparados com crescimentos de clones de Eucalyptus grandis registrados em literatura. Vettorazzo (1989) apresenta resultados médios para DAP iguais a 14,2 cm e Altura média de 23,0 metros para clones de E. grandis aos 8,4 anos de idade. Garcia (1998), em testes de híbridos da mesma espécie, obteve resultados médios de 15,3 cm para DAP e 23,3 metros para Altura aos 5 anos de idade. Pode-se, portanto, considerar que o 
desenvolvimento médio das árvores está dentro do esperado para a espécie na idade avaliada.

\subsection{Resultados Preliminares - Análise de Variância e Esti- mativas de Componentes de Variância}

Com o objetivo de realizar uma avaliação preliminar dos dados e obter as estimativas iniciais de componentes de variância e herdabilidades para o processo iterativo, foram realizadas as análises da variância para DAP, Altura e Volume.

Utilizou-se o programa SAS, apresentado no apêndice 1, para processamento dos dados visando obter as estimativas iniciais de componentes de variância. Os resultados das análises, realizadas para cada uma das variáveis, são apresentados nas Tabelas 5 e 6.

Tabela 5. Resultados da análise da variância tradicional

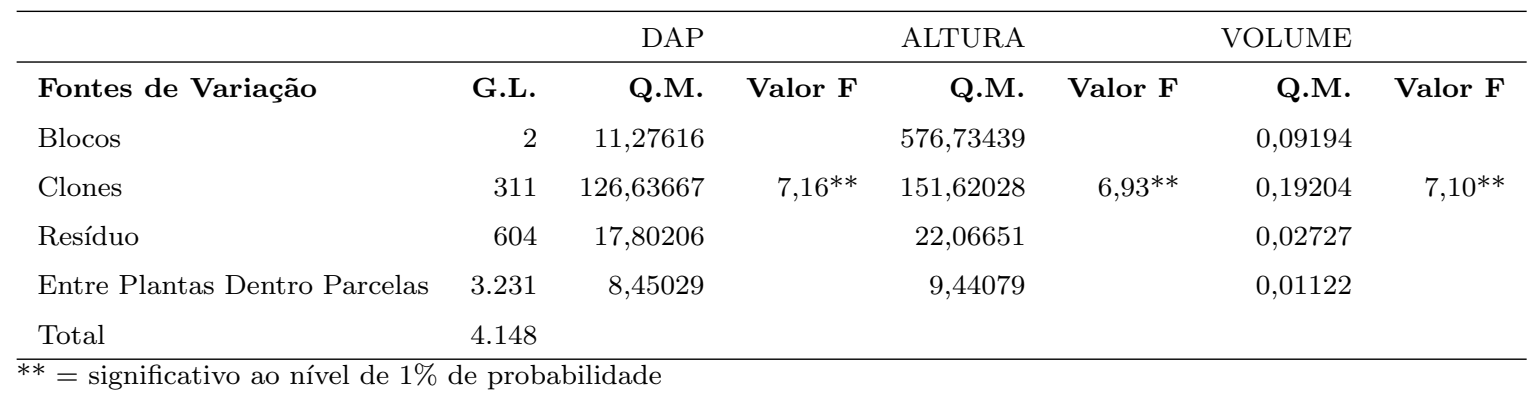

Detectou-se diferença significativa entre médias de clones ao nível de $1 \%$ de probabilidade, mostrando que existem clones com médias superiores a outros, o que poderá ser útil na seleção de clones mais produtivos. A diferença significativa entre clones permite que se efetue a seleção.

Os valores de Coeficiente de Variação experimental obtidos para DAP, Altura e Volume foram, respectivamente, 17,56; 11,84 e 37,32\%. Esses valores podem ser classificados como médios, de acordo com a proposição de Garcia (1987). O maior coeficiente de variação para a variável Volume já era esperado e se deu em função da dimensão do caráter, que é composto basicamente pelo produto das variáveis DAP e 
Altura. Segundo Houle (1992), caracteres compostos apresentam maior coeficiente de variação. Os valores dos coeficientes de variação atestam a eficiência do delineamento estatístico utilizado.

A Tabela 6 apresenta os valores de quadrados médios (QM) e suas respectivas esperanças $(\mathrm{E}[\mathrm{QM}])$, obtidos pelo comando RANDOM do PROC GLM/SAS, e utilizados para estimar os componentes de variância.

Tabela 6. Valores de Quadrados Médios e respectivas Esperanças obtidos para as características DAP, Altura e Volume

\begin{tabular}{lrrrc}
\hline F.V. & QM DAP & QM Alt & QM Vol & E[QM] \\
\hline Blocos & 11,276 & 576,734 & 0,09194 & $\operatorname{Var}($ Erro Dentro $)+4,2273 \operatorname{Var}(\operatorname{Res})+$. Q(Blocos $)$ \\
Clones & 126,637 & 151,620 & 0,1920 & $\operatorname{Var}($ Erro Dentro $)+4,4065 \operatorname{Var}(\operatorname{Res})+12,.967 \operatorname{Var}($ Clones $)$ \\
Resíduo & 17,802 & 22,067 & 0,0273 & $\operatorname{Var}($ Erro Dentro $)+4,4684 \operatorname{Var}($ Res. $)$ \\
Erro Dentro & 8,450 & 9,441 & 0,011 & $\operatorname{Var}($ Erro Dentro $)$ \\
\hline
\end{tabular}

A partir dos resultados apresentados na Tabela 6, e igualando-se os quadrados médios às suas respectivas esperanças, obteve-se estimativas iniciais de componentes de variância e herdabilidade, cujos valores foram:

a) Variável DAP:

$\hat{\sigma}_{g}^{2}=$ Estimativa da variância genotípica entre clones $=9,70654$

$\hat{\sigma}_{p}^{2}=$ Estimativa da variância do erro experimental entre parcelas $=2,09287$;

$\hat{\sigma}_{e}^{2}=$ Estimativa da variância entre árvores dentro de parcelas $=8,45029$.

A Variância Fenotípica $\left(\sigma_{f}^{2}\right)$ é estimada por:

$$
\hat{\sigma}_{f}^{2}=\hat{\sigma}_{g}^{2}+\hat{\sigma}_{p}^{2}+\hat{\sigma}_{e}^{2}=20,24970 .
$$

A herdabilidade é um dos parâmetros mais importantes dentro do programa de melhoramento genético. Ela indica, para cada caracter individualmente, quanto da variacão fenotípica corresponde à variação genética. Quanto mais altos 
os valores de herdabilidade para um caracter mais fácil se torna seu melhoramento, de acordo com Borges (1980). Altos valores de herdabilidade também indicam que mudanças no ambiente pouco influem no fenótipo, refletindo num alto controle genético.

A estimativa da herdabilidade individual no sentido amplo é dada por:

$$
\hat{h}_{g}^{2}=\hat{\sigma}_{g}^{2} / \hat{\sigma}_{f}^{2}=9,70654 / 20,24970=0,47934 .
$$

O Coeficiente de correlação entre os indivíduos da mesma parcela $\left(c^{2}\right)$, devido ao ambiente comum é obtido por:

$$
\hat{c}^{2}=\hat{\sigma}_{p}^{2} / \hat{\sigma}_{f}^{2}=2,09287 / 20,24970=0,10335 .
$$

Os parâmetros $\lambda_{1}$ e $\lambda_{2}$, que medem relações entre variâncias, são obtidos por:

$$
\begin{aligned}
& \hat{\lambda}_{1}=\frac{\hat{\sigma}_{e}^{2}}{\hat{\sigma}_{g}^{2}}=\frac{8,45029}{9,70654}=0,87058 ; \\
& \hat{\lambda}_{2}=\frac{\hat{\sigma}_{e}^{2}}{\hat{\sigma}_{p}^{2}}=\frac{8,45029}{2,09287}=4,03766 .
\end{aligned}
$$

b) Variável Altura:

$\hat{\sigma}_{g}^{2}=$ Estimativa da variância genotípica entre clones $=9,44625 ;$

$\hat{\sigma}_{p}^{2}=$ Estimativa da variância do erro experimental entre parcelas $=4,46840$;

$\hat{\sigma}_{e}^{2}=$ Estimativa da variância entre árvores dentro de parcelas $=9,44079$.

$\hat{\sigma}_{f}^{2}=\hat{\sigma}_{g}^{2}+\hat{\sigma}_{p}^{2}+\hat{\sigma}_{e}^{2}=23,35544$.

$\hat{h}_{g}^{2}=\hat{\sigma}_{g}^{2} / \hat{\sigma}_{f}^{2}=9,44625 / 23,35544=0,40446$.

$\hat{c}^{2}=\hat{\sigma}_{p}^{2} / \hat{\sigma}_{f}^{2}=4,46840 / 23,35544=0,19132$.

$\hat{\lambda}_{1}=\hat{\sigma}_{e}^{2} / \hat{\sigma}_{g}^{2}=9,44079 / 9,44625=0,99422$;

$\hat{\lambda}_{2}=\hat{\sigma}_{e}^{2} / \hat{\sigma}_{p}^{2}=9,44079 / 4,46840=2,11280$.

c) Variável Volume: 
$\hat{\sigma}_{g}^{2}=$ Estimativa da variância genotípica entre clones $=0,01274 ;$

$\hat{\sigma}_{p}^{2}=$ Estimativa da variância do erro experimental entre parcelas $=0,00359$;

$\hat{\sigma}_{e}^{2}=$ Estimativa da variância entre árvores dentro de parcelas $=0,01122$;

$\hat{\sigma}_{f}^{2}=\hat{\sigma}_{g}^{2}+\hat{\sigma}_{p}^{2}+\hat{\sigma}_{e}^{2}=0,02755$

$\hat{h}_{g}^{2}=\hat{\sigma}_{g}^{2} / \hat{\sigma}_{f}^{2}=0,01274 / 0,02755=0,46238 ;$

$\hat{c}^{2}=\hat{\sigma}_{p}^{2} / \hat{\sigma}_{f}^{2}=0,00359 / 0,02755=0,13039 ;$

$\hat{\lambda}_{1}=\hat{\sigma}_{e}^{2} / \hat{\sigma}_{g}^{2}=0,01122 / 0,01274=0,88074$;

$\hat{\lambda}_{2}=\hat{\sigma}_{e}^{2} / \hat{\sigma}_{p}^{2}=0,01122 / 0,00359=3,12320$.

O resumo das estimativas obtidas para as três características em estudo é apresentado na Tabela 7 .

Tabela 7. Estimativas preliminares de componentes de variância, herdabilidades, coeficientes de correlação intra-classe e lâmbdas obtidas para as variáveis DAP, Altura e Volume

\begin{tabular}{crrr}
\hline ESTIMATIVAS & DAP & ALTURA & VOLUME \\
\hline$\hat{\sigma}_{g}^{2}$ & 9,70654 & 9,44625 & 0,01274 \\
$\hat{\sigma}_{p}^{2}$ & 2,09287 & 4,46840 & 0,00359 \\
$\hat{\sigma}_{e}^{2}$ & 8,45029 & 9,44079 & 0,01123 \\
$\hat{\sigma}_{f}^{2}$ & 20,24970 & 23,35544 & 0,02755 \\
$\hat{h}_{g}^{2}$ & 0,47934 & 0,40446 & 0,46238 \\
$\hat{c}^{2}$ & 0,10335 & 0,19132 & 0,13039 \\
$\hat{\lambda}_{1}$ & 0,87058 & 0,99422 & 0,88074 \\
$\hat{\lambda}_{2}$ & 4,03766 & 2,11280 & 3,12320 \\
\hline
\end{tabular}

em que:

$\sigma_{g}^{2}=$ Variância genotípica entre clones;

$\sigma_{p}^{2}=$ Variância do erro experimental entre parcelas;

$\sigma_{e}^{2}=$ Variância entre árvores dentro de parcelas;

$\sigma_{f}^{2}=$ Variância fenotípica;

$h_{g}^{2}=$ Herdabilidade individual no sentido amplo;

$c^{2}=$ Coeficiente de correlação entre as plantas da parcela devido ao ambiente comum. 
Os valores de $\hat{h}_{g}^{2}$ e $\hat{c}^{2}$ obtidos para cada caracter foram utilizados como valores iniciais no processo iterativo de predição dos valores genotípicos dos clones pelo SELEGEN, que aplica a metodologia proposta neste estudo.

\subsection{Resultados de Análise pelo Método REM/BLUP}

As estimativas de componentes de variância obtidas pela análise tradicional foram aplicadas como estimativas iniciais para processamento pelo SELEGEN. Após a conclusão do processo iterativo, foram obtidos os seguintes resultados de componentes de variância, valor fenotípico, herdabilidade e coeficiente de correlação intraclasse (Tabela 8):

Tabela 8. Estimativas obtidas com o programa SELEGEN para as variáveis DAP, Altura e Volume

\begin{tabular}{crrr}
\hline ESTIMATIVAS & DAP & ALTURA & VOLUME \\
\hline$\hat{\sigma}_{g}^{2}$ & 8,66633 & 10,74664 & 0,01276 \\
$\hat{\sigma}_{p}^{2}$ & 2,08765 & 2,84824 & 0,00359 \\
$\hat{\sigma}_{e}^{2}$ & 8,47117 & 9,47090 & 0,01123 \\
$\hat{\sigma}_{f}^{2}$ & 19,22515 & 23,06578 & 0,02759 \\
$\hat{h}_{g}^{2}$ & 0,45078 & 0,46591 & 0,46256 \\
$\hat{c}^{2}$ & 0,10859 & 0,12348 & 0,13030 \\
Média geral & 16,40599 & 25,78720 & 0,27889 \\
\hline
\end{tabular}

Segundo Vencovsky \& Barriga (1992), a estimativa de parâmetros genéticos possibilita a obtenção de informações sobre a natureza de ação gênica envolvida na herança dos caracteres e se prestam para avaliação do progresso (ganho genético) esperado na seleção, além de contribuir para a definição do método de seleção a ser adotado. Segundo Falconer (1989) uma característica com alta herdabilidade pode ser melhorada através de seleção massal fenotípica, enquanto que para características de baixa herdabilidade a seleção genética por meio de teste de progênies seria mais eficiente.

Constatou-se que os novos valores estimados ficaram muito próximos 
das estimativas obtidas anteriormente com a utilização da análise de variância tradicional. Isso se deve ao fato de que a sobrevivência média do experimento tenha sido elevada, embora fosse observado desbalanceamento dentro de blocos e pelo fato de os efeitos fixos serem de apenas 3 blocos, o que pouco influenciou no ajuste dos efeitos aleatórios do modelo.

A utilização de metodologias estatísticas mais sofisticadas (modelos mistos) propiciou um pequeno ajuste das estimativas dos parâmetros genéticos das características avaliadas. Verificou-se que, para a variável Altura, a aplicação da metodologia de modelos mistos resultou numa correção do valor da herdabilidade, aproximando-o dos valores de herdabilidade estimados para as variáveis DAP e Volume, o que tornou o estudo mais consistente e sua aplicação mais interessante.

De modo geral, as estimativas dos coeficientes de herdabilidade obtidos foram muito boas, evidenciando bom controle genético na expressão dos caracteres e mostrando existir potencial para seleção dentro do experimento, com boas perspectivas de avanço genético. A herdabilidade para a variável Altura foi superior à da variável Volume, que por sua vez foi superior à da variável DAP. Kikuti (1988) registrou tendência diferente para os valores de herdabilidade obtidos em teste clonal de E. grandis avaliado aos 30 meses de idade. Os valores encontrados pelo autor foram: 0,36 para Volume; 0,28 para DAP e 0,26 para Altura.

Os desvios padrão das herdabilidades obtidos através da fórmula de Falconer (1989), para as três características foram muito semelhantes, sendo todas próximas de 0,11. Resende (2002a) cita que desvios padrão da ordem de até $20 \%$ do valor da herdabilidade seriam desejáveis para uso na predição de valores genéticos. No presente estudo, os desvios padrão corresponderam, em média, a $23 \%$ dos valores das herdabilidades. Já os coeficientes de correlação intraclasse ficaram dentro dos valores aceitáveis (em torno de 10\%), segundo proposto por Resende (2002a).

Muro-Abad et al. (2003), avaliando um teste de progênies de meios irmãos de E. pellita aos 3 anos de idade, obteve estimativas de herdabilidades para 
Altura e Volume (0,14 e 0,15 respectivamente) muito baixas em relação aos resultados obtidos neste estudo, podendo ser reflexo da idade da população ou das condições do local de instalação (região amazônica).

Para a espécie E. grandis foram obtidos valores mais altos de herdabilidade, conforme resultados de teste de progênies de meios-irmãos de E. grandis, aos 30 meses de idade, avaliado por Borges (1980). As herdabilidades (sentido restrito) obtidas, iguais a 0,48 para DAP e 0,58 para Altura, se aproximaram bastante dos resultados obtidos no teste clonal em estudo, apesar da diferença de idades observada entre os experimentos e deste último se tratar de ensaio de propagação vegetativa, no qual se estima a herdabilidade no sentido amplo.

Outros resultados para E. grandis foram apresentados por Mori \& Santos (1989) em testes de progênies, avaliados aos 7 anos de idade. Os valores obtidos, 0,13; 0,28 e 0,10 respectivamente para as características DAP, Altura e Volume, coincidem com os resultados apresentados por Kageyama (1979), que obteve herdabilidades iguais a 0,11 para DAP, 0,23 para Altura e 0,16 para Volume, para a mesma espécie, aos 5 anos de idade, porém inferiores aos valores obtidos no presente estudo.

Valores maiores de herdabilidade foram obtidas a partir de avaliação de clones de E. grandis, E. urophylla e híbridos de E. grandis por Resende (2002a). As herdabilidades para a variável volume foram iguais a 0,31, 0,30 e 0,33 para cada espécie, respectivamente.

Comparando esses resultados com os obtidos no experimento em estudo, pode-se concluir que os valores de herdabilidade obtidos em testes clonais tendem a ser superiores aos obtidos em testes de progênies. Essa tendência foi verificada por Kikuti (1988), que ao comparar estimativas de parâmetros genéticos em progênies de meios-irmãos e em testes clonais, detectou valores de herdabilidade no sentido amplo maiores que valores de herdabilidade no sentido restrito, tanto em nível de plantas individuais como em nível de médias de progênies. 
Segundo Kikuti (1988), os diferentes valores de herdabilidade encontrados por diversos autores para uma mesma espécie são função, principalmente, dos diferentes métodos utilizados na sua determinação, diferentes materiais genéticos, locais e idades, entre outros fatores.

De acordo com Eldridge (1993), o ganho genético ou progresso na seleção é o parâmetro que exprime o avanço da geração seguinte em relação à população original, decorrente da seleção efetuada. Assim, o ganho genético de seleção entre clones significa o ganho a ser obtido quando os melhores clones forem novamente propagados vegetativamente. Ainda, segundo Resende (2002a), o ganho genético pode ser definido como a superioridade (diferença) da população melhorada em relação à população não melhorada. Corresponde, portanto, ao ganho relativo de cada clone sobre a média do experimento.

O valor fenotípico corresponde aos valores observados no experimento enquanto que os valores genotípicos correspondem aos valores observados livres do efeito do ambiente. Na propagação clonal os valores genotípicos capitalizam os efeitos aditivos e de dominância. Em testes de progênies, somente os efeitos aditivos são transmitidos à descendência.

O vetor de soluções das equações de modelos mistos, processadas pelo SELEGEN, apresenta os efeitos genotípicos preditos para os 312 clones testados. Os valores genotípicos de cada clone foram obtidos somando-se cada efeito genotípico à média geral do experimento. O ganho genético equivale à média dos valores genéticos preditos para os clones selecionados. A média geral somada ao ganho genético resulta na média da população melhorada. O desempenho relativo de cada clone foi obtido pela relação entre as médias da população melhorada de cada clone e a média do clone de maior valor genotípico. Foram acrescentados, na penúltima coluna, os valores fenotípicos de cada clone, correspondentes aos valores observados no experimento.

As Tabelas 11, 12 e 13, em anexo, apresentam os efeitos genotípicos preditos $(\hat{g})$, valores genotípicos $(\mathrm{VG})$, ganhos genéticos $(\mathrm{G})$, média da população 
melhorada (MPM), valores fenotípicos (VF) e desempenho relativo (DR\%) dos 312 clones em relação às variáveis DAP, Altura e Volume, respectivamente.

Para a variável DAP, a melhor testemunha (clone 373) ocupou a posição 49 no ranking, com valor genotípico igual a 19,30 cm. A outra testemunha (clone 361) ocupou a posição 105 no ranking com valor genotípico de 17,78 cm. Dos 312 clones, 168 apresentam desempenho relativo superior a 80,0\%, sendo inviável, para a característica DAP, a seleção pelo critério adotado.

Para a variável Altura, a testemunha 373 apresentou efeito genotípico de 29,11 metros. A segunda testemunha, clone 361, apresentou valor genotípico de 26,64 metros. Neste caso, 31 clones foram superiores à melhor testemunha (373). Além disso, 100\% dos clones apresentam desempenho relativo superior a 80,0\%, sendo inviável a seleção dos clones pelo caracter Altura, adotando o critério estabelecido.

Para a variável Volume, a testemunha 373 ocupou a posição 51 com valor genotípico igual $0,39 \mathrm{~m}^{3}$ e desempenho relativo de 74,58\%. O clone 361 ocupou a posição 119 no ranking com valor genotípico igual a 0,32 $\mathrm{m}^{3}$. Seu desempenho relativo foi de apenas $66,10 \%$. Do total, 26 clones apresentaram desempenho relativo superior a $80 \%$, sendo, portanto, selecionados para propagação.

A relação dos clones selecionados em função dos valores genotípicos obtidos para a variável Volume $\left(\mathrm{m}^{3}\right)$ é apresentada na Tabela 9. Do total de 312 clones foram selecionados 23 procedentes da Aracruz (urograndis), dois de Avaré (híbridos de E. urophylla) e um originário de Cardwell, Austrália (E. grandis puro).

Todos os clones selecionados apresentaram desempenho relativo superior ao das testemunhas. Pode-se concluir que a seleção de grande maioria de material genético oriundo da Aracruz se deve ao fato das condições edafo-climáticas serem semelhantes às do local do experimento.

Selecionando-se os clones com desempenho relativo superior a 80,0\% espera-se uma nova média de volume igual a $0,519 \mathrm{~m}^{3}$ correspondendo a um aumento de 22,8\% em relação à média das testemunhas (clones de E. grandis, origem Rio 
Tabela 9. Clones selecionados em função dos valores genotípicos preditos para a variável Volume

\begin{tabular}{cccccccc}
\hline Clone & Espécie & Origem & $\begin{array}{c}\text { Média da População } \\
\text { Melhorada }\end{array}$ & Clone & Espécie & Origem & $\begin{array}{c}\text { Média da População } \\
\text { Melhorada }\end{array}$ \\
\hline 865 & urograndis & Aracruz & 0,59 & 229 & grandis & Cardwell & 0,51 \\
1028 & urograndis & Aracruz & 0,58 & 928 & urograndis & Aracruz & 0,51 \\
975 & urograndis & Aracruz & 0,57 & 981 & urograndis & Aracruz & 0,50 \\
1016 & urograndis & Aracruz & 0,56 & 1023 & urograndis & Aracruz & 0,50 \\
986 & urograndis & Aracruz & 0,55 & 1052 & urograndis & Aracruz & 0,50 \\
925 & urograndis & Aracruz & 0,55 & 1014 & urograndis & Aracruz & 0,49 \\
1006 & urograndis & Aracruz & 0,54 & 955 & urograndis & Aracruz & 0,49 \\
831 & urophylla & Avaré & 0,54 & 1044 & urograndis & Aracruz & 0,49 \\
1072 & urophylla & Avaré & 0,53 & 945 & urograndis & Aracruz & 0,49 \\
880 & urograndis & Aracruz & 0,53 & 322 & urograndis & Aracruz & 0,48 \\
931 & urograndis & Aracruz & 0,52 & 43 & urograndis & Aracruz & 0,48 \\
7 & urograndis & Aracruz & 0,52 & 1083 & urograndis & Aracruz & 0,48 \\
919 & urograndis & Aracruz & 0,51 & 832 & urograndis & Aracruz & 0,48 \\
\hline
\end{tabular}

Claro), que foi de $0,415 \mathrm{~m}^{3}$, e ganho de $36,8 \%$ em relação à média do experimento, que foi equivalente a $0,380 \mathrm{~m}^{3}$.

Para os caracteres DAP e Altura os ganhos de seleção estimados foram $15,4 \%$ e 8,9\% respectivamente em relação à média do experimento e 9,0\% e 5,1\% em relação à média das testemunhas.

A escolha dos clones com desempenho relativo superior a $80 \%$ como critério de seleção foi viável somente para a variável Volume. Para as demais variáveis poder-se-ia utilizar como critério a seleção de apenas 10,0\% dos clones, resultando na escolha de 31 clones, ao invés de 26.

Uma vez que foram retiradas amostras dos clones para avaliação tecnológica da madeira, recomenda-se que sejam realizados estudos associando as propriedades tecnológicas da madeira aos dados observados para análise através de modelos multivariados ou multidimensionais. 


\section{CONCLUSÕES}

Com base nos resultados dos estudos realizados, pode-se concluir que:

a) A análise do experimento utilizando a metodologia de modelos mistos mostrouse adequado para avaliação do teste clonal de Eucalyptus spp, possibilitando obter as estimativas de componentes de variância e a predição de valores genotípicos visando a seleção de clones.

b) Os valores de herdabilidade, obtidos a partir das estimativas dos componentes de variância pelo método proposto, foram iguais a 0,451 para DAP, 0,466 para Altura e 0,463 para Volume. Os valores foram considerados altos, em comparação com resultados apresentados em literatura. Aliados a baixos valores de desvio padrão, as herdabilidades evidenciam bom controle genético na expressão dos caracteres e mostram bom potencial para seleção dentro do experimento, com ótimas perspectivas de avanço genético.

c) A seleção dos clones com desempenho relativo superior a $80 \%$ para a variável volume resultou num aumento de 22,8\% em relação à média das testemunhas (clones de E. grandis, origem Rio Claro), e de 36,8\% em relação à média do experimento. Do total de 312 clones foram selecionados 26, sendo 23 clones procedentes da Aracruz (E. urograndis), dois de Avaré (híbridos de E. urophylla) e um originário de Cardwell, Austrália (E. grandis puro).

d) Para as variáveis DAP e Altura, poder-se-ia utilizar como critério a seleção de apenas $10 \%$ dos clones, selecionando 31 clones, uma vez que o critério adotado não se mostrou adequado para seleção com base nestas duas características. 
ANEXOS 
Tabela 10. Identificação dos tratamentos - codificação e procedência do material genético

\begin{tabular}{|c|c|c|c|c|c|c|c|}
\hline Clone & Procedência & Clone & Procedência & Clone & Procedência & Clone & Procedência \\
\hline 2 & Aracruz & 47 & Rio Claro & 146 & Mount Spurgeon & 219 & Cardwell \\
\hline 3 & Rio Claro & 48 & Rio Claro & 147 & África do Sul & 221 & Cardwell \\
\hline 5 & Aracruz & 49 & Rio Claro & 148 & Mount Lewis C & 223 & Cardwell \\
\hline 6 & Aracruz & 51 & Rio Claro & 149 & Mount Lewis B & 224 & Cardwell \\
\hline 7 & Aracruz & 52 & Rio Claro & 150 & Atherton SF 194 & 225 & Cardwell \\
\hline 8 & Aracruz & 53 & África do Sul & 151 & Mount Spurgeon & 226 & Cardwell \\
\hline 9 & Aracruz & 54 & Rio Claro & 152 & Mount Spurgeon & 227 & Cardwell \\
\hline 10 & Aracruz & 56 & Rio Claro & 153 & Mount Lewis A & 228 & Cardwell \\
\hline 11 & Aracruz & 57 & Mount Lewis C & 154 & Mount Lewis A & 229 & Cardwell \\
\hline 12 & Aracruz & 58 & Mount Spurgeon & 155 & Tina Road SF 185 & 230 & Cardwell \\
\hline 13 & Rio Claro & 60 & Atherton SF 194 & 158 & Mount Spurgeon & 233 & Cardwell \\
\hline 14 & Aracruz & 62 & Mount Lewis C & 159 & Atherton SF 194 & 234 & Cardwell \\
\hline 15 & Aracruz & 64 & Mount Spurgeon & 162 & Atherton SF 194 & 235 & Cardwell \\
\hline 16 & Aracruz & 70 & Atherton SF 194 & 163 & Atherton SF 195 & 236 & Cardwell \\
\hline 17 & Aracruz & 76 & Mount Lewis C & 164 & Mount Spurgeon & 238 & Rio Claro \\
\hline 18 & Aracruz & 78 & Mount Spurgeon & 165 & Tina Road SF 185 & 253 & Kiogle APS 2 \\
\hline 19 & Aracruz & 79 & Mount Lewis C & 167 & Mount Lewis C & 259 & Não consta \\
\hline 20 & Aracruz & 80 & Atherton SF 194 & 168 & Mount Lewis A & 261 & Não consta \\
\hline 21 & Rio Claro & 83 & Mount Lewis C & 171 & Atherton SF 194 & 262 & Não consta \\
\hline 22 & Aracruz & 84 & Mount Spurgeon & 176 & Tina Road SF 185 & 263 & Não consta \\
\hline 23 & Aracruz & 93 & Mount Spurgeon & 182 & Mount Lewis B & 264 & Não consta \\
\hline 24 & Aracruz & 94 & Mount Lewis C & 185 & West Herberton & 265 & Aracruz \\
\hline 25 & Aracruz & 98 & Mount Lewis C & 186 & West Herberton & 266 & Aracruz \\
\hline 26 & Aracruz & 101 & Atherton & 191 & West Herberton & 267 & Aracruz \\
\hline 27 & Aracruz & 103 & Mount Spurgeon & 192 & West Herberton & 268 & Aracruz \\
\hline 28 & Aracruz & 106 & Atherton SF 194 & 196 & Kirrima SF & 269 & Aracruz \\
\hline 29 & Aracruz & 125 & Mount Spurgeon & 198 & Kiogle APS 2 & 270 & Aracruz \\
\hline 30 & Aracruz & 127 & Mount Lewis C & 199 & Cardwell & 271 & Aracruz \\
\hline 31 & Aracruz & 128 & Mount Spurgeon & 201 & Cardwell & 272 & Aracruz \\
\hline 32 & Aracruz & 130 & Rio Claro & 202 & Cardwell & 273 & Aracruz \\
\hline 33 & Aracruz & 133 & Windsor Tablelands & 203 & Cardwell & 274 & Não consta \\
\hline 38 & Aracruz & 134 & Mount Lewis C & 204 & Cardwell & 275 & Aracruz \\
\hline 39 & Rio Claro & 135 & Tina Road SF 185 & 205 & Cardwell & 276 & Não consta \\
\hline 40 & Aracruz & 139 & Mount Spurgeon & 208 & Cardwell & 277 & Aracruz \\
\hline 41 & Aracruz & 140 & Mount Lewis C & 209 & Cardwell & 278 & Não consta \\
\hline 42 & Aracruz & 141 & Mount Spurgeon & 210 & Cardwell & 279 & Aracruz \\
\hline 43 & Aracruz & 143 & Mount Lewis A & 214 & Cardwell & 280 & Aracruz \\
\hline 44 & Rio Claro & 144 & Mount Spurgeon & 215 & Cardwell & 281 & Aracruz \\
\hline 45 & Rio Claro & 145 & Mount Spurgeon & 218 & Cardwell & 282 & Aracruz \\
\hline
\end{tabular}


Tabela 10. Identificação dos tratamentos - codificação e procedência do material genético

\begin{tabular}{|c|c|c|c|c|c|c|c|}
\hline Clone & Procedência & Clone & Procedência & Clone & Procedência & Clone & Procedência \\
\hline 284 & Aracruz & 836 & Avaré & 892 & Aracruz & 997 & Aracruz \\
\hline 285 & Aracruz & 837 & Rio Claro & 894 & Aracruz & 1001 & Aracruz \\
\hline 286 & Aracruz & 838 & Rio Claro & 903 & Aracruz & 1003 & Aracruz \\
\hline 288 & Aracruz & 839 & Rio Claro & 910 & Aracruz & 1004 & Aracruz \\
\hline 295 & Aracruz & 840 & Não consta & 918 & Aracruz & 1006 & Aracruz \\
\hline 306 & Aracruz & 841 & Rio Claro & 919 & Aracruz & 1007 & Aracruz \\
\hline 307 & Aracruz & 842 & Avaré & 920 & Aracruz & 1010 & Aracruz \\
\hline 310 & Aracruz & 843 & Rio Claro & 922 & Aracruz & 1014 & Aracruz \\
\hline 311 & Aracruz & 844 & Avaré & 925 & Aracruz & 1016 & Aracruz \\
\hline 312 & Aracruz & 845 & Avaré & 927 & Aracruz & 1019 & Aracruz \\
\hline 313 & Aracruz & 846 & Avaré & 928 & Aracruz & 1023 & Aracruz \\
\hline 314 & Aracruz & 847 & Avaré & 929 & Aracruz & 1028 & Aracruz \\
\hline 315 & Aracruz & 848 & Avaré & 930 & Aracruz & 1031 & Aracruz \\
\hline 316 & Aracruz & 849 & Não consta & 931 & Aracruz & 1034 & Aracruz \\
\hline 317 & Aracruz & 850 & Aracruz & 933 & Aracruz & 1044 & Aracruz \\
\hline 318 & Aracruz & 851 & Rio Claro & 935 & Aracruz & 1045 & Aracruz \\
\hline 319 & Aracruz & 852 & Avaré & 937 & Aracruz & 1052 & Aracruz \\
\hline 320 & Aracruz & 853 & Avaré & 945 & Aracruz & 1061 & Rio Claro \\
\hline 321 & Aracruz & 854 & Avaré & 947 & Aracruz & 1062 & Rio Claro \\
\hline 322 & Aracruz & 855 & Rio Claro & 948 & Aracruz & 1068 & Avaré \\
\hline 323 & Aracruz & 856 & Avaré & 949 & Aracruz & 1069 & Avaré \\
\hline 324 & Aracruz & 858 & Avaré & 952 & Aracruz & 1071 & Avaré \\
\hline 325 & Aracruz & 859 & Aracruz & 953 & Aracruz & 1072 & Avaré \\
\hline 326 & Aracruz & 860 & Avaré & 955 & Aracruz & 1073 & Avaré \\
\hline 327 & Aracruz & 861 & Aracruz & 956 & Aracruz & 1074 & Avaré \\
\hline 328 & Aracruz & 862 & Aracruz & 959 & Aracruz & 1075 & Avaré \\
\hline 361 & Rio Claro & 864 & Aracruz & 960 & Aracruz & 1076 & Avaré \\
\hline 373 & Rio Claro & 865 & Aracruz & 964 & Aracruz & 1077 & Avaré \\
\hline 528 & Rio Claro & 872 & Aracruz & 966 & Aracruz & 1081 & Aracruz \\
\hline 594 & Rio Claro & 873 & Aracruz & 968 & Aracruz & 1082 & Aracruz \\
\hline 645 & Aracruz & 875 & Aracruz & 975 & Aracruz & 1083 & Aracruz \\
\hline 828 & Rio Claro & 879 & Aracruz & 977 & Aracruz & 1085 & Mount Lewis C \\
\hline 829 & Não consta & 880 & Aracruz & 979 & Aracruz & 1086 & Atherton SF 194 \\
\hline 830 & Avaré & 881 & Aracruz & 980 & Aracruz & 1089 & Mount Lewis C \\
\hline 831 & Avaré & 882 & Aracruz & 981 & Aracruz & 1092 & Mount Spurgeon \\
\hline 832 & Aracruz & 884 & Aracruz & 986 & Aracruz & 1094 & Mount Spurgeon \\
\hline 833 & Rio Claro & 888 & Aracruz & 988 & Aracruz & 1095 & Mount Lewis C \\
\hline 834 & Avaré & 889 & Aracruz & 991 & Aracruz & 1096 & Rio Claro \\
\hline 835 & Rio Claro & 891 & Aracruz & 993 & Aracruz & 1099 & Aracruz \\
\hline
\end{tabular}


Tabela 11. Valores obtidos pelo SELEGEN para a variável DAP

\begin{tabular}{|c|c|c|c|c|c|c|c|c|c|c|c|c|c|}
\hline Clone & $\hat{g}$ & VG & Ganho & MPM & VF & DR\% & Clone & $\hat{g}$ & VG & Ganho & MPM & $\mathrm{VF}$ & DR\% \\
\hline 865 & 6,72 & 23,13 & 6,72 & 23,13 & 24,11 & 100,0 & 234 & 2,87 & 19,27 & 3,87 & 20,27 & 19,94 & 87,6 \\
\hline 1028 & 6,24 & 22,65 & 6,48 & 22,89 & 23,55 & 99,0 & 948 & 2,86 & 19,27 & 3,85 & 20,25 & 19,58 & 87,5 \\
\hline 975 & 5,83 & 22,23 & 6,26 & 22,67 & 23,07 & 98,0 & 191 & 2,82 & 19,23 & 3,83 & 20,23 & 19,59 & 87,5 \\
\hline 986 & 5,55 & 21,96 & 6,09 & 22,49 & 22,44 & 97,2 & 316 & 2,72 & 19,13 & 3,81 & 20,21 & 19,52 & 87,4 \\
\hline 1006 & 5,54 & 21,94 & 5,98 & 22,38 & 22,75 & 96,8 & 1096 & 2,64 & 19,05 & 3,79 & 20,19 & 19,50 & 87,3 \\
\hline 925 & 4,97 & 21,38 & 5,81 & 22,21 & 22,10 & 96,0 & 892 & 2,55 & 18,95 & 3,77 & 20,17 & 19,32 & 87,2 \\
\hline 1016 & 4,94 & 21,34 & 5,68 & 22,09 & 22,16 & 95,5 & 1007 & 2,54 & 18,94 & 3,75 & 20,15 & 19,30 & 87,1 \\
\hline 831 & 4,92 & 21,33 & 5,59 & 21,99 & 22,10 & 95,1 & 47 & 2,51 & 18,91 & 3,73 & 20,13 & 19,36 & 87,0 \\
\hline 880 & 4,77 & 21,17 & 5,50 & 21,90 & 21,85 & 94,7 & 949 & 2,50 & 18,91 & 3,71 & 20,11 & 19,27 & 86,9 \\
\hline 7 & 4,76 & 21,17 & 5,42 & 21,83 & 21,89 & 94,4 & 991 & 2,50 & 18,90 & 3,69 & 20,09 & 19,24 & 86,9 \\
\hline 1072 & 4,76 & 21,16 & 5,36 & 21,77 & 21,86 & 94,1 & 326 & 2,48 & 18,89 & 3,67 & 20,07 & 19,33 & 86,8 \\
\hline 229 & 4,56 & 20,96 & 5,30 & 21,70 & 21,62 & 93,8 & 281 & 2,46 & 18,87 & 3,65 & 20,05 & 19,18 & 86,7 \\
\hline 919 & 4,48 & 20,89 & 5,23 & 21,64 & 21,54 & 93,6 & 888 & 2,46 & 18,86 & 3,63 & 20,04 & 19,31 & 86,6 \\
\hline 981 & 4,43 & 20,83 & 5,18 & 21,58 & 21,48 & 93,3 & 922 & 2,41 & 18,81 & 3,61 & 20,02 & 19,16 & 86,6 \\
\hline 931 & 4,16 & 20,57 & 5,11 & 21,51 & 21,19 & 93,0 & 204 & 2,37 & 18,78 & 3,59 & 20,00 & 19,29 & 86,5 \\
\hline 928 & 4,10 & 20,50 & 5,04 & 21,45 & 21,26 & 92,7 & 645 & 2,28 & 18,69 & 3,57 & 19,98 & 19,32 & 86,4 \\
\hline 43 & 4,06 & 20,47 & 4,99 & 21,39 & 21,11 & 92,5 & 228 & 2,28 & 18,68 & 3,55 & 19,96 & 19,23 & 86,3 \\
\hline 1023 & 4,04 & 20,44 & 4,93 & 21,34 & 20,93 & 92,3 & 859 & 2,27 & 18,68 & 3,54 & 19,94 & 18,96 & 86,2 \\
\hline 968 & 3,88 & 20,29 & 4,88 & 21,28 & 20,86 & 92,0 & 226 & 2,26 & 18,66 & 3,52 & 19,92 & 18,99 & 86,1 \\
\hline 322 & 3,86 & 20,27 & 4,83 & 21,23 & 20,76 & 91,8 & 328 & 2,26 & 18,66 & 3,50 & 19,91 & 18,99 & 86,1 \\
\hline 1044 & 3,85 & 20,26 & 4,78 & 21,19 & 20,82 & 91,6 & 327 & 2,22 & 18,62 & 3,48 & 19,89 & 18,85 & 86,0 \\
\hline 1052 & 3,82 & 20,23 & 4,74 & 21,14 & 20,78 & 91,4 & 844 & 2,21 & 18,62 & 3,47 & 19,87 & 19,20 & 85,9 \\
\hline 945 & 3,81 & 20,22 & 4,70 & 21,10 & 20,68 & 91,2 & 1010 & 2,20 & 18,60 & 3,45 & 19,85 & 18,93 & 85,8 \\
\hline 832 & 3,80 & 20,20 & 4,66 & 21,07 & 20,75 & 91,1 & 22 & 2,18 & 18,59 & 3,43 & 19,84 & 18,91 & 85,8 \\
\hline 920 & 3,65 & 20,06 & 4,62 & 21,03 & 20,51 & 90,9 & 29 & 2,17 & 18,57 & 3,42 & 19,82 & 18,89 & 85,7 \\
\hline 24 & 3,63 & 20,03 & 4,58 & 20,99 & 20,51 & 90,7 & 1089 & 2,16 & 18,57 & 3,40 & 19,81 & 18,83 & 85,6 \\
\hline 964 & 3,56 & 19,96 & 4,54 & 20,95 & 20,57 & 90,6 & 143 & 2,15 & 18,55 & 3,38 & 19,79 & 18,84 & 85,6 \\
\hline 988 & 3,51 & 19,91 & 4,51 & 20,91 & 20,42 & 90,4 & 993 & 2,13 & 18,54 & 3,37 & 19,77 & 18,85 & 85,5 \\
\hline 1034 & 3,49 & 19,90 & 4,47 & 20,88 & 20,41 & 90,3 & 966 & 2,10 & 18,51 & 3,35 & 19,76 & 18,80 & 85,4 \\
\hline 952 & 3,43 & 19,83 & 4,44 & 20,84 & 20,33 & 90,1 & 881 & 2,10 & 18,51 & 3,34 & 19,74 & 18,81 & 85,3 \\
\hline 25 & 3,40 & 19,80 & 4,40 & 20,81 & 20,31 & 90,0 & 872 & 2,10 & 18,50 & 3,32 & 19,73 & 18,77 & 85,3 \\
\hline 186 & 3,36 & 19,77 & 4,37 & 20,78 & 20,36 & 89,8 & 929 & 2,03 & 18,44 & 3,31 & 19,71 & 18,74 & 85,2 \\
\hline 1004 & 3,36 & 19,77 & 4,34 & 20,75 & 20,26 & 89,7 & 834 & 2,00 & 18,40 & 3,29 & 19,70 & 18,70 & 85,2 \\
\hline 221 & 3,30 & 19,70 & 4,31 & 20,71 & 20,18 & 89,5 & 295 & 2,00 & 18,40 & 3,28 & 19,68 & 18,70 & 85,1 \\
\hline 1083 & 3,28 & 19,69 & 4,28 & 20,69 & 20,16 & 89,5 & 959 & 1,93 & 18,33 & 3,26 & 19,67 & 18,65 & 85,0 \\
\hline 1014 & 3,28 & 19,68 & 4,25 & 20,66 & 20,16 & 89,3 & 937 & 1,91 & 18,32 & 3,25 & 19,65 & 18,55 & 85,0 \\
\hline 927 & 3,25 & 19,66 & 4,22 & 20,63 & 20,13 & 89,2 & 17 & 1,89 & 18,29 & 3,23 & 19,64 & 18,63 & 84,9 \\
\hline 873 & 3,24 & 19,65 & 4,20 & 20,60 & 20,05 & 89,1 & 38 & 1,86 & 18,26 & 3,22 & 19,62 & 18,54 & 84,8 \\
\hline 320 & 3,22 & 19,63 & 4,17 & 20,58 & 20,10 & 89,0 & 1081 & 1,82 & 18,22 & 3,20 & 19,61 & 18,55 & 84,8 \\
\hline 935 & 3,18 & 19,59 & 4,15 & 20,55 & 20,14 & 88,8 & 910 & 1,79 & 18,19 & 3,18 & 19,59 & 18,22 & 84,7 \\
\hline 845 & 3,16 & 19,57 & 4,12 & 20,53 & 20,06 & 88,8 & 23 & 1,77 & 18,17 & 3,17 & 19,58 & 18,43 & 84,7 \\
\hline 57 & 3,13 & 19,53 & 4,10 & 20,51 & 19,72 & 88,7 & 202 & 1,69 & 18,10 & 3,15 & 19,56 & 18,51 & 84,6 \\
\hline 997 & 3,11 & 19,52 & 4,08 & 20,48 & 19,97 & 88,5 & 1003 & 1,68 & 18,09 & 3,14 & 19,54 & 18,33 & 84,5 \\
\hline 273 & 3,06 & 19,47 & 4,06 & 20,46 & 19,91 & 88,5 & 903 & 1,66 & 18,06 & 3,12 & 19,53 & 18,30 & 84,4 \\
\hline 875 & 3,03 & 19,44 & 4,03 & 20,44 & 19,86 & 88,4 & 263 & 1,62 & 18,02 & 3,11 & 19,51 & 18,26 & 84,3 \\
\hline 42 & 3,03 & 19,43 & 4,01 & 20,42 & 19,87 & 88,3 & 856 & 1,60 & 18,00 & 3,09 & 19,50 & 18,62 & 84,3 \\
\hline 225 & 3,02 & 19,42 & 3,99 & 20,40 & 19,86 & 88,2 & 33 & 1,55 & 17,95 & 3,08 & 19,48 & 18,13 & 84,2 \\
\hline 891 & 2,96 & 19,36 & 3,97 & 20,37 & 19,82 & 88,1 & 918 & 1,50 & 17,90 & 3,06 & 19,47 & 18,06 & 84,2 \\
\hline 373 & 2,90 & 19,30 & 3,95 & 20,35 & 19,73 & 88,0 & 930 & 1,44 & 17,85 & 3,04 & 19,45 & 18,08 & 84,1 \\
\hline 1045 & 2,89 & 19,29 & 3,92 & 20,33 & 19,65 & 87,9 & 1082 & 1,40 & 17,80 & 3,03 & 19,43 & 18,01 & 84,0 \\
\hline 1019 & 2,89 & 19,29 & 3,90 & 20,31 & 19,71 & 87,8 & 847 & 1,39 & 17,79 & 3,01 & 19,42 & 17,83 & 84,0 \\
\hline 955 & 2,87 & 19,28 & 3,88 & 20,29 & 19,88 & 87,7 & 196 & 1,38 & 17,79 & 3,00 & 19,40 & 18,08 & 83,9 \\
\hline
\end{tabular}


Tabela 11. Valores obtidos pelo SELEGEN para a variável DAP

\begin{tabular}{|c|c|c|c|c|c|c|c|c|c|c|c|c|c|}
\hline Clone & $\hat{g}$ & VG & Ganho & MPM & $\mathrm{VF}$ & DR\% & Clone & $\hat{g}$ & $\mathrm{VG}$ & Ganho & MPM & VF & DR\% \\
\hline 361 & 1,38 & 17,78 & 2,98 & 19,39 & 17,99 & 83,8 & 106 & 0,13 & 16,53 & 2,26 & 18,66 & 16,55 & 80,7 \\
\hline 1001 & 1,36 & 17,77 & 2,97 & 19,37 & 17,92 & 83,7 & 145 & 0,07 & 16,48 & 2,24 & 18,65 & 16,49 & 80,6 \\
\hline 311 & 1,30 & 17,70 & 2,95 & 19,36 & 17,89 & 83,7 & 862 & 0,06 & 16,46 & 2,23 & 18,64 & 16,60 & 80,6 \\
\hline 269 & 1,28 & 17,68 & 2,93 & 19,34 & 18,05 & 83,6 & 18 & 0,04 & 16,44 & 2,22 & 18,62 & 16,49 & 80,5 \\
\hline 853 & 1,27 & 17,68 & 2,92 & 19,33 & 18,00 & 83,6 & 128 & $-0,06$ & 16,34 & 2,20 & 18,61 & 16,43 & 80,5 \\
\hline 219 & 1,27 & 17,67 & 2,90 & 19,31 & 17,84 & 83,5 & 209 & $-0,08$ & 16,32 & 2,19 & 18,59 & 16,06 & 80,4 \\
\hline 977 & 1,27 & 17,67 & 2,89 & 19,30 & 17,86 & 83,4 & 158 & $-0,13$ & 16,27 & 2,17 & 18,58 & 16,26 & 80,3 \\
\hline 879 & 1,25 & 17,66 & 2,88 & 19,28 & 17,66 & 83,4 & 894 & $-0,13$ & 16,27 & 2,16 & 18,57 & 16,30 & 80,3 \\
\hline 846 & 1,21 & 17,62 & 2,86 & 19,27 & 17,86 & 83,3 & 850 & $-0,14$ & 16,27 & 2,15 & 18,55 & 16,11 & 80,2 \\
\hline 84 & 1,19 & 17,60 & 2,85 & 19,25 & 17,68 & 83,2 & 980 & $-0,16$ & 16,25 & 2,13 & 18,54 & 16,17 & 80,2 \\
\hline 164 & 1,17 & 17,58 & 2,83 & 19,24 & 17,72 & 83,2 & 176 & $-0,20$ & 16,20 & 2,12 & 18,52 & 16,14 & 80,1 \\
\hline 852 & 1,14 & 17,54 & 2,82 & 19,22 & 17,80 & 83,1 & 205 & $-0,21$ & 16,20 & 2,10 & 18,51 & 16,17 & 80,0 \\
\hline 6 & 1,13 & 17,53 & 2,80 & 19,21 & 17,70 & 83,1 & 1099 & $-0,24$ & 16,17 & 2,09 & 18,50 & 16,11 & 80,0 \\
\hline 310 & 1,13 & 17,53 & 2,79 & 19,19 & 17,70 & 83,0 & 80 & $-0,25$ & 16,16 & 2,08 & 18,48 & 16,13 & 79,9 \\
\hline 266 & 1,13 & 17,53 & 2,77 & 19,18 & 17,70 & 82,9 & 238 & $-0,25$ & 16,16 & 2,06 & 18,47 & 16,11 & 79,9 \\
\hline 979 & 1,05 & 17,46 & 2,76 & 19,17 & 17,61 & 82,9 & 224 & $-0,30$ & 16,11 & 2,05 & 18,46 & 16,06 & 79,8 \\
\hline 27 & 1,01 & 17,41 & 2,75 & 19,15 & 17,57 & 82,8 & 854 & $-0,31$ & 16,09 & 2,04 & 18,44 & 16,09 & 79,7 \\
\hline 185 & 0,99 & 17,40 & 2,73 & 19,14 & 17,43 & 82,7 & 76 & $-0,35$ & 16,06 & 2,02 & 18,43 & 16,01 & 79,7 \\
\hline 11 & 0,97 & 17,38 & 2,72 & 19,12 & 17,52 & 82,7 & 849 & $-0,35$ & 16,05 & 2,01 & 18,41 & 16,00 & 79,6 \\
\hline 933 & 0,97 & 17,38 & 2,70 & 19,11 & 17,42 & 82,6 & 313 & $-0,36$ & 16,04 & 1,99 & 18,40 & 16,11 & 79,6 \\
\hline 41 & 0,94 & 17,35 & 2,69 & 19,09 & 17,49 & 82,5 & 133 & $-0,36$ & 16,04 & 1,98 & 18,39 & 15,99 & 79,5 \\
\hline 306 & 0,91 & 17,32 & 2,67 & 19,08 & 17,45 & 82,5 & 40 & $-0,39$ & 16,01 & 1,97 & 18,37 & 15,94 & 79,4 \\
\hline 288 & 0,91 & 17,31 & 2,66 & 19,07 & 17,53 & 82,4 & 279 & $-0,42$ & 15,99 & 1,95 & 18,36 & 15,69 & 79,4 \\
\hline 198 & 0,89 & 17,29 & 2,65 & 19,05 & 17,42 & 82,4 & 271 & $-0,44$ & 15,97 & 1,94 & 18,35 & 15,90 & 79,3 \\
\hline 325 & 0,86 & 17,27 & 2,63 & 19,04 & 17,39 & 82,3 & 31 & $-0,47$ & 15,93 & 1,93 & 18,33 & 15,86 & 79,2 \\
\hline 307 & 0,86 & 17,26 & 2,62 & 19,02 & 17,40 & 82,2 & 56 & $-0,48$ & 15,93 & 1,92 & 18,32 & 15,79 & 79,2 \\
\hline 1085 & 0,86 & 17,26 & 2,61 & 19,01 & 17,48 & 82,2 & 5 & $-0,50$ & 15,90 & 1,90 & 18,31 & 15,89 & 79,2 \\
\hline 28 & 0,83 & 17,24 & 2,59 & 19,00 & 17,36 & 82,1 & 1077 & $-0,57$ & 15,84 & 1,89 & 18,29 & 15,65 & 79,1 \\
\hline 267 & 0,81 & 17,22 & 2,58 & 18,98 & 17,36 & 82,1 & 956 & $-0,57$ & 15,83 & 1,88 & 18,28 & 15,64 & 79,0 \\
\hline 953 & 0,79 & 17,20 & 2,57 & 18,97 & 17,32 & 82,0 & 1074 & $-0,67$ & 15,74 & 1,86 & 18,27 & 15,54 & 79,0 \\
\hline 889 & 0,77 & 17,17 & 2,55 & 18,96 & 17,18 & 82,0 & 167 & $-0,68$ & 15,72 & 1,85 & 18,25 & 15,53 & 78,9 \\
\hline 321 & 0,76 & 17,16 & 2,54 & 18,94 & 17,27 & 81,9 & 947 & $-0,73$ & 15,67 & 1,83 & 18,24 & 15,57 & 78,9 \\
\hline 152 & 0,73 & 17,14 & 2,53 & 18,93 & 17,26 & 81,8 & 1092 & $-0,74$ & 15,67 & 1,82 & 18,23 & 15,54 & 78,8 \\
\hline 830 & 0,71 & 17,12 & 2,51 & 18,92 & 17,99 & 81,8 & 235 & $-0,75$ & 15,66 & 1,81 & 18,21 & 15,66 & 78,7 \\
\hline 261 & 0,68 & 17,09 & 2,50 & 18,91 & 17,19 & 81,8 & 32 & $-0,76$ & 15,64 & 1,79 & 18,20 & 15,54 & 78,7 \\
\hline 861 & 0,63 & 17,04 & 2,49 & 18,89 & 17,12 & 81,7 & 314 & $-0,77$ & 15,64 & 1,78 & 18,19 & 15,52 & 78,6 \\
\hline 2 & 0,62 & 17,03 & 2,47 & 18,88 & 17,12 & 81,6 & 20 & $-0,78$ & 15,63 & 1,77 & 18,17 & 15,51 & 78,6 \\
\hline 864 & 0,58 & 16,99 & 2,46 & 18,87 & 17,14 & 81,6 & 208 & $-0,78$ & 15,63 & 1,75 & 18,16 & 15,51 & 78,5 \\
\hline 882 & 0,55 & 16,96 & 2,45 & 18,85 & 17,02 & 81,5 & 135 & $-0,80$ & 15,61 & 1,74 & 18,15 & 15,40 & 78,5 \\
\hline 15 & 0,55 & 16,96 & 2,43 & 18,84 & 17,04 & 81,5 & 1086 & $-0,83$ & 15,58 & 1,73 & 18,13 & 15,56 & 78,4 \\
\hline 842 & 0,52 & 16,93 & 2,42 & 18,83 & 17,29 & 81,4 & 64 & $-0,84$ & 15,56 & 1,71 & 18,12 & 15,12 & 78,3 \\
\hline 282 & 0,48 & 16,89 & 2,41 & 18,81 & 17,04 & 81,3 & 1031 & $-0,92$ & 15,49 & 1,70 & 18,11 & 15,35 & 78,3 \\
\hline 153 & 0,47 & 16,88 & 2,39 & 18,80 & 16,95 & 81,3 & 884 & $-0,92$ & 15,48 & 1,69 & 18,09 & 15,36 & 78,2 \\
\hline 214 & 0,43 & 16,84 & 2,38 & 18,79 & 16,90 & 81,2 & 192 & $-0,93$ & 15,48 & 1,67 & 18,08 & 15,15 & 78,2 \\
\hline 285 & 0,37 & 16,77 & 2,37 & 18,77 & 16,83 & 81,2 & 203 & $-0,98$ & 15,43 & 1,66 & 18,07 & 15,30 & 78,1 \\
\hline 171 & 0,34 & 16,75 & 2,35 & 18,76 & 16,80 & 81,1 & 151 & $-1,02$ & 15,39 & 1,65 & 18,05 & 15,35 & 78,0 \\
\hline 159 & 0,34 & 16,75 & 2,34 & 18,75 & 16,85 & 81,1 & 858 & $-1,07$ & 15,33 & 1,64 & 18,04 & 15,01 & 78,0 \\
\hline 268 & 0,25 & 16,65 & 2,33 & 18,73 & 16,69 & 81,0 & 26 & $-1,07$ & 15,33 & 1,62 & 18,03 & 15,17 & 78,0 \\
\hline 528 & 0,23 & 16,64 & 2,31 & 18,72 & 16,75 & 80,9 & 230 & $-1,25$ & 15,16 & 1,61 & 18,01 & 15,07 & 77,9 \\
\hline 319 & 0,23 & 16,63 & 2,30 & 18,70 & 16,59 & 80,8 & 317 & $-1,29$ & 15,11 & 1,59 & 18,00 & 14,81 & 77,8 \\
\hline 210 & 0,16 & 16,57 & 2,29 & 18,69 & 16,54 & 80,8 & 265 & $-1,36$ & 15,04 & 1,58 & 17,99 & 14,84 & 77,8 \\
\hline 127 & 0,14 & 16,55 & 2,27 & 18,68 & 16,56 & 80,8 & 1073 & $-1,37$ & 15,03 & 1,57 & 17,97 & 14,69 & 77,7 \\
\hline
\end{tabular}


Tabela 11. Valores obtidos pelo SELEGEN para a variável DAP

\begin{tabular}{|c|c|c|c|c|c|c|c|c|c|c|c|c|c|}
\hline Clone & $\hat{g}$ & $\mathrm{VG}$ & Ganho & MPM & VF & DR\% & Clone & $\hat{g}$ & VG & Ganho & MPM & VF & DR\% \\
\hline 223 & $-1,39$ & 15,02 & 1,55 & 17,96 & 14,85 & 77,6 & 218 & $-2,86$ & 13,54 & 0,82 & 17,22 & 13,13 & 74,4 \\
\hline 8 & $-1,42$ & 14,98 & 1,54 & 17,94 & 14,97 & 77,6 & 182 & $-2,87$ & 13,54 & 0,80 & 17,21 & 12,90 & 74,4 \\
\hline 1075 & $-1,45$ & 14,96 & 1,52 & 17,93 & 14,67 & 77,5 & 19 & $-2,91$ & 13,49 & 0,79 & 17,19 & 12,73 & 74,3 \\
\hline 144 & $-1,45$ & 14,96 & 1,51 & 17,91 & 14,75 & 77,4 & 843 & $-2,94$ & 13,47 & 0,77 & 17,18 & 12,10 & 74,3 \\
\hline 49 & $-1,46$ & 14,94 & 1,49 & 17,90 & 14,85 & 77,4 & 148 & $-3,00$ & 13,41 & 0,76 & 17,17 & 13,02 & 74,2 \\
\hline 16 & $-1,47$ & 14,93 & 1,48 & 17,89 & 14,58 & 77,3 & 53 & $-3,00$ & 13,40 & 0,75 & 17,15 & 13,03 & 74,1 \\
\hline 93 & $-1,50$ & 14,91 & 1,47 & 17,87 & 14,43 & 77,3 & 1068 & $-3,05$ & 13,36 & 0,73 & 17,14 & 12,97 & 74,1 \\
\hline 270 & $-1,50$ & 14,91 & 1,45 & 17,86 & 14,62 & 77,2 & 836 & $-3,09$ & 13,32 & 0,72 & 17,12 & 12,87 & 74,0 \\
\hline 1069 & $-1,50$ & 14,90 & 1,44 & 17,85 & 14,69 & 77,2 & 275 & $-3,16$ & 13,25 & 0,70 & 17,11 & 12,33 & 74,0 \\
\hline 134 & $-1,56$ & 14,85 & 1,43 & 17,83 & 14,62 & 77,1 & 835 & $-3,16$ & 13,24 & 0,69 & 17,09 & 12,78 & 73,9 \\
\hline 78 & $-1,59$ & 14,81 & 1,41 & 17,82 & 14,51 & 77,0 & 318 & $-3,20$ & 13,21 & 0,67 & 17,08 & 12,74 & 73,8 \\
\hline 3 & $-1,61$ & 14,79 & 1,40 & 17,80 & 14,56 & 77,0 & 215 & $-3,24$ & 13,17 & 0,66 & 17,07 & 12,69 & 73,8 \\
\hline 14 & $-1,65$ & 14,76 & 1,38 & 17,79 & 14,59 & 76,9 & 141 & $-3,24$ & 13,16 & 0,65 & 17,05 & 12,59 & 73,7 \\
\hline 154 & $-1,73$ & 14,68 & 1,37 & 17,78 & 14,55 & 76,9 & 44 & $-3,32$ & 13,09 & 0,63 & 17,04 & 12,61 & 73,7 \\
\hline 227 & $-1,74$ & 14,67 & 1,36 & 17,76 & 14,27 & 76,8 & 1076 & $-3,35$ & 13,05 & 0,62 & 17,02 & 12,41 & 73,6 \\
\hline 45 & $-1,91$ & 14,50 & 1,34 & 17,75 & 14,22 & 76,7 & 39 & $-3,43$ & 12,98 & 0,60 & 17,01 & 12,48 & 73,5 \\
\hline 236 & $-1,91$ & 14,49 & 1,33 & 17,73 & 14,27 & 76,7 & 272 & $-3,47$ & 12,93 & 0,59 & 16,99 & 12,50 & 73,5 \\
\hline 594 & $-1,93$ & 14,48 & 1,31 & 17,72 & 14,16 & 76,6 & 201 & $-3,57$ & 12,84 & 0,57 & 16,98 & 11,98 & 73,4 \\
\hline 280 & $-1,94$ & 14,47 & 1,30 & 17,70 & 14,15 & 76,5 & 323 & $-3,61$ & 12,79 & 0,56 & 16,96 & 12,27 & 73,3 \\
\hline 312 & $-1,96$ & 14,45 & 1,28 & 17,69 & 13,89 & 76,5 & 13 & $-3,62$ & 12,78 & 0,54 & 16,95 & 11,88 & 73,3 \\
\hline 168 & $-1,97$ & 14,43 & 1,27 & 17,68 & 14,14 & 76,4 & 51 & $-3,64$ & 12,76 & 0,53 & 16,93 & 12,23 & 73,2 \\
\hline 259 & $-2,02$ & 14,39 & 1,26 & 17,66 & 14,05 & 76,4 & 70 & $-3,76$ & 12,65 & 0,51 & 16,92 & 12,03 & 73,2 \\
\hline 163 & $-2,03$ & 14,38 & 1,24 & 17,65 & 14,15 & 76,3 & 199 & $-3,79$ & 12,61 & 0,50 & 16,90 & 12,11 & 73,1 \\
\hline 94 & $-2,07$ & 14,34 & 1,23 & 17,63 & 14,04 & 76,2 & 324 & $-3,81$ & 12,60 & 0,48 & 16,89 & 11,99 & 73,0 \\
\hline 139 & $-2,12$ & 14,28 & 1,21 & 17,62 & 13,94 & 76,2 & 839 & $-3,84$ & 12,56 & 0,47 & 16,87 & 12,07 & 72,9 \\
\hline 125 & $-2,14$ & 14,27 & 1,20 & 17,60 & 13,90 & 76,1 & 103 & $-3,87$ & 12,54 & 0,45 & 16,86 & 11,90 & 72,9 \\
\hline 54 & $-2,14$ & 14,26 & 1,18 & 17,59 & 13,95 & 76,0 & 264 & $-3,92$ & 12,49 & 0,44 & 16,84 & 11,89 & 72,8 \\
\hline 286 & $-2,19$ & 14,22 & 1,17 & 17,58 & 13,78 & 76,0 & 150 & $-3,95$ & 12,46 & 0,42 & 16,83 & 11,88 & 72,8 \\
\hline 233 & $-2,20$ & 14,21 & 1,16 & 17,56 & 13,89 & 75,9 & 162 & $-3,96$ & 12,45 & 0,41 & 16,81 & 11,69 & 72,7 \\
\hline 48 & $-2,22$ & 14,19 & 1,14 & 17,55 & 13,79 & 75,9 & 284 & $-3,99$ & 12,41 & 0,39 & 16,80 & 11,83 & 72,6 \\
\hline 62 & $-2,22$ & 14,18 & 1,13 & 17,53 & 13,86 & 75,8 & 58 & $-4,10$ & 12,30 & 0,38 & 16,78 & 11,66 & 72,5 \\
\hline 155 & $-2,23$ & 14,17 & 1,11 & 17,52 & 13,85 & 75,7 & 52 & $-4,14$ & 12,26 & 0,36 & 16,77 & 11,62 & 72,5 \\
\hline 10 & $-2,28$ & 14,13 & 1,10 & 17,51 & 13,79 & 75,7 & 149 & $-4,17$ & 12,24 & 0,34 & 16,75 & 11,63 & 72,4 \\
\hline 147 & $-2,28$ & 14,12 & 1,09 & 17,49 & 13,70 & 75,6 & 1062 & $-4,30$ & 12,11 & 0,33 & 16,73 & 11,14 & 72,3 \\
\hline 79 & $-2,32$ & 14,09 & 1,07 & 17,48 & 13,72 & 75,6 & 146 & $-4,30$ & 12,11 & 0,31 & 16,72 & 11,43 & 72,3 \\
\hline 30 & $-2,43$ & 13,97 & 1,06 & 17,46 & 13,58 & 75,5 & 829 & $-4,54$ & 11,86 & 0,30 & 16,70 & 11,06 & 72,2 \\
\hline 21 & $-2,44$ & 13,96 & 1,04 & 17,45 & 13,56 & 75,4 & 262 & $-4,61$ & 11,79 & 0,28 & 16,69 & 11,49 & 72,2 \\
\hline 1095 & $-2,53$ & 13,88 & 1,03 & 17,43 & 13,27 & 75,4 & 1094 & $-4,65$ & 11,75 & 0,26 & 16,67 & 11,08 & 72,1 \\
\hline 98 & $-2,53$ & 13,88 & 1,01 & 17,42 & 13,57 & 75,3 & 1071 & $-5,01$ & 11,39 & 0,25 & 16,65 & 10,61 & 72,0 \\
\hline 253 & $-2,53$ & 13,87 & 1,00 & 17,41 & 13,51 & 75,3 & 278 & $-5,11$ & 11,29 & 0,23 & 16,63 & 9,87 & 71,9 \\
\hline 101 & $-2,55$ & 13,85 & 0,99 & 17,39 & 13,43 & 75,2 & 848 & $-5,16$ & 11,25 & 0,21 & 16,62 & 10,66 & 71,9 \\
\hline 851 & $-2,56$ & 13,85 & 0,97 & 17,38 & 13,50 & 75,1 & 83 & $-5,30$ & 11,11 & 0,19 & 16,60 & 9,99 & 71,8 \\
\hline 140 & $-2,57$ & 13,83 & 0,96 & 17,36 & 13,53 & 75,1 & 277 & $-5,32$ & 11,08 & 0,17 & 16,58 & 10,20 & 71,7 \\
\hline 60 & $-2,60$ & 13,81 & 0,94 & 17,35 & 13,43 & 75,0 & 833 & $-5,34$ & 11,07 & 0,16 & 16,56 & 9,73 & 71,6 \\
\hline 960 & $-2,62$ & 13,79 & 0,93 & 17,34 & 13,33 & 75,0 & 828 & $-5,36$ & 11,05 & 0,14 & 16,54 & 10,11 & 71,5 \\
\hline 840 & $-2,66$ & 13,75 & 0,92 & 17,32 & 13,40 & 74,9 & 276 & $-5,44$ & 10,97 & 0,12 & 16,52 & 8,50 & 71,4 \\
\hline 165 & $-2,73$ & 13,68 & 0,90 & 17,31 & 13,21 & 74,8 & 838 & $-5,49$ & 10,92 & 0,10 & 16,51 & 10,06 & 71,4 \\
\hline 130 & $-2,74$ & 13,67 & 0,89 & 17,29 & 13,25 & 74,8 & 12 & $-5,77$ & 10,64 & 0,08 & 16,49 & 9,79 & 71,3 \\
\hline 274 & $-2,74$ & 13,66 & 0,87 & 17,28 & 13,26 & 74,7 & 855 & $-6,12$ & 10,28 & 0,06 & 16,47 & 8,77 & 71,2 \\
\hline 9 & $-2,75$ & 13,66 & 0,86 & 17,26 & 13,21 & 74,6 & 841 & $-6,13$ & 10,28 & 0,04 & 16,45 & 9,25 & 71,1 \\
\hline 1061 & $-2,76$ & 13,65 & 0,84 & 17,25 & 13,21 & 74,6 & 860 & $-6,34$ & 10,07 & 0,02 & 16,43 & 9,14 & 71,0 \\
\hline 315 & $-2,83$ & 13,58 & 0,83 & 17,24 & 13,24 & 74,5 & 837 & $-6,57$ & 9,84 & 0,00 & 16,41 & 8,40 & 70,9 \\
\hline
\end{tabular}

$\hat{g}=$ Efeito genotípico predito, VG = Valor genotípico predito, Ganho = Ganho genético, MPM = Média da população melhorada, $\mathrm{VF}=$ Valor fenotípico, $\mathrm{DR}=$ Desempenho relativo. 
Tabela 12. Valores obtidos pelo SELEGEN para a variável Altura

\begin{tabular}{|c|c|c|c|c|c|c|c|c|c|c|c|c|c|}
\hline Clone & $\hat{g}$ & VG & Ganho & MPM & VF & $\mathrm{DR} \%$ & Clone & $\hat{g}$ & VG & Ganho & MPM & VF & DR\% \\
\hline 1028 & 5,74 & 31,52 & 5,74 & 31,52 & 32,37 & 100,0 & 935 & 3,03 & 28,81 & 3,79 & 29,58 & 29,35 & 93,8 \\
\hline 865 & 5,74 & 31,52 & 5,74 & 31,52 & 32,37 & 100,0 & 327 & 3,02 & 28,81 & 3,78 & 29,56 & 29,18 & 93,8 \\
\hline 975 & 5,33 & 31,12 & 5,60 & 31,39 & 31,82 & 99,6 & 310 & 2,98 & 28,76 & 3,76 & 29,55 & 29,20 & 93,8 \\
\hline 1016 & 5,25 & 31,03 & 5,51 & 31,30 & 31,96 & 99,3 & 927 & 2,92 & 28,70 & 3,75 & 29,54 & 29,13 & 93,7 \\
\hline 1072 & 5,10 & 30,89 & 5,43 & 31,22 & 31,68 & 99,0 & 873 & 2,89 & 28,68 & 3,73 & 29,52 & 29,04 & 93,7 \\
\hline 880 & 4,93 & 30,72 & 5,35 & 31,13 & 31,39 & 98,8 & 892 & 2,89 & 28,68 & 3,72 & 29,51 & 29,10 & 93,6 \\
\hline 1052 & 4,81 & 30,59 & 5,27 & 31,06 & 31,30 & 98,5 & 1019 & 2,86 & 28,65 & 3,70 & 29,49 & 29,07 & 93,6 \\
\hline 919 & 4,57 & 30,36 & 5,18 & 30,97 & 31,03 & 98,3 & 186 & 2,83 & 28,62 & 3,69 & 29,48 & 29,12 & 93,5 \\
\hline 925 & 4,54 & 30,33 & 5,11 & 30,90 & 31,00 & 98,0 & 1083 & 2,82 & 28,61 & 3,68 & 29,46 & 29,11 & 93,5 \\
\hline 845 & 4,50 & 30,29 & 5,05 & 30,84 & 30,93 & 97,8 & 856 & 2,81 & 28,59 & 3,66 & 29,45 & 29,64 & 93,4 \\
\hline 952 & 4,46 & 30,24 & 5,00 & 30,78 & 30,90 & 97,7 & 891 & 2,81 & 28,59 & 3,65 & 29,43 & 29,04 & 93,4 \\
\hline 1006 & 4,43 & 30,22 & 4,95 & 30,74 & 30,87 & 97,5 & 17 & 2,80 & 28,59 & 3,63 & 29,42 & 29,00 & 93,3 \\
\hline 1044 & 4,34 & 30,13 & 4,90 & 30,69 & 30,77 & 97,4 & 306 & 2,74 & 28,53 & 3,62 & 29,41 & 28,93 & 93,3 \\
\hline 931 & 4,24 & 30,03 & 4,86 & 30,64 & 30,64 & 97,2 & 234 & 2,73 & 28,52 & 3,61 & 29,39 & 29,45 & 93,2 \\
\hline 7 & 4,23 & 30,02 & 4,81 & 30,60 & 30,62 & 97,1 & 325 & 2,71 & 28,50 & 3,59 & 29,38 & 28,90 & 93,2 \\
\hline 981 & 4,14 & 29,92 & 4,77 & 30,56 & 30,53 & 97,0 & 57 & 2,65 & 28,44 & 3,58 & 29,37 & 28,54 & 93,2 \\
\hline 47 & 4,09 & 29,88 & 4,73 & 30,52 & 30,57 & 96,8 & 225 & 2,57 & 28,36 & 3,57 & 29,35 & 28,73 & 93,1 \\
\hline 928 & 4,08 & 29,87 & 4,70 & 30,48 & 30,61 & 96,7 & 266 & 2,57 & 28,36 & 3,55 & 29,34 & 28,73 & 93,1 \\
\hline 273 & 3,99 & 29,78 & 4,66 & 30,45 & 30,37 & 96,6 & 859 & 2,57 & 28,35 & 3,54 & 29,32 & 28,64 & 93,0 \\
\hline 875 & 3,83 & 29,61 & 4,62 & 30,40 & 30,21 & 96,4 & 191 & 2,56 & 28,35 & 3,52 & 29,31 & 28,75 & 93,0 \\
\hline 1023 & 3,82 & 29,61 & 4,58 & 30,37 & 30,25 & 96,4 & 929 & 2,54 & 28,33 & 3,51 & 29,30 & 28,70 & 93,0 \\
\hline 831 & 3,78 & 29,57 & 4,54 & 30,33 & 30,11 & 96,2 & 847 & 2,53 & 28,32 & 3,50 & 29,28 & 28,38 & 92,9 \\
\hline 834 & 3,76 & 29,55 & 4,51 & 30,30 & 30,10 & 96,1 & 645 & 2,53 & 28,32 & 3,48 & 29,27 & 29,00 & 92,9 \\
\hline 986 & 3,75 & 29,53 & 4,48 & 30,26 & 29,85 & 96,0 & 143 & 2,47 & 28,26 & 3,47 & 29,26 & 28,50 & 92,8 \\
\hline 1045 & 3,68 & 29,47 & 4,44 & 30,23 & 29,92 & 95,9 & 288 & 2,47 & 28,25 & 3,46 & 29,24 & 28,69 & 92,8 \\
\hline 316 & 3,64 & 29,43 & 4,41 & 30,20 & 29,97 & 95,8 & 204 & 2,40 & 28,19 & 3,44 & 29,23 & 29,00 & 92,7 \\
\hline 229 & 3,61 & 29,40 & 4,38 & 30,17 & 29,93 & 95,7 & 930 & 2,37 & 28,16 & 3,43 & 29,22 & 28,54 & 92,7 \\
\hline 988 & 3,41 & 29,20 & 4,35 & 30,14 & 29,70 & 95,6 & 1089 & 2,37 & 28,15 & 3,42 & 29,20 & 28,46 & 92,6 \\
\hline 964 & 3,39 & 29,18 & 4,32 & 30,10 & 29,75 & 95,5 & 295 & 2,36 & 28,15 & 3,40 & 29,19 & 28,50 & 92,6 \\
\hline 320 & 3,38 & 29,17 & 4,29 & 30,07 & 29,67 & 95,4 & 853 & 2,32 & 28,11 & 3,39 & 29,18 & 28,95 & 92,6 \\
\hline 328 & 3,32 & 29,11 & 4,25 & 30,04 & 29,60 & 95,3 & 955 & 2,32 & 28,11 & 3,38 & 29,17 & 28,64 & 92,5 \\
\hline 373 & 3,32 & 29,11 & 4,23 & 30,01 & 29,60 & 95,2 & 872 & 2,31 & 28,10 & 3,37 & 29,15 & 28,36 & 92,5 \\
\hline 322 & 3,31 & 29,09 & 4,20 & 29,98 & 29,58 & 95,1 & 953 & 2,31 & 28,09 & 3,35 & 29,14 & 28,43 & 92,4 \\
\hline 945 & 3,29 & 29,08 & 4,17 & 29,96 & 29,54 & 95,1 & 23 & 2,28 & 28,06 & 3,34 & 29,13 & 28,40 & 92,4 \\
\hline 832 & 3,27 & 29,05 & 4,14 & 29,93 & 29,53 & 95,0 & 269 & 2,27 & 28,06 & 3,33 & 29,12 & 28,58 & 92,4 \\
\hline 948 & 3,22 & 29,01 & 4,12 & 29,91 & 29,43 & 94,9 & 25 & 2,27 & 28,06 & 3,32 & 29,10 & 28,39 & 92,3 \\
\hline 281 & 3,20 & 28,98 & 4,09 & 29,88 & 29,43 & 94,8 & 29 & 2,25 & 28,04 & 3,30 & 29,09 & 28,37 & 92,3 \\
\hline 888 & 3,18 & 28,97 & 4,07 & 29,86 & 29,54 & 94,7 & 968 & 2,21 & 27,99 & 3,29 & 29,08 & 28,25 & 92,3 \\
\hline 844 & 3,18 & 28,97 & 4,05 & 29,83 & 30,06 & 94,6 & 922 & 2,19 & 27,98 & 3,28 & 29,07 & 28,30 & 92,2 \\
\hline 1007 & 3,15 & 28,94 & 4,03 & 29,81 & 29,39 & 94,6 & 881 & 2,16 & 27,95 & 3,27 & 29,05 & 28,27 & 92,2 \\
\hline 24 & 3,15 & 28,94 & 4,00 & 29,79 & 29,39 & 94,5 & 1010 & 2,16 & 27,94 & 3,26 & 29,04 & 28,25 & 92,1 \\
\hline 221 & 3,12 & 28,91 & 3,98 & 29,77 & 29,37 & 94,4 & 918 & 2,06 & 27,85 & 3,24 & 29,03 & 28,00 & 92,1 \\
\hline 326 & 3,11 & 28,90 & 3,96 & 29,75 & 29,43 & 94,4 & 1081 & 2,06 & 27,84 & 3,23 & 29,02 & 28,05 & 92,1 \\
\hline 1004 & 3,09 & 28,88 & 3,94 & 29,73 & 29,33 & 94,3 & 991 & 2,05 & 27,84 & 3,22 & 29,01 & 28,18 & 92,0 \\
\hline 1014 & 3,09 & 28,88 & 3,92 & 29,71 & 29,33 & 94,3 & 910 & 2,05 & 27,84 & 3,21 & 28,99 & 27,92 & 92,0 \\
\hline 42 & 3,09 & 28,88 & 3,91 & 29,69 & 29,33 & 94,2 & 226 & 2,02 & 27,80 & 3,19 & 28,98 & 28,10 & 91,9 \\
\hline 43 & 3,08 & 28,87 & 3,89 & 29,68 & 29,36 & 94,2 & 1082 & 2,02 & 27,80 & 3,18 & 28,97 & 28,10 & 91,9 \\
\hline 1096 & 3,07 & 28,85 & 3,87 & 29,66 & 29,54 & 94,1 & 920 & 1,97 & 27,76 & 3,17 & 28,96 & 28,04 & 91,9 \\
\hline 1034 & 3,05 & 28,83 & 3,85 & 29,64 & 29,29 & 94,0 & 830 & 1,95 & 27,73 & 3,16 & 28,95 & 29,00 & 91,8 \\
\hline 311 & 3,04 & 28,82 & 3,84 & 29,62 & 29,29 & 94,0 & 38 & 1,85 & 27,64 & 3,15 & 28,93 & 27,86 & 91,8 \\
\hline 993 & 3,03 & 28,82 & 3,82 & 29,61 & 29,27 & 93,9 & 33 & 1,83 & 27,62 & 3,13 & 28,92 & 27,89 & 91,8 \\
\hline 997 & 3,03 & 28,82 & 3,81 & 29,59 & 29,27 & 93,9 & 1001 & 1,82 & 27,60 & 3,12 & 28,91 & 27,82 & 91,7 \\
\hline
\end{tabular}


Tabela 12. Valores obtidos pelo SELEGEN para a variável Altura

\begin{tabular}{|c|c|c|c|c|c|c|c|c|c|c|c|c|c|}
\hline Clone & $\hat{g}$ & VG & Ganho & MPM & $\mathrm{VF}$ & $\mathrm{DR} \%$ & Clone & $\hat{g}$ & VG & Ganho & MPM & VF & DR\% \\
\hline 22 & 1,73 & 27,51 & 3,11 & 28,89 & 27,77 & 91,7 & 317 & 0,54 & 26,33 & 2,44 & 28,23 & 26,25 & 89,6 \\
\hline 219 & 1,68 & 27,47 & 3,09 & 28,88 & 27,71 & 91,6 & 238 & 0,54 & 26,32 & 2,43 & 28,22 & 26,42 & 89,5 \\
\hline 966 & 1,68 & 27,46 & 3,08 & 28,87 & 27,61 & 91,6 & 151 & 0,44 & 26,23 & 2,42 & 28,21 & 26,43 & 89,5 \\
\hline 933 & 1,66 & 27,44 & 3,07 & 28,85 & 27,57 & 91,5 & 854 & 0,41 & 26,20 & 2,41 & 28,19 & 26,27 & 89,4 \\
\hline 862 & 1,65 & 27,44 & 3,05 & 28,84 & 27,81 & 91,5 & 26 & 0,33 & 26,12 & 2,39 & 28,18 & 26,17 & 89,4 \\
\hline 202 & 1,63 & 27,41 & 3,04 & 28,83 & 28,10 & 91,5 & 903 & 0,33 & 26,12 & 2,38 & 28,17 & 26,17 & 89,4 \\
\hline 228 & 1,63 & 27,41 & 3,03 & 28,82 & 28,10 & 91,4 & 1003 & 0,33 & 26,12 & 2,37 & 28,16 & 26,17 & 89,3 \\
\hline 979 & 1,61 & 27,40 & 3,02 & 28,80 & 27,63 & 91,4 & 128 & 0,25 & 26,04 & 2,36 & 28,14 & 26,11 & 89,3 \\
\hline 307 & 1,55 & 27,33 & 3,00 & 28,79 & 27,58 & 91,3 & 313 & 0,18 & 25,97 & 2,34 & 28,13 & 26,13 & 89,2 \\
\hline 319 & 1,52 & 27,31 & 2,99 & 28,78 & 27,43 & 91,3 & 1099 & 0,14 & 25,93 & 2,33 & 28,12 & 25,80 & 89,2 \\
\hline 196 & 1,47 & 27,26 & 2,98 & 28,76 & 27,61 & 91,2 & 1077 & 0,14 & 25,92 & 2,32 & 28,10 & 25,77 & 89,1 \\
\hline 937 & 1,44 & 27,23 & 2,96 & 28,75 & 27,32 & 91,2 & 282 & 0,10 & 25,88 & 2,30 & 28,09 & 25,93 & 89,1 \\
\hline 842 & 1,43 & 27,22 & 2,95 & 28,74 & 28,00 & 91,2 & 271 & 0,07 & 25,86 & 2,29 & 28,08 & 25,87 & 89,1 \\
\hline 321 & 1,38 & 27,16 & 2,94 & 28,72 & 27,37 & 91,1 & 214 & 0,04 & 25,83 & 2,28 & 28,06 & 25,83 & 89,0 \\
\hline 40 & 1,36 & 27,14 & 2,92 & 28,71 & 27,29 & 91,1 & 1069 & 0,04 & 25,82 & 2,26 & 28,05 & 25,75 & 89,0 \\
\hline 846 & 1,30 & 27,08 & 2,91 & 28,70 & 27,43 & 91,1 & 1092 & 0,03 & 25,81 & 2,25 & 28,04 & 25,82 & 89,0 \\
\hline 263 & 1,29 & 27,08 & 2,90 & 28,68 & 27,27 & 91,0 & 267 & 0,01 & 25,80 & 2,24 & 28,02 & 25,85 & 88,9 \\
\hline 977 & 1,29 & 27,08 & 2,88 & 28,67 & 27,27 & 91,0 & 93 & 0,01 & 25,80 & 2,22 & 28,01 & 25,83 & 88,9 \\
\hline 28 & 1,29 & 27,08 & 2,87 & 28,66 & 27,27 & 90,9 & 133 & $-0,02$ & 25,77 & 2,21 & 28,00 & 25,77 & 88,8 \\
\hline 153 & 1,23 & 27,02 & 2,86 & 28,64 & 27,20 & 90,9 & 32 & $-0,05$ & 25,73 & 2,20 & 27,99 & 25,68 & 88,8 \\
\hline 198 & 1,23 & 27,02 & 2,84 & 28,63 & 27,20 & 90,8 & 171 & $-0,11$ & 25,68 & 2,19 & 27,97 & 25,67 & 88,7 \\
\hline 18 & 1,22 & 27,01 & 2,83 & 28,62 & 27,27 & 90,8 & 209 & $-0,15$ & 25,64 & 2,17 & 27,96 & 25,36 & 88,7 \\
\hline 959 & 1,19 & 26,97 & 2,82 & 28,61 & 27,17 & 90,8 & 64 & $-0,16$ & 25,62 & 2,16 & 27,95 & 25,25 & 88,7 \\
\hline 852 & 1,15 & 26,93 & 2,81 & 28,59 & 27,12 & 90,7 & 185 & $-0,19$ & 25,60 & 2,15 & 27,93 & 25,42 & 88,6 \\
\hline 861 & 1,13 & 26,91 & 2,79 & 28,58 & 27,07 & 90,7 & 1074 & $-0,20$ & 25,58 & 2,13 & 27,92 & 25,81 & 88,6 \\
\hline 84 & 1,10 & 26,89 & 2,78 & 28,57 & 27,00 & 90,6 & 980 & $-0,23$ & 25,56 & 2,12 & 27,91 & 25,54 & 88,5 \\
\hline 1085 & 1,09 & 26,87 & 2,77 & 28,55 & 27,08 & 90,6 & 76 & $-0,28$ & 25,51 & 2,11 & 27,89 & 25,47 & 88,5 \\
\hline 56 & 1,04 & 26,83 & 2,75 & 28,54 & 26,91 & 90,5 & 106 & $-0,28$ & 25,51 & 2,09 & 27,88 & 25,47 & 88,5 \\
\hline 850 & 1,04 & 26,83 & 2,74 & 28,53 & 26,94 & 90,5 & 882 & $-0,29$ & 25,50 & 2,08 & 27,87 & 25,42 & 88,4 \\
\hline 6 & 0,97 & 26,76 & 2,73 & 28,51 & 26,90 & 90,5 & 230 & $-0,30$ & 25,49 & 2,07 & 27,86 & 25,62 & 88,4 \\
\hline 158 & 0,94 & 26,73 & 2,71 & 28,50 & 26,87 & 90,4 & 145 & $-0,34$ & 25,45 & 2,06 & 27,84 & 25,40 & 88,3 \\
\hline 152 & 0,94 & 26,72 & 2,70 & 28,49 & 26,88 & 90,4 & 849 & $-0,40$ & 25,39 & 2,04 & 27,83 & 25,33 & 88,3 \\
\hline 27 & 0,93 & 26,72 & 2,69 & 28,48 & 27,00 & 90,4 & 3 & $-0,40$ & 25,39 & 2,03 & 27,82 & 25,33 & 88,3 \\
\hline 164 & 0,92 & 26,71 & 2,68 & 28,46 & 26,79 & 90,3 & 192 & $-0,46$ & 25,32 & 2,02 & 27,80 & 24,90 & 88,2 \\
\hline 127 & 0,92 & 26,71 & 2,66 & 28,45 & 26,86 & 90,3 & 14 & $-0,49$ & 25,30 & 2,00 & 27,79 & 25,27 & 88,2 \\
\hline 41 & 0,91 & 26,70 & 2,65 & 28,44 & 26,83 & 90,2 & 879 & $-0,49$ & 25,29 & 1,99 & 27,78 & 25,00 & 88,1 \\
\hline 889 & 0,91 & 26,70 & 2,64 & 28,42 & 26,75 & 90,2 & 956 & $-0,59$ & 25,20 & 1,98 & 27,76 & 24,93 & 88,1 \\
\hline 361 & 0,85 & 26,64 & 2,62 & 28,41 & 26,77 & 90,1 & 45 & $-0,63$ & 25,16 & 1,96 & 27,75 & 25,07 & 88,0 \\
\hline 268 & 0,85 & 26,64 & 2,61 & 28,40 & 26,77 & 90,1 & 224 & $-0,63$ & 25,16 & 1,95 & 27,74 & 25,07 & 88,0 \\
\hline 11 & 0,85 & 26,64 & 2,60 & 28,39 & 26,77 & 90,1 & 20 & $-0,63$ & 25,16 & 1,94 & 27,72 & 25,07 & 87,9 \\
\hline 279 & 0,83 & 26,62 & 2,59 & 28,38 & 26,43 & 90,0 & 314 & $-0,66$ & 25,13 & 1,92 & 27,71 & 25,03 & 87,9 \\
\hline 949 & 0,82 & 26,61 & 2,58 & 28,36 & 26,73 & 90,0 & 884 & $-0,71$ & 25,07 & 1,91 & 27,70 & 25,07 & 87,9 \\
\hline 528 & 0,81 & 26,60 & 2,56 & 28,35 & 26,75 & 89,9 & 205 & $-0,80$ & 24,98 & 1,90 & 27,68 & 24,87 & 87,8 \\
\hline 80 & 0,79 & 26,58 & 2,55 & 28,34 & 26,77 & 89,9 & 270 & $-0,83$ & 24,96 & 1,88 & 27,67 & 24,83 & 87,8 \\
\hline 261 & 0,71 & 26,50 & 2,54 & 28,33 & 26,60 & 89,9 & 210 & $-0,86$ & 24,93 & 1,87 & 27,66 & 24,75 & 87,8 \\
\hline 894 & 0,69 & 26,48 & 2,53 & 28,31 & 26,64 & 89,8 & 5 & $-0,90$ & 24,89 & 1,86 & 27,64 & 24,79 & 87,7 \\
\hline 285 & 0,68 & 26,47 & 2,52 & 28,30 & 26,57 & 89,8 & 208 & $-0,95$ & 24,84 & 1,84 & 27,63 & 24,70 & 87,7 \\
\hline 176 & 0,67 & 26,46 & 2,50 & 28,29 & 26,61 & 89,8 & 1086 & $-0,96$ & 24,83 & 1,83 & 27,62 & 24,91 & 87,6 \\
\hline 159 & 0,67 & 26,46 & 2,49 & 28,28 & 26,57 & 89,7 & 167 & $-0,99$ & 24,80 & 1,81 & 27,60 & 24,86 & 87,6 \\
\hline 864 & 0,67 & 26,45 & 2,48 & 28,27 & 26,46 & 89,7 & 154 & $-1,03$ & 24,75 & 1,80 & 27,59 & 24,75 & 87,5 \\
\hline 15 & 0,65 & 26,44 & 2,47 & 28,25 & 26,53 & 89,6 & 851 & $-1,11$ & 24,68 & 1,79 & 27,57 & 24,50 & 87,5 \\
\hline 2 & 0,62 & 26,41 & 2,46 & 28,24 & 26,50 & 89,6 & 168 & $-1,12$ & 24,67 & 1,77 & 27,56 & 24,50 & 87,4 \\
\hline
\end{tabular}


Tabela 12. Valores obtidos pelo SELEGEN para a variável Altura

\begin{tabular}{|c|c|c|c|c|c|c|c|c|c|c|c|c|c|}
\hline Clone & $\hat{g}$ & $\mathrm{VG}$ & Ganho & MPM & VF & DR\% & Clone & $\hat{g}$ & VG & Ganho & MPM & VF & DR\% \\
\hline 947 & $-1,12$ & 24,67 & 1,76 & 27,55 & 24,50 & 87,4 & 594 & $-3,00$ & 22,79 & 0,98 & 26,77 & 22,25 & 84,9 \\
\hline 858 & $-1,16$ & 24,63 & 1,75 & 27,53 & 24,21 & 87,3 & 275 & $-3,05$ & 22,74 & 0,97 & 26,76 & 21,64 & 84,9 \\
\hline 31 & $-1,18$ & 24,61 & 1,73 & 27,52 & 24,43 & 87,3 & 835 & $-3,07$ & 22,72 & 0,95 & 26,74 & 22,27 & 84,8 \\
\hline 144 & $-1,27$ & 24,52 & 1,72 & 27,50 & 24,33 & 87,2 & 60 & $-3,10$ & 22,69 & 0,94 & 26,73 & 22,23 & 84,8 \\
\hline 265 & $-1,30$ & 24,49 & 1,70 & 27,49 & 24,30 & 87,2 & 79 & $-3,10$ & 22,69 & 0,92 & 26,71 & 22,30 & 84,7 \\
\hline 8 & $-1,42$ & 24,37 & 1,69 & 27,48 & 24,27 & 87,2 & 155 & $-3,30$ & 22,49 & 0,91 & 26,69 & 22,00 & 84,7 \\
\hline 1031 & $-1,44$ & 24,35 & 1,67 & 27,46 & 24,13 & 87,1 & 272 & $-3,35$ & 22,44 & 0,89 & 26,68 & 22,11 & 84,6 \\
\hline 280 & $-1,57$ & 24,21 & 1,66 & 27,45 & 24,00 & 87,1 & 58 & $-3,35$ & 22,43 & 0,88 & 26,66 & 21,82 & 84,6 \\
\hline 125 & $-1,58$ & 24,21 & 1,64 & 27,43 & 23,85 & 87,0 & 315 & $-3,38$ & 22,41 & 0,86 & 26,65 & 21,96 & 84,5 \\
\hline 1073 & $-1,62$ & 24,16 & 1,63 & 27,42 & 23,92 & 87,0 & 1068 & $-3,41$ & 22,38 & 0,84 & 26,63 & 22,13 & 84,5 \\
\hline 286 & $-1,68$ & 24,10 & 1,61 & 27,40 & 23,81 & 86,9 & 51 & $-3,45$ & 22,34 & 0,83 & 26,61 & 21,83 & 84,4 \\
\hline 840 & $-1,69$ & 24,10 & 1,60 & 27,39 & 23,80 & 86,9 & 13 & $-3,47$ & 22,32 & 0,81 & 26,60 & 21,06 & 84,4 \\
\hline 94 & $-1,70$ & 24,08 & 1,58 & 27,37 & 23,83 & 86,8 & 836 & $-3,53$ & 22,25 & 0,80 & 26,58 & 21,73 & 84,3 \\
\hline 236 & $-1,73$ & 24,06 & 1,57 & 27,36 & 23,93 & 86,8 & 30 & $-3,55$ & 22,23 & 0,78 & 26,57 & 21,81 & 84,3 \\
\hline 140 & $-1,74$ & 24,05 & 1,55 & 27,34 & 23,93 & 86,7 & 9 & $-3,58$ & 22,21 & 0,76 & 26,55 & 21,57 & 84,2 \\
\hline 135 & $-1,77$ & 24,02 & 1,54 & 27,33 & 23,77 & 86,7 & 233 & $-3,68$ & 22,11 & 0,75 & 26,54 & 21,57 & 84,2 \\
\hline 147 & $-1,82$ & 23,97 & 1,52 & 27,31 & 23,54 & 86,6 & 182 & $-3,76$ & 22,03 & 0,73 & 26,52 & 21,13 & 84,1 \\
\hline 1075 & $-1,84$ & 23,95 & 1,51 & 27,30 & 23,58 & 86,6 & 62 & $-3,88$ & 21,90 & 0,72 & 26,50 & 21,33 & 84,1 \\
\hline 259 & $-1,90$ & 23,89 & 1,49 & 27,28 & 23,57 & 86,5 & 199 & $-4,06$ & 21,72 & 0,70 & 26,49 & 21,14 & 84,0 \\
\hline 134 & $-1,91$ & 23,88 & 1,48 & 27,27 & 23,60 & 86,5 & 284 & $-4,12$ & 21,67 & 0,68 & 26,47 & 21,07 & 84,0 \\
\hline 253 & $-1,94$ & 23,85 & 1,46 & 27,25 & 23,57 & 86,5 & 201 & $-4,24$ & 21,54 & 0,66 & 26,45 & 20,64 & 83,9 \\
\hline 163 & $-1,94$ & 23,85 & 1,45 & 27,24 & 23,77 & 86,4 & 101 & $-4,31$ & 21,47 & 0,65 & 26,43 & 20,73 & 83,9 \\
\hline 223 & $-2,03$ & 23,76 & 1,43 & 27,22 & 23,43 & 86,4 & 1095 & $-4,32$ & 21,47 & 0,63 & 26,42 & 20,31 & 83,8 \\
\hline 165 & $-2,04$ & 23,74 & 1,42 & 27,21 & 23,31 & 86,3 & 150 & $-4,35$ & 21,44 & 0,61 & 26,40 & 20,80 & 83,8 \\
\hline 203 & $-2,05$ & 23,74 & 1,40 & 27,19 & 23,50 & 86,3 & 162 & $-4,36$ & 21,43 & 0,59 & 26,38 & 20,50 & 83,7 \\
\hline 39 & $-2,06$ & 23,73 & 1,39 & 27,18 & 23,54 & 86,2 & 215 & $-4,61$ & 21,18 & 0,58 & 26,36 & 20,54 & 83,6 \\
\hline 49 & $-2,20$ & 23,59 & 1,37 & 27,16 & 23,39 & 86,2 & 828 & $-4,62$ & 21,17 & 0,56 & 26,34 & 20,17 & 83,6 \\
\hline 235 & $-2,22$ & 23,57 & 1,36 & 27,15 & 23,42 & 86,1 & 323 & $-4,81$ & 20,97 & 0,54 & 26,33 & 20,27 & 83,5 \\
\hline 78 & $-2,22$ & 23,57 & 1,34 & 27,13 & 23,08 & 86,1 & 149 & $-4,81$ & 20,97 & 0,52 & 26,31 & 20,27 & 83,5 \\
\hline 48 & $-2,25$ & 23,54 & 1,33 & 27,12 & 23,04 & 86,0 & 839 & $-4,86$ & 20,92 & 0,50 & 26,29 & 20,05 & 83,4 \\
\hline 274 & $-2,26$ & 23,53 & 1,31 & 27,10 & 23,20 & 86,0 & 262 & $-5,09$ & 20,70 & 0,48 & 26,27 & 20,90 & 83,3 \\
\hline 19 & $-2,30$ & 23,49 & 1,30 & 27,09 & 23,00 & 85,9 & 829 & $-5,20$ & 20,59 & 0,46 & 26,25 & 19,69 & 83,3 \\
\hline 44 & $-2,34$ & 23,44 & 1,28 & 27,07 & 23,10 & 85,9 & 70 & $-5,21$ & 20,58 & 0,44 & 26,23 & 19,71 & 83,2 \\
\hline 21 & $-2,39$ & 23,40 & 1,27 & 27,06 & 22,96 & 85,9 & 1062 & $-5,35$ & 20,44 & 0,42 & 26,21 & 19,06 & 83,2 \\
\hline 10 & $-2,40$ & 23,39 & 1,25 & 27,04 & 23,03 & 85,8 & 103 & $-5,36$ & 20,43 & 0,40 & 26,19 & 19,54 & 83,1 \\
\hline 54 & $-2,43$ & 23,36 & 1,24 & 27,03 & 23,00 & 85,8 & 276 & $-5,37$ & 20,42 & 0,38 & 26,17 & 17,40 & 83,0 \\
\hline 227 & $-2,44$ & 23,34 & 1,22 & 27,01 & 22,89 & 85,7 & 841 & $-5,40$ & 20,38 & 0,36 & 26,15 & 19,45 & 83,0 \\
\hline 960 & $-2,49$ & 23,30 & 1,21 & 27,00 & 22,81 & 85,7 & 52 & $-5,53$ & 20,25 & 0,35 & 26,13 & 19,17 & 82,9 \\
\hline 1076 & $-2,55$ & 23,23 & 1,19 & 26,98 & 22,73 & 85,6 & 1094 & $-5,56$ & 20,23 & 0,33 & 26,11 & 19,39 & 82,8 \\
\hline 98 & $-2,57$ & 23,22 & 1,18 & 26,97 & 22,96 & 85,6 & 83 & $-5,73$ & 20,05 & 0,31 & 26,09 & 18,83 & 82,8 \\
\hline 148 & $-2,57$ & 23,21 & 1,16 & 26,95 & 22,93 & 85,5 & 146 & $-5,98$ & 19,81 & 0,28 & 26,07 & 18,89 & 82,7 \\
\hline 130 & $-2,57$ & 23,21 & 1,15 & 26,94 & 22,63 & 85,5 & 848 & $-6,05$ & 19,73 & 0,26 & 26,05 & 19,33 & 82,6 \\
\hline 53 & $-2,61$ & 23,17 & 1,13 & 26,92 & 22,77 & 85,4 & 264 & $-6,20$ & 19,59 & 0,24 & 26,03 & 18,64 & 82,6 \\
\hline 16 & $-2,66$ & 23,13 & 1,12 & 26,91 & 22,50 & 85,4 & 1071 & $-6,26$ & 19,52 & 0,22 & 26,01 & 18,42 & 82,5 \\
\hline 843 & $-2,66$ & 23,13 & 1,10 & 26,89 & 21,30 & 85,3 & 12 & $-6,28$ & 19,51 & 0,20 & 25,99 & 18,73 & 82,5 \\
\hline 318 & $-2,66$ & 23,12 & 1,09 & 26,88 & 22,73 & 85,3 & 838 & $-7,72$ & 18,06 & 0,17 & 25,96 & 16,79 & 82,4 \\
\hline 312 & $-2,70$ & 23,08 & 1,07 & 26,86 & 22,36 & 85,2 & 277 & $-8,23$ & 17,56 & 0,15 & 25,93 & 16,19 & 82,3 \\
\hline 1061 & $-2,75$ & 23,04 & 1,06 & 26,85 & 22,91 & 85,2 & 855 & $-8,84$ & 16,95 & 0,12 & 25,90 & 14,56 & 82,2 \\
\hline 139 & $-2,76$ & 23,03 & 1,04 & 26,83 & 22,58 & 85,1 & 833 & $-8,89$ & 16,90 & 0,09 & 25,87 & 14,75 & 82,1 \\
\hline 218 & $-2,78$ & 23,01 & 1,03 & 26,82 & 22,60 & 85,1 & 278 & $-8,98$ & 16,81 & 0,06 & 25,85 & 13,86 & 82,0 \\
\hline 141 & $-2,80$ & 22,99 & 1,01 & 26,80 & 22,59 & 85,0 & 837 & $-9,06$ & 16,73 & 0,03 & 25,82 & 14,19 & 81,9 \\
\hline 324 & $-2,87$ & 22,92 & 1,00 & 26,79 & 22,54 & 85,0 & 860 & $-9,07$ & 16,71 & 0,00 & 25,79 & 15,36 & 81,8 \\
\hline
\end{tabular}

$\hat{g}=$ Efeito genotípico predito, VG = Valor genotípico predito, Ganho = Ganho genético, MPM = Média da população melhorada, $\mathrm{VF}=$ Valor fenotípico, $\mathrm{DR}=$ Desempenho relativo. 
Tabela 13. Valores obtidos pelo SELEGEN para a variável Volume

\begin{tabular}{|c|c|c|c|c|c|c|c|c|c|c|c|c|c|}
\hline Clone & $\hat{g}$ & VG & Ganho & MPM & $\mathrm{VF}$ & DR\% & Clone & $\hat{g}$ & VG & Ganho & MPM & $\mathrm{VF}$ & DR\% \\
\hline 865 & 0,31 & 0,59 & 0,31 & 0,59 & 0,63 & 100,0 & 997 & 0,11 & 0,39 & 0,16 & 0,44 & 0,40 & 74,6 \\
\hline 1028 & 0,29 & 0,57 & 0,30 & 0,58 & 0,61 & 98,3 & 47 & 0,11 & 0,39 & 0,16 & 0,44 & 0,40 & 74,6 \\
\hline 975 & 0,27 & 0,54 & 0,29 & 0,57 & 0,58 & 96,6 & 888 & 0,11 & 0,38 & 0,16 & 0,44 & 0,41 & 74,6 \\
\hline 1016 & 0,26 & 0,54 & 0,28 & 0,56 & 0,59 & 94,9 & 1019 & 0,11 & 0,38 & 0,16 & 0,44 & 0,42 & 74,6 \\
\hline 986 & 0,24 & 0,52 & 0,27 & 0,55 & 0,55 & 93,2 & 225 & 0,10 & 0,38 & 0,16 & 0,44 & 0,40 & 74,6 \\
\hline 925 & 0,24 & 0,52 & 0,27 & 0,55 & 0,53 & 93,2 & 834 & 0,10 & 0,38 & 0,16 & 0,44 & 0,40 & 74,6 \\
\hline 1006 & 0,23 & 0,51 & 0,26 & 0,54 & 0,53 & 91,5 & 234 & 0,10 & 0,38 & 0,16 & 0,43 & 0,37 & 72,9 \\
\hline 831 & 0,21 & 0,49 & 0,26 & 0,54 & 0,55 & 91,5 & 281 & 0,10 & 0,38 & 0,15 & 0,43 & 0,41 & 72,9 \\
\hline 1072 & 0,21 & 0,49 & 0,25 & 0,53 & 0,51 & 89,8 & 327 & 0,10 & 0,38 & 0,15 & 0,43 & 0,39 & 72,9 \\
\hline 880 & 0,20 & 0,48 & 0,25 & 0,53 & 0,52 & 89,8 & 1007 & 0,10 & 0,38 & 0,15 & 0,43 & 0,39 & 72,9 \\
\hline 931 & 0,19 & 0,47 & 0,24 & 0,52 & 0,50 & 88,1 & 1096 & 0,09 & 0,37 & 0,15 & 0,43 & 0,39 & 72,9 \\
\hline 7 & 0,19 & 0,47 & 0,24 & 0,52 & 0,50 & 88,1 & 326 & 0,09 & 0,37 & 0,15 & 0,43 & 0,37 & 72,9 \\
\hline 919 & 0,19 & 0,47 & 0,23 & 0,51 & 0,49 & 86,4 & 892 & 0,09 & 0,37 & 0,15 & 0,43 & 0,39 & 72,9 \\
\hline 229 & 0,18 & 0,46 & 0,23 & 0,51 & 0,50 & 86,4 & 844 & 0,09 & 0,37 & 0,15 & 0,43 & 0,37 & 72,9 \\
\hline 928 & 0,18 & 0,46 & 0,23 & 0,51 & 0,49 & 86,4 & 859 & 0,08 & 0,36 & 0,15 & 0,43 & 0,38 & 72,9 \\
\hline 981 & 0,18 & 0,46 & 0,22 & 0,50 & 0,48 & 84,7 & 328 & 0,08 & 0,36 & 0,15 & 0,43 & 0,39 & 72,9 \\
\hline 1023 & 0,18 & 0,46 & 0,22 & 0,50 & 0,48 & 84,7 & 143 & 0,08 & 0,36 & 0,15 & 0,43 & 0,39 & 72,9 \\
\hline 1052 & 0,17 & 0,45 & 0,22 & 0,50 & 0,47 & 84,7 & 959 & 0,08 & 0,36 & 0,15 & 0,42 & 0,37 & 71,2 \\
\hline 1014 & 0,16 & 0,44 & 0,21 & 0,49 & 0,45 & 83,1 & 991 & 0,08 & 0,36 & 0,14 & 0,42 & 0,37 & 71,2 \\
\hline 955 & 0,16 & 0,44 & 0,21 & 0,49 & 0,47 & 83,1 & 204 & 0,08 & 0,36 & 0,14 & 0,42 & 0,38 & 71,2 \\
\hline 1044 & 0,16 & 0,43 & 0,21 & 0,49 & 0,47 & 83,1 & 993 & 0,08 & 0,36 & 0,14 & 0,42 & 0,38 & 71,2 \\
\hline 945 & 0,15 & 0,43 & 0,21 & 0,49 & 0,46 & 83,1 & 929 & 0,08 & 0,36 & 0,14 & 0,42 & 0,35 & 71,2 \\
\hline 322 & 0,15 & 0,43 & 0,20 & 0,48 & 0,45 & 81,4 & 17 & 0,08 & 0,35 & 0,14 & 0,42 & 0,37 & 71,2 \\
\hline 43 & 0,15 & 0,43 & 0,20 & 0,48 & 0,45 & 81,4 & 29 & 0,07 & 0,35 & 0,14 & 0,42 & 0,37 & 71,2 \\
\hline 1083 & 0,15 & 0,43 & 0,20 & 0,48 & 0,45 & 81,4 & 1089 & 0,07 & 0,35 & 0,14 & 0,42 & 0,37 & 71,2 \\
\hline 832 & 0,15 & 0,43 & 0,20 & 0,48 & 0,45 & 81,4 & 645 & 0,07 & 0,35 & 0,14 & 0,42 & 0,37 & 71,2 \\
\hline 988 & 0,15 & 0,42 & 0,20 & 0,47 & 0,44 & 79,7 & 910 & 0,07 & 0,35 & 0,14 & 0,42 & 0,36 & 71,2 \\
\hline 952 & 0,14 & 0,42 & 0,19 & 0,47 & 0,42 & 79,7 & 1010 & 0,07 & 0,35 & 0,14 & 0,42 & 0,36 & 71,2 \\
\hline 1004 & 0,14 & 0,42 & 0,19 & 0,47 & 0,44 & 79,7 & 922 & 0,07 & 0,35 & 0,14 & 0,41 & 0,35 & 69,5 \\
\hline 24 & 0,14 & 0,42 & 0,19 & 0,47 & 0,45 & 79,7 & 856 & 0,07 & 0,35 & 0,14 & 0,41 & 0,35 & 69,5 \\
\hline 221 & 0,14 & 0,42 & 0,19 & 0,47 & 0,45 & 79,7 & 872 & 0,07 & 0,35 & 0,13 & 0,41 & 0,36 & 69,5 \\
\hline 57 & 0,14 & 0,42 & 0,19 & 0,47 & 0,44 & 79,7 & 949 & 0,07 & 0,35 & 0,13 & 0,41 & 0,36 & 69,5 \\
\hline 964 & 0,14 & 0,42 & 0,19 & 0,46 & 0,43 & 78,0 & 879 & 0,07 & 0,35 & 0,13 & 0,41 & 0,38 & 69,5 \\
\hline 927 & 0,14 & 0,41 & 0,18 & 0,46 & 0,42 & 78,0 & 295 & 0,07 & 0,35 & 0,13 & 0,41 & 0,36 & 69,5 \\
\hline 845 & 0,13 & 0,41 & 0,18 & 0,46 & 0,43 & 78,0 & 22 & 0,07 & 0,34 & 0,13 & 0,41 & 0,35 & 69,5 \\
\hline 948 & 0,13 & 0,41 & 0,18 & 0,46 & 0,43 & 78,0 & 977 & 0,06 & 0,34 & 0,13 & 0,41 & 0,35 & 69,5 \\
\hline 875 & 0,13 & 0,41 & 0,18 & 0,46 & 0,44 & 78,0 & 937 & 0,06 & 0,34 & 0,13 & 0,41 & 0,35 & 69,5 \\
\hline 1034 & 0,13 & 0,41 & 0,18 & 0,46 & 0,43 & 78,0 & 226 & 0,06 & 0,34 & 0,13 & 0,41 & 0,36 & 69,5 \\
\hline 891 & 0,13 & 0,40 & 0,18 & 0,46 & 0,44 & 78,0 & 918 & 0,06 & 0,34 & 0,13 & 0,41 & 0,35 & 69,5 \\
\hline 873 & 0,12 & 0,40 & 0,18 & 0,46 & 0,43 & 78,0 & 228 & 0,06 & 0,34 & 0,13 & 0,41 & 0,36 & 69,5 \\
\hline 191 & 0,12 & 0,40 & 0,17 & 0,45 & 0,42 & 76,3 & 881 & 0,06 & 0,34 & 0,13 & 0,41 & 0,35 & 69,5 \\
\hline 25 & 0,12 & 0,40 & 0,17 & 0,45 & 0,41 & 76,3 & 966 & 0,06 & 0,34 & 0,13 & 0,41 & 0,35 & 69,5 \\
\hline 273 & 0,12 & 0,40 & 0,17 & 0,45 & 0,42 & 76,3 & 311 & 0,06 & 0,34 & 0,13 & 0,40 & 0,34 & 67,8 \\
\hline 968 & 0,12 & 0,40 & 0,17 & 0,45 & 0,42 & 76,3 & 1001 & 0,06 & 0,34 & 0,12 & 0,40 & 0,34 & 67,8 \\
\hline 320 & 0,12 & 0,40 & 0,17 & 0,45 & 0,42 & 76,3 & 1081 & 0,06 & 0,33 & 0,12 & 0,40 & 0,34 & 67,8 \\
\hline 186 & 0,12 & 0,40 & 0,17 & 0,45 & 0,42 & 76,3 & 903 & 0,05 & 0,33 & 0,12 & 0,40 & 0,34 & 67,8 \\
\hline 42 & 0,12 & 0,40 & 0,17 & 0,45 & 0,42 & 76,3 & 830 & 0,05 & 0,33 & 0,12 & 0,40 & 0,34 & 67,8 \\
\hline 1045 & 0,12 & 0,40 & 0,17 & 0,45 & 0,41 & 76,3 & 23 & 0,05 & 0,33 & 0,12 & 0,40 & 0,35 & 67,8 \\
\hline 935 & 0,12 & 0,40 & 0,17 & 0,44 & 0,41 & 74,6 & 266 & 0,05 & 0,33 & 0,12 & 0,40 & 0,38 & 67,8 \\
\hline 316 & 0,12 & 0,39 & 0,16 & 0,44 & 0,40 & 74,6 & 38 & 0,05 & 0,33 & 0,12 & 0,40 & 0,34 & 67,8 \\
\hline 373 & 0,11 & 0,39 & 0,16 & 0,44 & 0,41 & 74,6 & 847 & 0,05 & 0,33 & 0,12 & 0,40 & 0,33 & 67,8 \\
\hline 920 & 0,11 & 0,39 & 0,16 & 0,44 & 0,41 & 74,6 & 263 & 0,05 & 0,33 & 0,12 & 0,40 & 0,34 & 67,8 \\
\hline
\end{tabular}


Tabela 13. Valores obtidos pelo SELEGEN para a variável Volume

\begin{tabular}{|c|c|c|c|c|c|c|c|c|c|c|c|c|c|}
\hline Clone & $\hat{g}$ & VG & Ganho & MPM & $\mathrm{VF}$ & $\mathrm{DR} \%$ & Clone & $\hat{g}$ & VG & Ganho & MPM & VF & DR\% \\
\hline 930 & 0,05 & 0,33 & 0,12 & 0,40 & 0,34 & 67,8 & 127 & $-0,01$ & 0,27 & 0,09 & 0,37 & 0,28 & 62,7 \\
\hline 196 & 0,05 & 0,33 & 0,12 & 0,40 & 0,34 & 67,8 & 214 & $-0,01$ & 0,27 & 0,09 & 0,36 & 0,25 & 61,0 \\
\hline 1082 & 0,05 & 0,33 & 0,12 & 0,40 & 0,34 & 67,8 & 956 & $-0,01$ & 0,27 & 0,09 & 0,36 & 0,26 & 61,0 \\
\hline 846 & 0,05 & 0,32 & 0,12 & 0,40 & 0,33 & 67,8 & 128 & $-0,01$ & 0,27 & 0,08 & 0,36 & 0,26 & 61,0 \\
\hline 202 & 0,05 & 0,32 & 0,12 & 0,39 & 0,33 & 66,1 & 106 & $-0,01$ & 0,27 & 0,08 & 0,36 & 0,27 & 61,0 \\
\hline 1003 & 0,04 & 0,32 & 0,12 & 0,39 & 0,31 & 66,1 & 210 & $-0,01$ & 0,27 & 0,08 & 0,36 & 0,26 & 61,0 \\
\hline 853 & 0,04 & 0,32 & 0,11 & 0,39 & 0,34 & 66,1 & 282 & $-0,01$ & 0,27 & 0,08 & 0,36 & 0,25 & 61,0 \\
\hline 267 & 0,04 & 0,32 & 0,11 & 0,39 & 0,32 & 66,1 & 1077 & $-0,01$ & 0,27 & 0,08 & 0,36 & 0,25 & 61,0 \\
\hline 33 & 0,04 & 0,32 & 0,11 & 0,39 & 0,33 & 66,1 & 133 & $-0,02$ & 0,26 & 0,08 & 0,36 & 0,25 & 61,0 \\
\hline 269 & 0,04 & 0,32 & 0,11 & 0,39 & 0,34 & 66,1 & 894 & $-0,02$ & 0,26 & 0,08 & 0,36 & 0,26 & 61,0 \\
\hline 310 & 0,04 & 0,32 & 0,11 & 0,39 & 0,32 & 66,1 & 80 & $-0,02$ & 0,26 & 0,08 & 0,36 & 0,27 & 61,0 \\
\hline 219 & 0,04 & 0,32 & 0,11 & 0,39 & 0,32 & 66,1 & 209 & $-0,02$ & 0,26 & 0,08 & 0,36 & 0,26 & 61,0 \\
\hline 933 & 0,04 & 0,32 & 0,11 & 0,39 & 0,32 & 66,1 & 238 & $-0,02$ & 0,26 & 0,08 & 0,36 & 0,27 & 61,0 \\
\hline 953 & 0,04 & 0,32 & 0,11 & 0,39 & 0,31 & 66,1 & 850 & $-0,02$ & 0,26 & 0,08 & 0,36 & 0,25 & 61,0 \\
\hline 361 & 0,04 & 0,32 & 0,11 & 0,39 & 0,32 & 66,1 & 56 & $-0,02$ & 0,26 & 0,08 & 0,36 & 0,25 & 61,0 \\
\hline 852 & 0,03 & 0,31 & 0,11 & 0,39 & 0,32 & 66,1 & 158 & $-0,02$ & 0,26 & 0,08 & 0,36 & 0,26 & 61,0 \\
\hline 306 & 0,03 & 0,31 & 0,11 & 0,39 & 0,34 & 66,1 & 854 & $-0,02$ & 0,26 & 0,08 & 0,36 & 0,27 & 61,0 \\
\hline 325 & 0,03 & 0,31 & 0,11 & 0,39 & 0,32 & 66,1 & 205 & $-0,02$ & 0,26 & 0,08 & 0,36 & 0,26 & 61,0 \\
\hline 288 & 0,03 & 0,31 & 0,11 & 0,39 & 0,32 & 66,1 & 40 & $-0,02$ & 0,26 & 0,08 & 0,35 & 0,24 & 59,3 \\
\hline 84 & 0,03 & 0,31 & 0,11 & 0,39 & 0,33 & 66,1 & 980 & $-0,02$ & 0,26 & 0,08 & 0,35 & 0,24 & 59,3 \\
\hline 152 & 0,02 & 0,30 & 0,11 & 0,38 & 0,30 & 64,4 & 279 & $-0,03$ & 0,25 & 0,07 & 0,35 & 0,25 & 59,3 \\
\hline 979 & 0,02 & 0,30 & 0,11 & 0,38 & 0,30 & 64,4 & 271 & $-0,03$ & 0,25 & 0,07 & 0,35 & 0,22 & 59,3 \\
\hline 6 & 0,02 & 0,30 & 0,10 & 0,38 & 0,30 & 64,4 & 145 & $-0,03$ & 0,25 & 0,07 & 0,35 & 0,24 & 59,3 \\
\hline 864 & 0,02 & 0,30 & 0,10 & 0,38 & 0,29 & 64,4 & 313 & $-0,03$ & 0,25 & 0,07 & 0,35 & 0,25 & 59,3 \\
\hline 307 & 0,02 & 0,30 & 0,10 & 0,38 & 0,30 & 64,4 & 1099 & $-0,03$ & 0,25 & 0,07 & 0,35 & 0,24 & 59,3 \\
\hline 164 & 0,02 & 0,30 & 0,10 & 0,38 & 0,31 & 64,4 & 20 & $-0,03$ & 0,25 & 0,07 & 0,35 & 0,24 & 59,3 \\
\hline 889 & 0,02 & 0,30 & 0,10 & 0,38 & 0,30 & 64,4 & 849 & $-0,03$ & 0,25 & 0,07 & 0,35 & 0,24 & 59,3 \\
\hline 882 & 0,02 & 0,30 & 0,10 & 0,38 & 0,29 & 64,4 & 1092 & $-0,03$ & 0,25 & 0,07 & 0,35 & 0,25 & 59,3 \\
\hline 41 & 0,02 & 0,30 & 0,10 & 0,38 & 0,30 & 64,4 & 76 & $-0,04$ & 0,24 & 0,07 & 0,35 & 0,24 & 59,3 \\
\hline 1085 & 0,02 & 0,30 & 0,10 & 0,38 & 0,30 & 64,4 & 167 & $-0,04$ & 0,24 & 0,07 & 0,35 & 0,25 & 59,3 \\
\hline 198 & 0,02 & 0,29 & 0,10 & 0,38 & 0,29 & 64,4 & 64 & $-0,04$ & 0,24 & 0,07 & 0,35 & 0,24 & 59,3 \\
\hline 11 & 0,02 & 0,29 & 0,10 & 0,38 & 0,31 & 64,4 & 224 & $-0,04$ & 0,24 & 0,07 & 0,35 & 0,25 & 59,3 \\
\hline 185 & 0,02 & 0,29 & 0,10 & 0,38 & 0,30 & 64,4 & 1031 & $-0,04$ & 0,24 & 0,07 & 0,35 & 0,23 & 59,3 \\
\hline 27 & 0,01 & 0,29 & 0,10 & 0,38 & 0,30 & 64,4 & 151 & $-0,04$ & 0,24 & 0,07 & 0,35 & 0,24 & 59,3 \\
\hline 861 & 0,01 & 0,29 & 0,10 & 0,38 & 0,30 & 64,4 & 5 & $-0,04$ & 0,24 & 0,07 & 0,35 & 0,24 & 59,3 \\
\hline 28 & 0,01 & 0,29 & 0,10 & 0,38 & 0,30 & 64,4 & 858 & $-0,04$ & 0,24 & 0,07 & 0,34 & 0,22 & 57,6 \\
\hline 842 & 0,01 & 0,29 & 0,10 & 0,37 & 0,28 & 62,7 & 192 & $-0,04$ & 0,24 & 0,07 & 0,34 & 0,22 & 57,6 \\
\hline 321 & 0,01 & 0,29 & 0,10 & 0,37 & 0,27 & 62,7 & 32 & $-0,04$ & 0,24 & 0,06 & 0,34 & 0,23 & 57,6 \\
\hline 862 & 0,01 & 0,29 & 0,09 & 0,37 & 0,28 & 62,7 & 26 & $-0,04$ & 0,24 & 0,06 & 0,34 & 0,23 & 57,6 \\
\hline 285 & 0,01 & 0,29 & 0,09 & 0,37 & 0,27 & 62,7 & 208 & $-0,04$ & 0,24 & 0,06 & 0,34 & 0,23 & 57,6 \\
\hline 176 & 0,01 & 0,29 & 0,09 & 0,37 & 0,28 & 62,7 & 16 & $-0,04$ & 0,24 & 0,06 & 0,34 & 0,21 & 57,6 \\
\hline 268 & 0,01 & 0,28 & 0,09 & 0,37 & 0,28 & 62,7 & 31 & $-0,05$ & 0,23 & 0,06 & 0,34 & 0,21 & 57,6 \\
\hline 528 & 0,01 & 0,28 & 0,09 & 0,37 & 0,28 & 62,7 & 317 & $-0,05$ & 0,23 & 0,06 & 0,34 & 0,22 & 57,6 \\
\hline 2 & 0,00 & 0,28 & 0,09 & 0,37 & 0,29 & 62,7 & 1086 & $-0,05$ & 0,23 & 0,06 & 0,34 & 0,23 & 57,6 \\
\hline 153 & 0,00 & 0,28 & 0,09 & 0,37 & 0,28 & 62,7 & 884 & $-0,05$ & 0,23 & 0,06 & 0,34 & 0,22 & 57,6 \\
\hline 261 & 0,00 & 0,28 & 0,09 & 0,37 & 0,28 & 62,7 & 314 & $-0,05$ & 0,23 & 0,06 & 0,34 & 0,22 & 57,6 \\
\hline 319 & 0,00 & 0,28 & 0,09 & 0,37 & 0,29 & 62,7 & 1075 & $-0,05$ & 0,23 & 0,06 & 0,34 & 0,22 & 57,6 \\
\hline 18 & 0,00 & 0,28 & 0,09 & 0,37 & 0,28 & 62,7 & 947 & $-0,05$ & 0,23 & 0,06 & 0,34 & 0,22 & 57,6 \\
\hline 171 & 0,00 & 0,28 & 0,09 & 0,37 & 0,29 & 62,7 & 135 & $-0,05$ & 0,23 & 0,06 & 0,34 & 0,22 & 57,6 \\
\hline 159 & 0,00 & 0,28 & 0,09 & 0,37 & 0,29 & 62,7 & 230 & $-0,05$ & 0,22 & 0,06 & 0,34 & 0,22 & 57,6 \\
\hline 15 & 0,00 & 0,27 & 0,09 & 0,37 & 0,31 & 62,7 & 1069 & $-0,06$ & 0,22 & 0,06 & 0,34 & 0,22 & 57,6 \\
\hline 1074 & 0,00 & 0,27 & 0,09 & 0,37 & 0,30 & 62,7 & 93 & $-0,06$ & 0,22 & 0,06 & 0,34 & 0,21 & 57,6 \\
\hline
\end{tabular}


Tabela 13. Valores obtidos pelo SELEGEN para a variável Volume

\begin{tabular}{|c|c|c|c|c|c|c|c|c|c|c|c|c|c|}
\hline Clone & $\hat{g}$ & $\mathrm{VG}$ & Ganho & MPM & $\mathrm{VF}$ & DR\% & Clone & $\hat{g}$ & $\mathrm{VG}$ & Ganho & MPM & $\mathrm{VF}$ & DR\% \\
\hline 8 & $-0,06$ & 0,22 & 0,06 & 0,34 & 0,22 & 57,6 & 1095 & $-0,11$ & 0,17 & 0,03 & 0,31 & 0,15 & 52,5 \\
\hline 235 & $-0,06$ & 0,22 & 0,06 & 0,34 & 0,23 & 57,6 & 53 & $-0,11$ & 0,17 & 0,03 & 0,31 & 0,12 & 52,5 \\
\hline 49 & $-0,06$ & 0,22 & 0,06 & 0,33 & 0,20 & 55,9 & 218 & $-0,11$ & 0,17 & 0,03 & 0,31 & 0,15 & 52,5 \\
\hline 14 & $-0,07$ & 0,21 & 0,06 & 0,33 & 0,21 & 55,9 & 141 & $-0,11$ & 0,17 & 0,03 & 0,31 & 0,14 & 52,5 \\
\hline 203 & $-0,07$ & 0,21 & 0,05 & 0,33 & 0,19 & 55,9 & 1061 & $-0,11$ & 0,17 & 0,03 & 0,30 & 0,14 & 50,8 \\
\hline 3 & $-0,07$ & 0,21 & 0,05 & 0,33 & 0,21 & 55,9 & 148 & $-0,11$ & 0,17 & 0,03 & 0,30 & 0,12 & 50,8 \\
\hline 154 & $-0,07$ & 0,21 & 0,05 & 0,33 & 0,19 & 55,9 & 9 & $-0,11$ & 0,16 & 0,02 & 0,30 & 0,14 & 50,8 \\
\hline 265 & $-0,07$ & 0,21 & 0,05 & 0,33 & 0,19 & 55,9 & 101 & $-0,12$ & 0,16 & 0,02 & 0,30 & 0,14 & 50,8 \\
\hline 270 & $-0,07$ & 0,21 & 0,05 & 0,33 & 0,19 & 55,9 & 315 & $-0,12$ & 0,16 & 0,02 & 0,30 & 0,13 & 50,8 \\
\hline 155 & $-0,07$ & 0,21 & 0,05 & 0,33 & 0,19 & 55,9 & 318 & $-0,12$ & 0,16 & 0,02 & 0,30 & 0,12 & 50,8 \\
\hline 1073 & $-0,07$ & 0,20 & 0,05 & 0,33 & 0,20 & 55,9 & 1076 & $-0,12$ & 0,16 & 0,02 & 0,30 & 0,14 & 50,8 \\
\hline 147 & $-0,07$ & 0,20 & 0,05 & 0,33 & 0,20 & 55,9 & 44 & $-0,12$ & 0,16 & 0,02 & 0,30 & 0,15 & 50,8 \\
\hline 144 & $-0,08$ & 0,20 & 0,05 & 0,33 & 0,20 & 55,9 & 836 & $-0,12$ & 0,16 & 0,02 & 0,30 & 0,12 & 50,8 \\
\hline 94 & $-0,08$ & 0,20 & 0,05 & 0,33 & 0,19 & 55,9 & 1068 & $-0,12$ & 0,16 & 0,02 & 0,30 & 0,13 & 50,8 \\
\hline 227 & $-0,08$ & 0,20 & 0,05 & 0,33 & 0,19 & 55,9 & 201 & $-0,12$ & 0,16 & 0,02 & 0,30 & 0,12 & 50,8 \\
\hline 78 & $-0,08$ & 0,20 & 0,05 & 0,33 & 0,20 & 55,9 & 39 & $-0,12$ & 0,16 & 0,02 & 0,30 & 0,14 & 50,8 \\
\hline 594 & $-0,08$ & 0,20 & 0,05 & 0,33 & 0,20 & 55,9 & 272 & $-0,12$ & 0,16 & 0,02 & 0,30 & 0,15 & 50,8 \\
\hline 45 & $-0,08$ & 0,20 & 0,05 & 0,33 & 0,19 & 55,9 & 13 & $-0,13$ & 0,15 & 0,02 & 0,30 & 0,14 & 50,8 \\
\hline 223 & $-0,08$ & 0,20 & 0,05 & 0,33 & 0,19 & 55,9 & 51 & $-0,13$ & 0,15 & 0,02 & 0,30 & 0,13 & 50,8 \\
\hline 54 & $-0,08$ & 0,20 & 0,05 & 0,32 & 0,17 & 54,2 & 324 & $-0,13$ & 0,15 & 0,02 & 0,30 & 0,14 & 50,8 \\
\hline 134 & $-0,08$ & 0,20 & 0,05 & 0,32 & 0,18 & 54,2 & 162 & $-0,14$ & 0,14 & 0,02 & 0,30 & 0,15 & 50,8 \\
\hline 280 & $-0,08$ & 0,20 & 0,04 & 0,32 & 0,19 & 54,2 & 215 & $-0,14$ & 0,14 & 0,02 & 0,30 & 0,14 & 50,8 \\
\hline 163 & $-0,08$ & 0,20 & 0,04 & 0,32 & 0,17 & 54,2 & 58 & $-0,14$ & 0,14 & 0,02 & 0,30 & 0,14 & 50,8 \\
\hline 312 & $-0,08$ & 0,20 & 0,04 & 0,32 & 0,17 & 54,2 & 199 & $-0,14$ & 0,14 & 0,02 & 0,29 & 0,10 & 49,2 \\
\hline 48 & $-0,08$ & 0,20 & 0,04 & 0,32 & 0,17 & 54,2 & 70 & $-0,14$ & 0,14 & 0,02 & 0,29 & 0,11 & 49,2 \\
\hline 168 & $-0,08$ & 0,19 & 0,04 & 0,32 & 0,19 & 54,2 & 150 & $-0,14$ & 0,14 & 0,01 & 0,29 & 0,08 & 49,2 \\
\hline 236 & $-0,09$ & 0,19 & 0,04 & 0,32 & 0,17 & 54,2 & 262 & $-0,14$ & 0,14 & 0,01 & 0,29 & 0,10 & 49,2 \\
\hline 286 & $-0,09$ & 0,19 & 0,04 & 0,32 & 0,19 & 54,2 & 323 & $-0,14$ & 0,14 & 0,01 & 0,29 & 0,10 & 49,2 \\
\hline 139 & $-0,09$ & 0,19 & 0,04 & 0,32 & 0,18 & 54,2 & 284 & $-0,14$ & 0,13 & 0,01 & 0,29 & 0,11 & 49,2 \\
\hline 840 & $-0,09$ & 0,19 & 0,04 & 0,32 & 0,16 & 54,2 & 839 & $-0,14$ & 0,13 & 0,01 & 0,29 & 0,12 & 49,2 \\
\hline 259 & $-0,09$ & 0,19 & 0,04 & 0,32 & 0,18 & 54,2 & 149 & $-0,14$ & 0,13 & 0,01 & 0,29 & 0,12 & 49,2 \\
\hline 253 & $-0,09$ & 0,19 & 0,04 & 0,32 & 0,17 & 54,2 & 829 & $-0,15$ & 0,13 & 0,01 & 0,29 & 0,13 & 49,2 \\
\hline 125 & $-0,09$ & 0,19 & 0,04 & 0,32 & 0,17 & 54,2 & 52 & $-0,15$ & 0,13 & 0,01 & 0,29 & 0,10 & 49,2 \\
\hline 79 & $-0,09$ & 0,19 & 0,04 & 0,32 & 0,19 & 54,2 & 1062 & $-0,15$ & 0,13 & 0,01 & 0,29 & 0,05 & 49,2 \\
\hline 130 & $-0,09$ & 0,19 & 0,04 & 0,32 & 0,17 & 54,2 & 848 & $-0,15$ & 0,13 & 0,01 & 0,29 & 0,11 & 49,2 \\
\hline 30 & $-0,10$ & 0,18 & 0,04 & 0,32 & 0,17 & 54,2 & 103 & $-0,15$ & 0,13 & 0,01 & 0,29 & 0,11 & 49,2 \\
\hline 182 & $-0,10$ & 0,18 & 0,04 & 0,32 & 0,18 & 54,2 & 276 & $-0,15$ & 0,13 & 0,01 & 0,29 & 0,11 & 49,2 \\
\hline 851 & $-0,10$ & 0,18 & 0,04 & 0,32 & 0,17 & 54,2 & 264 & $-0,15$ & 0,12 & 0,01 & 0,29 & 0,11 & 49,2 \\
\hline 98 & $-0,10$ & 0,18 & 0,04 & 0,31 & 0,16 & 52,5 & 146 & $-0,15$ & 0,12 & 0,01 & 0,29 & 0,11 & 49,2 \\
\hline 140 & $-0,10$ & 0,18 & 0,04 & 0,31 & 0,14 & 52,5 & 1094 & $-0,16$ & 0,12 & 0,01 & 0,29 & 0,10 & 49,2 \\
\hline 10 & $-0,10$ & 0,18 & 0,03 & 0,31 & 0,16 & 52,5 & 83 & $-0,16$ & 0,12 & 0,01 & 0,29 & 0,09 & 49,2 \\
\hline 21 & $-0,10$ & 0,18 & 0,03 & 0,31 & 0,15 & 52,5 & 828 & $-0,17$ & 0,11 & 0,01 & 0,28 & 0,07 & 47,5 \\
\hline 165 & $-0,10$ & 0,18 & 0,03 & 0,31 & 0,15 & 52,5 & 1071 & $-0,17$ & 0,11 & 0,01 & 0,28 & 0,06 & 47,5 \\
\hline 843 & $-0,10$ & 0,18 & 0,03 & 0,31 & 0,16 & 52,5 & 278 & $-0,18$ & 0,10 & 0,00 & 0,28 & 0,05 & 47,5 \\
\hline 960 & $-0,11$ & 0,17 & 0,03 & 0,31 & 0,17 & 52,5 & 12 & $-0,18$ & 0,10 & 0,00 & 0,28 & 0,08 & 47,5 \\
\hline 62 & $-0,11$ & 0,17 & 0,03 & 0,31 & 0,17 & 52,5 & 838 & $-0,18$ & 0,10 & 0,00 & 0,28 & 0,05 & 47,5 \\
\hline 19 & $-0,11$ & 0,17 & 0,03 & 0,31 & 0,15 & 52,5 & 833 & $-0,18$ & 0,10 & 0,00 & 0,28 & 0,04 & 47,5 \\
\hline 60 & $-0,11$ & 0,17 & 0,03 & 0,31 & 0,16 & 52,5 & 841 & $-0,18$ & 0,10 & 0,00 & 0,28 & 0,07 & 47,5 \\
\hline 274 & $-0,11$ & 0,17 & 0,03 & 0,31 & 0,15 & 52,5 & 277 & $-0,18$ & 0,09 & 0,00 & 0,28 & 0,07 & 47,5 \\
\hline 275 & $-0,11$ & 0,17 & 0,03 & 0,31 & 0,15 & 52,5 & 855 & $-0,19$ & 0,09 & 0,00 & 0,28 & 0,04 & 47,5 \\
\hline 835 & $-0,11$ & 0,17 & 0,03 & 0,31 & 0,15 & 52,5 & 837 & $-0,19$ & 0,09 & 0,00 & 0,28 & 0,05 & 47,5 \\
\hline 233 & $-0,11$ & 0,17 & 0,03 & 0,31 & 0,14 & 52,5 & 860 & $-0,20$ & 0,08 & 0,00 & 0,28 & 0,08 & 47,5 \\
\hline
\end{tabular}

$\hat{g}=$ Efeito genotípico predito, VG = Valor genotípico predito, Ganho = Ganho genético, MPM = Média da população melhorada, $\mathrm{VF}=$ Valor fenotípico, $\mathrm{DR}=$ Desempenho relativo. 


\section{REFERÊNCIAS BIBLIOGRÁFICAS}

ANDRADE, E.N. O eucalipto. 2.ed. Jundiaí: Companhia Paulista de Estradas de Ferro. 1961. 170p.

ANDRÉ, C.M.G. Avaliação da melhor predição linear não tendenciosa (BLUP) associada ao uso de marcadores moleculares na análise dialélica. Lavras, 1999. 101p. Dissertação (Mestrado) - Universidade Federal de Lavras.

ASSOCIAÇÃO BRASILEIRA DE CELULOSE E PAPEL. Relatório anual - 2002. São Paulo, 2002. 50p.

BARBIN, D. Aspectos estatísticos de alguns modelos matemáticos usados no melhoramento do gado de corte. Piracicaba, 1977. 110p. Tese (Livre Docência) Escola Superior de Agricultura "Luiz de Queiroz", Universidade de São Paulo.

BARBIN, D. Componentes de Variância. Teoria e Aplicações. Piracicaba: Fundação de Estudos Agrários Luiz de Queiroz - FEALQ, 2000. 43p.

BORGES, R.C.G. Estimativas de herdabilidade e correlações entre caracteres de crescimento em Eucalyptus grandis. Viçosa, 1980. 82p. Tese (Mestrado) Universidade Federal de Viçosa.

BUENO FILHO, J.S.S. Modelos mistos na predição de valores genéticos aditivos em testes de progênies florestais. Piracicaba, 1997. 118p. Tese (Doutorado) Escola Superior de Agricultura "Luiz de Queiroz", Universidade de São Paulo. 
CASTELLANO, F.S.; HENRIQUEZ, J.J.G.; SANTANA, P.S. Estimación del modelo de efectos aleatorios vía el algoritmo EM, 2002. 18p. Departamento de Matemáticas, Universidad de Las Palmas de Gran Canaria, Campus Universitario de Tafira, Las Palmas.

CORBEIL, R.R.; SEARLE, S.R. Restricted maximum likelihood (REML) estimation of variance components in the mixed model. Technometrics, v.18, p.31-38, 1976.

CRUZ, C.D. Programa genes: aplicativo computacional em genética e estatística. Viçosa: Universidade Federal de Viçosa. 1997. 422p.

CRUZ, C.D.; REGAZZI, A.J. Modelos biométricos aplicados ao melhoramento genético. Viçosa: UFV, 1994. 402p.

DEMPSTER, A.P.; LAIRD, N.M.; RUBIN, D.B. Maximum likelihood from incomplete data via the EM algorithm. Journal of the Royal Statistic Society, v.39, p. 1-38, 1977.

ELDRIDGE, K. Eucalypt domestication and breeding: Clarendon Press. 1993. 287p.

FALCONER, D.S. Introduction to quantitative genetics. 3.ed. Ed. Longman, 1989. 438p.

FARIAS NETO, J.T.; MOCHIUTTI, S.; CASTRO, A.W.V. Influência do número de repetições nas estimativas de parâmetros genéticos em progênies de meios-irmãos de taxi-branco (Sclerolobium paniculatum). Acta Amazônica, v.29, n.3, p.429-435, set.1999.

FERREIRA, M. Escolha de espécies de eucalipto. Circular Técnica IPEF, v.47, p.1-30. jul./dez.1993. 
FIORAVANTE, A.M. Uma aplicação do algoritmo EM. Piracicaba: ESALQ, Departamento de Ciências Exatas. Escola Superior de Agricultura "Luiz de Queiroz", Universidade de São Paulo. 1993. 12p.

FREITAS, A.R.; FAVORETTI, A.C.; ALENCAR, M.M.; PEGORIN, M.J. Uso da máxima verossimilhança restrita e transformação canônica para estimação de parâmetros genéticos de características de crescimento em bovinos. Revista da Sociedade Brasileira de Zootecnia , v.23, n.3, p.394-401, 1994.

FU, Y.; CLARKE, G.P.Y.; NAMKOONG, G.; YANCHUK, A.D. Incomplete block designs for genetic testing: statistical efficiencies of estimating family means. Canadian Journal of Forest Research, v.28, n.7, p.977-986, 1988.

GARCIA, C.H. Tabelas para classificação do coeficiente de variação. Circular Técnica IPEF, n.171, p.1-11. 1987.

GARCIA, C.H.; MORA, A.L. A cultura do eucalipto no Brasil. São Paulo, SP: Sociedade Brasileira de Silvicultura. 2000. 103p.

GARCIA, S.L.R. Importância de características de crescimento, de qualidade da madeira e da polpa na diversidade genética de clones de eucalipto. Viçosa, 1998. 78p. Dissertação (Mestrado) - Universidade Federal de Viçosa.

GILMOUR, A.R.; THOMPSON, R.; CULLIS, B.R. Average information REML: an efficient algorithm for parameter estimation in linear mixed models. Biometrics, v.51, p.1440-1450, 1995.

GRASER, H.U.; SMITH, S.P.; TIER, B. A derivative free approach for estimating variance components in animal models by restricted maximum likelihood. Journal of Animal Science, v.64, n.5, p.1362-1370, 1987. 
HARTLEY, H.O.; RAO, J.N.K. Maximum likelihood estimation for the mixed analysis of variance model. Biometrika, v.54, p.93-108, 1967.

HARVILLE, D.A. Maximum likelihood approaches to variances component estimation and to related problems. Journal of the American Statistical Association, v.72, p.320-340, 1977.

HENDERSON, C.R. Estimation of changes in herd environment. Journal of Dairy Science, v.32, p.709, 1949.

HENDERSON, C.R. Estimation of variance and covariance components. Biometrics, v.9, p.266-252, 1953.

HENDERSON, C.R. General flexibility of linear models for sire evaluation. Journal of Dairy Science, v.57, n.8, p.963-972, 1974.

HENDERSON, C.R. Sire evaluation and genetic trends. In: Animal Breeding And Genetics Symposium In Honor Of J. Lush. Proceedings. Champaign: American Society of Annimal Science, III, 1973. p.10-41.

HENDERSON, C.R. The best linear umbiased estimation and prediction under a selection model. Biometrics, v.31, p.423-449, 1975.

HENDERSON, C.R. Prediction of future records. POLLACK, E.; KEMPTHORNE, O.; BAILEY, I. In: International Conference On quantitative genetics. Ames, 1977. Proceedings. Ames: Iowa State University, 1977.

HENDERSON, C.R. Aplications of linear models in animal breeding. Guelph: University of Guelph, 1984. 114p.

HENDERSON, C.R.; KEMPTHORNE, O.; SEARLE, S.R.; VON KROSIGH, C.M. The estimation of environmental and genetic trends from records subject to culling. Biometrics, v.15, p.192, 1959. 
HICKS, C.R. Fundamental concepts in the design of experiments. 2.ed., New York: Holt, Rinehart and Winston, 1973. 509p.

HIGA, A. R. Pesquisa com o Eucalipto no Brasil: Evolução e Contribuição. Curitiba: EMBRAPA/CNPF, 1995. 12p.

HOULE, D. Comparing evolvability and variability of quantitative traits. Genetics, n.30, p.195-204, jan. 1992.

IEMMA, M. Uso do melhor preditor linear não viesado (BLUP) em análises dialélicas e predição de híbridos. Piracicaba, 2003. 81p. Dissertação (Mestrado) - Escola Superior de Agricultura "Luiz de Queiroz", Universidade de São Paulo.

JOHNSON, D.L.; THOMPSON, R. Restricted maximum likelihook estimation of variance components for univariate animal models using sparse matrix techniques and average information. Journal of Dairy Science, v.78. p.449-456, 1955 .

KAGEYAMA, P.Y. Determinação de parâmetros genéticos com espécies florestais. Piracicaba, SP: Instituto de Pesqusias e Estudos Florestais, 1979. $22 \mathrm{p}$.

KENNEDY, B.W. Variance component estimation and prediction of breeding values. Canadian Journal of Genetics and Cytology, v.23, n.4, p.565$578,1981$.

KIKUTI, P. Parâmetros genéticos em progênies de meios irmãos e clonais numa população de Eucalyptus grandis na região de Telêmaco Borba. Piracicaba, 1988. 119p. Dissertação (Mestrado) - Escola Superior de Agricultura "Luiz de Queiroz", Universidade de São Paulo. 
LUZ, H.F. Manejo de florestas de eucalipto para usos múltiplos. In: CONGRESSO FLORESTAL PANAMERICANO 1., bf Anais. São Paulo: Sociedade Brasileira de Silvicultura, 1993. p.283-289.

MEYER, K. Estimation of genetic parameters. In: HILL, W.G.; MACKEY, T.F.C. Evolution And Animal Breeding. Wallingford: CAB International, 1989. p.161-167

MILliKen, G.A.; JOHNSON, D.E. Analysis of messy data. New York: Chapman \& Hall. 1992. v.1. 473p.

MOOD, A.M. Introduction to the theory of statistics. New York: McGrawHill. 1950. 443p.

MORA, A.L. Aumento da produção de sementes geneticamente melhoradas de Acacia mearnsii de Wild (acácia negra) no Rio Grande do Sul. Curitiba, 2002. 145p. Tese (Doutorado) - Universidade Federal do Paraná.

MORA, A.L. Interação com espaçamentos e locais em clones de Eucalyptus no norte do estado da Bahia. Piracicaba, 1986. 101p. Dissertação (Mestrado) Escola Superior de Agricultura "Luiz de Queiroz", Universidade de São Paulo.

MORI, E; SANTOS. P.E.T. Programa cooperativo interação genótipos x ambientes. Série Técnica IPEF, v.6, n.21, p.1-34, nov., 1989.

MURO-ABAD, J.I.; CÂNCIO, O.N.; ROCHA, R.B.; CRUZ, C.D.; ARAÚJO, E.F. Ferramentas de seleção no melhoramento genético do eucalipto: utilização de BLUP para obtenção do valor genético e REML para os componentes de variância em teste de progênie de Eucalyptus pellita em três ambientes na Amazônia brasileira. In: CONGRESSO FLORESTAL BRASILEIRO, 8., bf Anais. São Paulo, SP. Sociedade Brasileira de Silvicultura, 2003. p312-318. 
PATTERSON, H.D.; THOMPSON, R. Recovery of inter-block information when block sizes are unequal. Biometrika, v.58, p.545-554, 1971.

PERRI, S.H.V.; IEMMA, A.F. Ajuste de modelos mistos através do sistema estatístico SAS. Piracicaba: Escola Superior de Agricultura "Luiz de Queiroz", Universidade de São Paulo. 1996. 75p.

RAMALHO, M.A.P.; SANTOS, J.B.; ZIMMERMANN, M.J.O. Genética quantitativa no melhoramento de plantas autógamas. Goiânia: Universidade Federal de Goiás, 1993. 271p.

RAMALHO, M.A.P.; FERREIRA, D.F.; OLIVEIRA, A.C. Experimentação genética e melhoramento de plantas. Lavras: UFLA, 2000. 303p.

RAO, P.S. Variance components: Mixed models methodologies and applications. Boca Raton: CRC Press, 1997. 204p.

RESENDE, M.D.V. Análise estatística de modelos mistos via REML/BLUP na experimentação em melhoramento de plantas perenes. Colombo: Embrapa Florestas, n.47, p.1-101, 2000. (Documentos 47) 102p.

RESENDE, M.D.V. Genética biométrica e estatística no melhoramento de plantas perenes. Brasília: Embrapa Informação Tecnológica, 2002a. $920 \mathrm{p}$.

RESENDE, M.D.V. Software Selegen-REMLBLUP. Colombo: Embrapa Florestas, Dez. 2002b. (Documentos 77) 12p.

RESENDE, M.D.V.; ARAUJO, A.J. Modelo genético-estatístico para estimação de componentes da variação genética e parâmetros genéticos em testes de progênies com indivíduos repetidos clonalmente. Floresta, v.23, n.1/2, p.35-45, jul./dez. 1993. 
RESENDE, M.D.V.; HIGA, A.R. Estimação de valores genéticos no melhoramento de Eucalyptus: seleção em um caráter com base em informações do indivíduo e de seus parentes. Boletim de Pesquisa Florestal, n.28/29, p.1136, jan./dez.1994.

RESENDE, M.D.V.; MENDES, S. Estimação de componentes de variância e predição de valores genéticos pelo método da máxima verossimilhança restrita (REML) e melhor predição não viciada (BLUP) em Pinus. Boletim de Pesquisa Florestal, n.32/33, p.23-42, jan./dez, 1996.

RESENDE, M.D.V.; PEREZ, J.R.H. Melhoramento animal: Predição de valores genéticos pelo modelo animal-BLUP em bovinos de leite, bovinos de corte, ovinos e suínos. Curitiba: Departamento de Zootecnia, Setor de Ciências Agrárias da Universidade Federal do Paraná. 1999. 8p.

RESENDE, M.D.V.; MORAES, M.L.T.; PAIVA, J.R. Comparação de métodos de avaliação genética e seleção no melhoramento da seringueira [Hevea brasiliensis (Willd. Ex Adr. de Juss.) Muell. Arg.]. Floresta, v.26, n.1/2, p.27-48, jun./dez. 1996a.

RESENDE, M.D.V.; HIGA, A.R.; SOUZA, S.M.; STEIN, P.P. Estudos da variação genética e métodos de seleção em teste de progênies da Acácia mearnsii no Rio Grande do Sul. Boletim de Pesquisa Florestal, n.22/23, p.45-59, 1991.

RESENDE, M.D.V.; PRATES, D.F.; JESUS, A.; YAMADA, C.K. Melhor predição linear não viciada (BLUP) de valores genéticos no melhoramento de Pinus. Boletim de Pesquisa Florestal, n.32/33, p.3-22, jan./dez. 1996b.

SAS INSTITUTE. SAS System for Mixed Models. Cary, NC, USA. 1996. $635 \mathrm{p}$.

SEARLE, S.R. Linear models. New York: John Wiley, 1971. 532p. 
SEARLE, S.R.; CASELA, G.; MCCULLOCH, C.E. Variance components. New York: John Wiley, 1992. 501p.

SHAW, R.G. Maximum-likelihood approaches to quantitative genetics of natural populations. Evolution, v.41, p.812-826, 1987.

SILVA, M.A.A. Horto florestal Navarro de Andrade. http://www.geocities.com/motorCity/street/4741/museurc.html. 1999. (20 de mar. de 2003).

SOCIEDADE BRASILEIRA DE SILVICULTURA. O setor florestal brasileiro - Fatos e números. São Paulo: Sociedade Brasileira de Silvicultura. 2003. 29p.

STEEL, R.G.D; TORRIE, J.H. Principles and procedures of statistics. 2.ed. New York: Mc Graw Hill, 1980. 633p.

THOMPSON, R.; HILL, W.G. Univariate REML analysis for multivariate data with the animal model. In: WORLD CONGRESS ON GENETICS APPLIED TO LIVESTOCK PRODUCTION, 4. Edinburgh, 1990. Anais. The University of Edinburgh, p.484-497, 1990. v3.

VAN VLECK, L.D.; POLLAK, E.J.; OLTENACU, E.A.B. Genetics for the animal science. New York: W.H. Freeman, 1987. 391p.

VENCOVSKY, R. Herança quantitativa. In: PATERNIANI, E; VIEGA, G.P. Melhoramento e produção do milho. Campinas: Fundação Cargill, 1987. p.137-214.

VENCOVSKY, R.; BARRIGA, P. Genética biométrica no fitomelhoramento. Ribeirão Preto: Sociedade Brasileira de Genética, 1992. 486p. 
VETTORAZZO, S.C. Efeito de fatores do solo e de genótipos no crescimento, nutrição e atividade da fosfatase ácida em clones de Eucalyptus grandis. Piracicaba, 1989. 115p. Dissertação (Mestrado) - Escola Superior de Agricultura "Luiz de Queiroz", Universidade de São Paulo.

WHITE, T.L.; HODGE, G. Prediction breeding values with application in forest tree improvement. London: Kluwer, 1989. 367p.

WILLIANS, E.; MATHESON, A.C. Experimental designs and analysis for use in tree improvement. Victoria: CSIRO, 1994. 174p. 
APÊNDICE 
APÊNDICE 1 - Programa SAS utilizado para obtenção da estimativa inicial dos componentes de variância.

Data tese;

Infile "c:dadostese.txt";

Input indiv clone bloco parcela arvore dap alt vol;

Proc glm;

Class bloco clone;

Model dap alt vol = bloco clone bloco*clone / SS3;

Random clone bloco*clone/test;

Run; 